\title{
New Fossil Lepidoptera (Insecta: Amphiesmenoptera) from the Middle Jurassic Jiulongshan Formation of Northeastern China
}

\author{
Weiting Zhang ${ }^{1,6}$, Chungkun Shih ${ }^{1}$, Conrad C. Labandeira ${ }^{1,2,3}$, Jae-Cheon Sohn ${ }^{2,3,4}$, Donald R. Davis ${ }^{4}$, \\ Jorge A. Santiago-Blay ${ }^{2,5}$, Oliver Flint ${ }^{4}$, Dong Ren ${ }^{1 *}$ \\ 1 College of Life Sciences, Capital Normal University, Beijing, China, 2 Department of Paleobiology, National Museum of Natural History, Smithsonian Institution, \\ Washington, Distirict of Columbia, United States of America, 3 Department of Entomology and BEES Program, University of Maryland, College Park, Maryland, United \\ States of America, 4 Department of Entomology, National Museum of Natural History, Smithsonian Institution, Washington, District of Columbia, United States of America, \\ 5 Department of Crop and Agroenvironmental Sciences, University of Puerto Rico Mayagüez, Puerto Rico, United States of America, 6 Geoscience Museum, Shijiazhuang \\ University of Economics, Shijiazhuang, China
}

\begin{abstract}
Background: The early history of the Lepidoptera is poorly known, a feature attributable to an inadequate preservational potential and an exceptionally low occurrence of moth fossils in relevant mid-Mesozoic deposits. In this study, we examine a particularly rich assemblage of morphologically basal moths that contribute significantly toward the understanding of early lepidopteran biodiversity.

Methodology/Principal Findings: Our documentation of early fossil moths involved light- and scanning electron microscopic examination of specimens, supported by various illumination and specimen contrast techniques. A total of 20 moths were collected from the late Middle Jurassic Jiulongshan Formation in Northeastern China. Our principal results were the recognition and description of seven new genera and seven new species assigned to the Eolepidopterigidae; one new genus with four new species assigned to the Mesokristenseniidae; three new genera with three new species assigned to the Ascololepidopterigidae fam. nov.; and one specimen unassigned to family. Lepidopteran assignment of these taxa is supported by apomorphies of extant lineages, including the $M_{1}$ vein, after separation from the $M_{2}$ vein, subtending an angle greater than 60 degrees that is sharply angulate at the junction with the $r-m$ crossvein (variable in Trichoptera); presence of a foretibial epiphysis; the forewing $\mathrm{M}$ vein often bearing three branches; and the presence of piliform scales along wing veins.
\end{abstract}

Conclusions/Significance: The diversity of these late Middle Jurassic lepidopterans supports a conclusion that the Lepidoptera-Trichoptera divergence occurred by the Early Jurassic.

Citation: Zhang W, Shih C, Labandeira CC, Sohn J-C, Davis DR, et al. (2013) New Fossil Lepidoptera (Insecta: Amphiesmenoptera) from the Middle Jurassic Jiulongshan Formation of Northeastern China. PLoS ONE 8(11): e79500. doi:10.1371/journal.pone.0079500

Editor: David Frayer, University of Kansas, United States of America

Received June 6, 2013; Accepted September 17, 2013; Published November 22, 2013

Copyright: (c) 2013 Zhang et al. This is an open-access article distributed under the terms of the Creative Commons Attribution License, which permits unrestricted use, distribution, and reproduction in any medium, provided the original author and source are credited.

Funding: This research was supported by the National Basic Research Program of China (973 Program) (grant 2012CB821906), National Natural Science Foundation of China (grants 31172143, 31230065, 31272352 and 41272006), Project of Great Wall Scholar and KEY project of Beijing Municipal Commission of Education (grants KZ201310028033), and the China Geological Survey (grant 1212011120115). Support for JCS was provided by the United States National Science Foundation's Assembling the Tree of Life program, award 0531769, and the Maryland Agricultural Experiment Station. The funders had no role in study design, data collection and analysis, decision to publish, or preparation of the manuscript.

Competing Interests: The authors have declared that no competing interests exist.

*E-mail: rendong@mail.cnu.edu.cn

\section{Introduction}

The Lepidoptera, or butterflies and moths, are one of the most speciose lineages of herbivores, currently including about 157,500 described species encompassing the four suborders of Zeugloptera, Aglossata, Heterobathmiina, and Glossata [1]. In contrast to the documented paleodiversity of otherdiverse insect lineages [2], the Lepidopteran fossil record is depauperate [3]. Only two extant suborders, Zeugloptera and Glossata, and an extinct suborder, Eolepidopterigina proposed by Rasnitsyn [4], are represented in the fossil record. Speciosity of the basal lepidopteran lineages is minimal in the fossil record, as in the extant fauna. This may be a consequence of the Lepidoptera once constituting a minor group of the world's fauna, following their evolution from the stemgroup, the Amphiesmenoptera (Fig. 1A) [5], a major holometabolan lineage comprising two distinctive insect orders, the Lepidoptera and the Trichoptera. The taxonomic boundary between Lepidoptera and Trichoptera is often obscured in their early fossil record [3], attributable to an overall morphological similarity and presence of few apomorphic characters visible in fossil specimens [5].

Because of the rarity of Mesozoic Lepidoptera, only 24 genera, of which two are extant, have been described from the Mesozoic (Table 1) [3,6-8]. In addition, undescribed Mesozoic fossils have been reported, including unequivocal Lepidoptera larvae [5,9], and other evidence such as unequivocal or possible Lepidoptera 

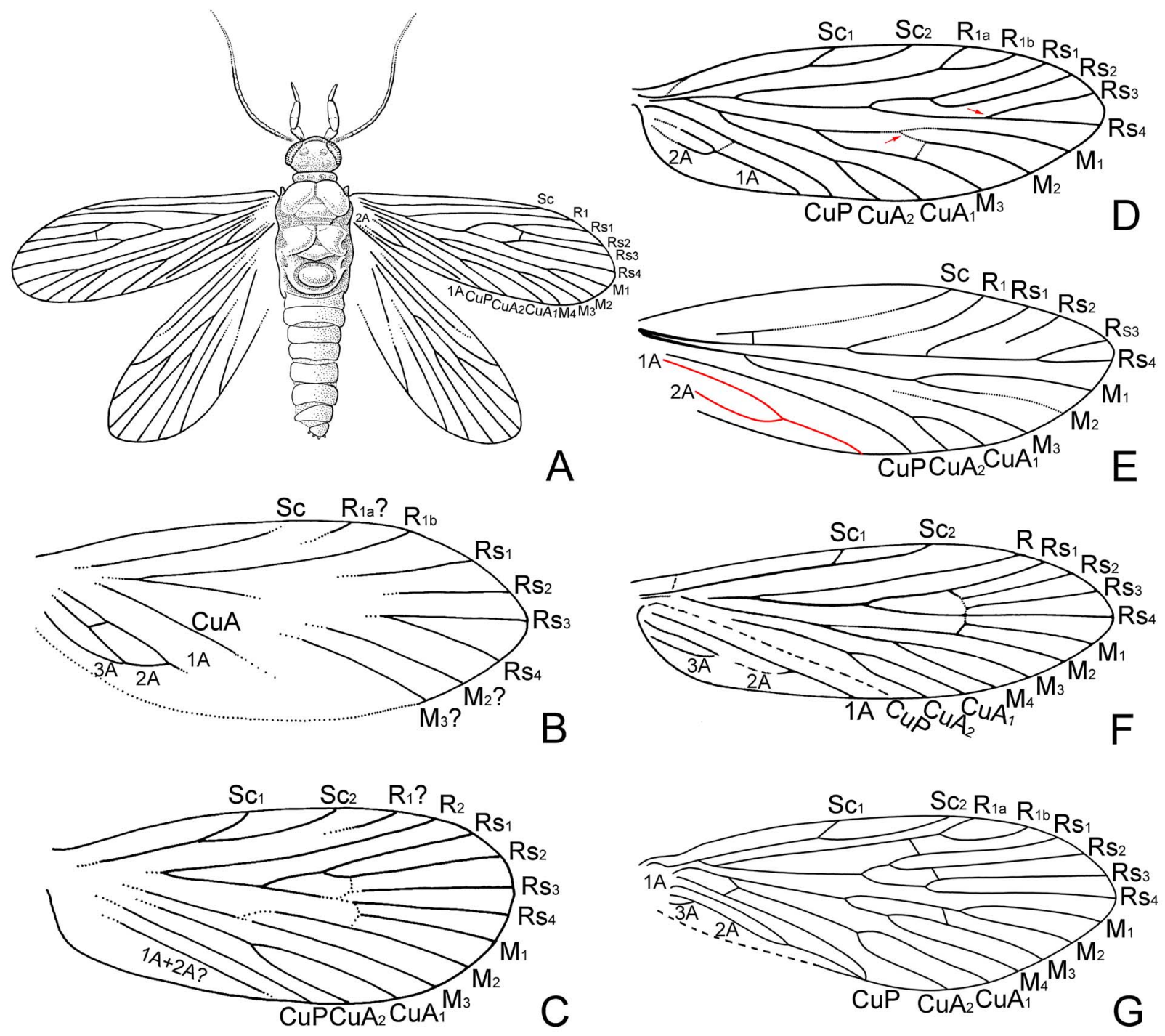

Figure 1. A stem-group amphiesmenopteran, lepidopterans, and a trichopteran. (A), A stem-group amphiesmenopteran, Necrotaulius tener, modified after Grimaldi and Engel [5]. (B-F), Lepidopteran forewings. (B), Archaeolepis mane, from Grimaldi and Engel [5]. (C), Forewing of an Early Jurassic Germany lepidopteran, from Grimaldi and Engel [5]. (D), Undopterix sukatshevae, modified after Skalski [10]; the red arrowhead showing $\mathrm{Rs}_{3+4}$ furcation beyond the $\mathrm{M}_{1+2}$ furcation. (E), Netoxena nana, modified after Martins-Neto [24]; red line indicates a single-Y configuration. (F), Mesokristensenia sinica, modified after Huang et al. [25]. (G), A trichopteran, Juraphilopotamus lubricus, modified after Gao et al. [43]. doi:10.1371/journal.pone.0079500.g001

wing scales [10-12] and unequivocal Lepidoptera leaf mines $[13,14]$. Mesozoic fossil Lepidoptera are principally assigned to two extinct families, the Eolepidopterigidae and the Mesokristenseniidae, and an extant family, the Micropterigidae, the latter considered the most basal extant lineage of Lepidoptera [15,16]. In addition, Kozlov erected an extinct family, the Undopterigidae to accommodate Undopterix Skalski, 1979 [10], but its phylogenetic placement is uncertain.

The earliest unequivocal lepidopteran fossil hitherto established is Archaeolepis mane Whalley, 1985 (Fig. 1B) from the Early Jurassic, about 190 million years ago (Ma), of Dorset, England [5,18,19]. The next, more recent, early fossils are eight non-monophyletic genera, dated to approximately $180 \mathrm{Ma}$, from the uppermost Lias of Dobbertin, Germany [5], which were described by Handlirsch as Necrotauliidae. However, Ansorge [21,22] disputed the necrotaulid affiliations of the Handlirsch's specimens and other well-preserved wings from the Grimmen locality of Germany, and assigned most of these to the Lepidoptera on the basis of the 3branched $\mathrm{M}$ vein and the presence of scales on the forewings. These fossils overwhelmingly are represented by wings. A representative forewing is shown in Fig. 1C, indicating a $\mathrm{M}$ with 3 branches and the $\mathrm{M}_{1}$, separated from the $\mathrm{M}_{2}$ at an angle of about 70 degrees, and sharply angulate at the junction with crossvein $\mathrm{r}-\mathrm{m}$. Additionally, a forewing of Undopterix sukatshevae, within the Undopterigidae [23], is shown in Fig. 1D, as is a forewing of Netoxena nana in the Eolepidopterigidae [3,24], in Fig. 1E. Huang et al. [25] described Mesokristensenia sinica in the Mesokristenseniidae, the forewing of which is shown in Fig. 1F. For comparison, the forewing of a trichopteran, furaphilopotamus lubricus Wang, Zhao \& Ren, 2009 [17], is shown in Fig. 1G.

Recently, we collected 20 well-preserved, nearly complete fossil lepidopterans from the Jiulongshan Formation at Daohugou Village, Shantou Township, Ningcheng County, Inner Mongolia, in China. This deposit was radiometrically dated by ${ }^{40} \mathrm{~K} /{ }^{40} \mathrm{Ar}$ at 
Table 1. Known fossil records of Mesozoic Lepidoptera.

\begin{tabular}{|c|c|c|c|c|c|c|}
\hline Suborder & Family & Genus & Species & Epoch & Country & Reference \\
\hline$?$ & Archaeolepidae & Archaeolepis Whalley, 1985 & A. mane Whalley, 1985 & $J 1$ & United Kingdom & [18] \\
\hline Eolepidopterigina & Eolepidopterigidae & Eolepidopterix Rasnitsyn, 1983 & E. jurassica Rasnitsyn, 1983 & $\mathrm{J3}$ & Kazakhstan & [4] \\
\hline Eolepidopterigina & Eolepidopterigidae & Palaeolepidopterix Kozlov, 1989 & P. aurea Kozlov, 1989 & J3 & Kazakhstan & {$[40]$} \\
\hline Eolepidopterigina & Eolepidopterigidae & Daiopterix Skalski, 1984 & D. rasnitsyni Skalski, 1984 & $\mathrm{~K} 1$ & Russia & {$[23]$} \\
\hline Eolepidopterigina & Eolepidopterigidae & Daiopterix Skalski, 1984 & D. olgae Kozlov, 1989 & K1 & Russia & {$[40]$} \\
\hline Eolepidopterigina & Eolepidopterigidae & Netoxena Sohn, 2012 & N. nana (Martins-Neto, 1999) & $\mathrm{K} 1$ & Brazil & {$[24,52]$} \\
\hline Eolepidopterigina & Eolepidopterigidae & Undopterix Skalski, 1979 & U. sukatshevae Skalski, 1979 & K1 & Russia & {$[10]$} \\
\hline Eolepidopterigina & Eolepidopterigidae & Undopterix Skalski, 1979 & $\begin{array}{l}\text { U. caririensis Martins-Neto \& Vulcano, } \\
1989\end{array}$ & $\mathrm{~K} 1$ & Brazil & [39] \\
\hline Eolepidopterigina & Eolepidopterigidae & $\begin{array}{l}\text { Gracileopterix Neto \& Vulcano, } \\
1989\end{array}$ & $\begin{array}{l}\text { G. pulchra Martins-Neto \& } \\
\text { Vulcano, } 1989\end{array}$ & $\mathrm{~K} 1$ & Brazil & [39] \\
\hline Zeugloptera & Micropterigidae & Sabatinca Walker, 1863 & S. perveta (Cockerell, 1919) & $\mathrm{K} 1$ & Burma & {$[12,42]$} \\
\hline Zeugloptera & Micropterigidae & Parasabatinca Whalley, 1978 & P. aftimacrai Whalley, 1978 & K1 & Lebanon & {$[45]$} \\
\hline Zeugloptera & Micropterigidae & Parasabatinca Whalley, 1978 & P. caldasae Martins-Neto \& Vulcano, 1989 & $\mathrm{~K} 1$ & Brazil & [39] \\
\hline Zeugloptera & Micropterigidae & Palaeosabatinca Kozlov, 1988 & P. zherichini Kozlov, 1988 & $\mathrm{~K} 1$ & Russia & {$[16]$} \\
\hline Zeugloptera & Micropterigidae & $?$ & $?$ & J1 & Germany & {$[21,22]$} \\
\hline Zeugloptera & Micropterigidae & $?$ & $?$ & $\mathrm{~K} 1$ & Lebanon & {$[53]$} \\
\hline Zeugloptera & Micropterigidae & $?$ & $?$ & $\mathrm{~K} 1$ & Burma & {$[5,52,54]$} \\
\hline Zeugloptera & Micropterigidae & $?$ & $?$ & K1 & Spain & {$[52,55]$} \\
\hline$?$ & $?$ & $?$ & $?$ & $?$ & Burma & {$[52,56]$} \\
\hline Zeugloptera & ?Micropterigidae & Auliepterix Kozlov, 1989 & A. mirabilis Kozlov, 1989 & $\mathrm{~J} 3$ & Kazakhstan & {$[40]$} \\
\hline Zeugloptera & ?Micropterigidae & Auliepterix Kozlov, 1989 & A. minima Kozlov, 1989 & $\mathrm{~J} 3 / \mathrm{K} 1$ & Mongolia & {$[40]$} \\
\hline Zeugloptera & ?Micropterigidae & $?$ & $?$ & $\mathrm{~J} 3 / \mathrm{K} 1$ & France & {$[9,16]$} \\
\hline Zeugloptera & ?Micropterigidae & $?$ & $?$ & $\mathrm{~J} 3 / \mathrm{K} 1$ & France & [57] \\
\hline$?$ & Mesokristenseniidae & $\begin{array}{l}\text { Mesokristensenia Huang et al., } \\
2010\end{array}$ & M. latipenna Huang et al., 2010 & $J 2$ & China & {$[25]$} \\
\hline$?$ & Mesokristenseniidae & $\begin{array}{l}\text { Mesokristensenia Huang et al., } \\
2010\end{array}$ & M. sinica Huang et al., 2010 & $J 2$ & China & {$[25]$} \\
\hline$?$ & Mesokristenseniidae & $\begin{array}{l}\text { Mesokristensenia Huang et al., } \\
2010\end{array}$ & M. angustipenna Huang et al., 2010 & $J 2$ & China & {$[25]$} \\
\hline Glossata & Bucculatricidae & Bucculatrix Zeller, 1839 & B. platani Kozlov, 1988 & $\mathrm{~K} 2$ & Kazakhstan & [16] \\
\hline Glossata & Incurvariidae & $?$ & $?$ & $\mathrm{~K} 2$ & Russia & {$[10]$} \\
\hline Glossata & Incurvariidae & $?$ & $?$ & $\mathrm{~K} 1$ & Brazil & {$[5]$} \\
\hline Glossata & Incurvariidae & $?$ & $?$ & K1 & Lebanon & {$[45]$} \\
\hline Glossata & ?Mnesarchaeidae & $?$ & $?$ & $\mathrm{~K} 2$ & Russia & {$[5,58]$} \\
\hline Glossata & ?Lophocoronidae & $?$ & $?$ & $\mathrm{~K} 2$ & Russia & {$[10]$} \\
\hline Glossata & $?$ & Protolepis Kozlov, 1989 & P. cuprealata Kozlov, 1989 & $\mathrm{~J} 3$ & Kazakhstan & {$[40]$} \\
\hline Glossata & $?$ & Karataunia Kozlov, 1989 & K. lapidaria Kozlov, 1989 & J3 & Kazakhstan & {$[40]$} \\
\hline$?$ & $?$ & Archiptilia Handlirsch, 1939 & A. ovata Handlirsch, 1939 & $J 1$ & Germany & {$[21,59]$} \\
\hline$?$ & $?$ & Epididontus Handlirsch, 1939 & E. geinitzianus Handlirsch, 1939 & J1 & Germany & {$[21,59]$} \\
\hline$?$ & $?$ & Metarchitaulius Handlirsch, 1939 & M. longus Handlirsch, 1939 & J1 & Germany & {$[21,59]$} \\
\hline$?$ & $?$ & $\begin{array}{l}\text { Nannotrichopteron Handlirsch, } \\
1906\end{array}$ & N. gracile Handlirsch, 1906 & $J 1$ & Germany & {$[20,21]$} \\
\hline$?$ & $?$ & Palaeotaulius Handlirsch, 1939 & P. vicinus Handlirsch, 1939 & $J 1$ & Germany & {$[21,59]$} \\
\hline$?$ & $?$ & Pararchitaulius Handlirsch, 1939 & P. ovalis Handlirsch, 1939 & J1 & Germany & {$[21,59]$} \\
\hline$?$ & $?$ & Parataulius Handlirsch, 1939 & P. jurassicus Handlirsch, 1939 & $\mathrm{~J} 1$ & Germany & {$[21,59]$} \\
\hline$?$ & $?$ & Pseudorthophlebia Handlirsch, 1906 & P. platyptera Handlirsch, 1906 & $J 1$ & Germany & {$[20,21]$} \\
\hline$?$ & $?$ & $\begin{array}{l}\text { ?Paratrichopteridium Handlirsch, } \\
1906\end{array}$ & P. efossum Handlirsch, 1939 & $\mathrm{~J} 1$ & Germany & {$[21,59]$} \\
\hline$?$ & $?$ & $\begin{array}{l}\text { ?Paratrichopteridium } \\
\text { Handlirsch, } 1906\end{array}$ & P. costale Handlirsch, 1939 & $J 1$ & Germany & {$[21,59]$} \\
\hline$?$ & $?$ & Necrotaulius Handlirsch, 1906 & N. tener Sukatsheva, 1990 & K1 & Russia & {$[50,60]$} \\
\hline
\end{tabular}


Table 1. Cont.

\begin{tabular}{|c|c|c|c|c|c|c|}
\hline Suborder & Family & Genus & Species & Epoch & Country & Reference \\
\hline Glossata & $?$ & ? & $?$ & K1 & Burma & [54] \\
\hline Glossata & $?$ & $?$ & $?$ & $\mathrm{~K} 2$ & USA & [61] \\
\hline Glossata $^{1}$ & Nepticulidae & $?$ & $?$ & K1 & USA & [13] \\
\hline Glossata $^{1}$ & Gracillariidae & $?$ & $?$ & $\mathrm{~K} 1$ & USA & [13] \\
\hline Glossata (larva) & ? & $?$ & ? & K1 & Lebanon & [62] \\
\hline Glossata (larva²) & $?$ & $?$ & $?$ & $\mathrm{~K} 2$ & Canada & [9] \\
\hline Glossata (larva) & ? & ? & ? & $\mathrm{K} 1$ & Lebanon & [5] \\
\hline$?$ & ? & ? & ? & K1 & Spain & [63] \\
\hline
\end{tabular}

Notes: ${ }^{1}$ Leaf mine;

${ }^{2}$ Head capsule. J1, Early Jurassic; J2, Middle Jurassic; J3, Late Jurassic; K1, Early Cretaceous; K2, Late Cretaceous.

doi:10.1371/journal.pone.0079500.t001

164-165 Ma [26], a date supported by slightly younger isotopic dates from overlying volcanic deposits [26,27]. This date corresponds to the Callovian-Oxfordian boundary interval of the latest Middle Jurassic, using the most recent, standard international time scale [28]. The deposit contain beautifully preserved fossils of insects and other animals [29-33]. After comparison of these fossils to other Mesozoic lepidopteran specimens, we recognized below eleven new genera and fourteen new species, assigned to the three families, the Eolepidopterigidae, the Mesokristenseniidae, and the Ascololepidopterigidae fam. nov. We used additional taxa to emend diagnoses of the two previously named families, the Eolepidopterigidae and the Mesokristenseniidae. With the fossils reported by Huang et al. [25], these new findings, now document the third oldest-known lineage of lepidopterans.

\section{Materials and Methods}

\section{Light Microscopy, Image Processing and Line Drawings}

All specimens were microphotographed and illustrated using a Leica MZ12.5 dissecting microscope accompanied with a drawing tube attachment in Beijing, and an Olympus SZX12 stereomicroscope in Washington, DC. Images were captured using dissecting microscopes equipped with digital cameras and image processing software. The image processing software for the Beijing computer-microscope-camera system was a Nikon DXM 1200C, with NIS-elements D 2.30; and in Washington, DC, an Image-Pro 6.1 (Media Cybernetics) platform. Alcohol was used to increase the contrast of specimen structures for some images. Line drawings in Beijing were made in conjunction with Photoshop CS2 graphic software.

\section{Electron Microscopy}

We used a Philips XL30 environmental scanning electron microscope to examine shrink-wrapped specimens. Compression fossils, such as the material studied herein, generally present minimal topographic relief. This absence of microtopographic differentiation and the uncoated state of the specimens, posed a demand on specimen imaging. By varying the microscopy conditions for each specimen, including sources of illumination, such as back-scattered electrons, gas emission secondary electrons and particle detector adjustment; or alternatively, varying microtopographic aspect, spot size or accelerating voltage; we strove to find the best combination of imaging conditions within a challenging SEM environment.
The fossil specimens studied under vacuum conditions of the electron microscope necessitated a modification of specimen preparation. The presence of a poorly consolidated sedimentary matrix surrounding the fossils resulted in the spalling of particles that interfered with normal operation of the vacuum tube. A protocol was devised that solved this problem. Any matrix material that sloughed from the specimen was isolated by heat-resistant polyalfin film, used in industrial kitchens to shrink-wrap food. In contrast to polyester shrink-wrap, polyalfin film does not melt or release gas in the vacuum chamber. The shrink-wrapping of stubmounted specimens in polyalfin film reduced the likelihood of costly specimen chamber contamination. Thereafter, the wrapping was carefully heat-sealed to reduce specimen bulk and promote ease of further examination. When the specimen was ready for microscopy, a window was opened over the area of interest by careful cutting of the wrapping, leaving a hole for specimen access. A thorough dusting of particles attached to the wrapping is necessary immediately preceding insertion of the specimen into the specimen chamber, particularly if the fossil has remained in storage for some time.

\section{Measurement and Anatomical Conventions}

Measurements, including body length and width, wing length and width, and wing index, follow Kristensen and Nielsen [34]. The wing index is defined as the ratio of wing width/wing length. All measurements are given in millimeters (mm). Amphiesmenopteran and lepidopteran apomorphies are taken from Kristensen and Skalski [15] and Huang et al. [25]. Family-level classification follows Nieukerken et al. [1]. Wing venation nomenclature is based on Wootton [35]. A proposed hypothetical forewing for Lepidoptera, modified from Kristensen and Skalski [15], is illustrated in Fig. 2A. In contrast, a hypothetical forewing for Trichoptera, modified from Holzenthal et al. [36], is presented in Fig. 2B. Wing veins are given as combinations of vein abbreviation and the number of vein branches. For example, Rs -4 means that the Rs has four branches; $\mathrm{Sc}-1 / 2$ indicates that the Sc has one or two branches. Wing vein forking of branches are described as occurring at the same level (equidistant) or at a different level (variable distance) from the base of the wing. The Lepidoptera ovipositor is defined as a composite of abdominal segments VIII, IX+X and associated intersegmental membranes. Additional abbreviations of morphology are provided in the figure captions. 

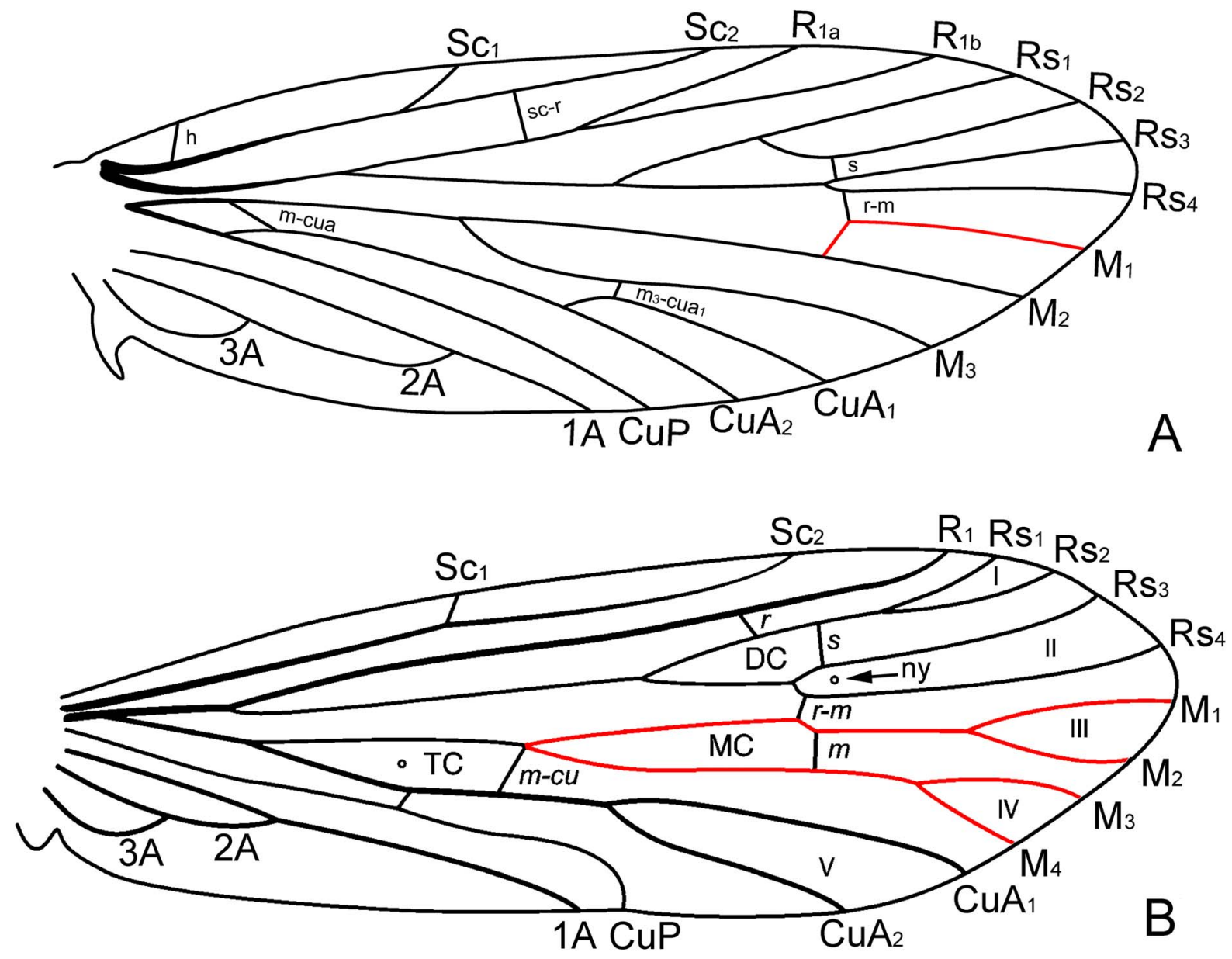

Figure 2. A hypothetical forewing of the Lepidoptera and Trichoptera. (A), A hypothetical forewing of the Lepidoptera modified after Kristensen \& Skalski [15]; red line indicates that $M_{1}$, after separation from $M_{2}$, subtends an angle greater than 60 degrees and is sharply angulate at the junction with the $r-m$ crossvein. (B), A hypothetical forewing of the Trichoptera modified after Holzenthal et al. [36]; red line indicates the separation of $M_{1+2}$, and $M_{1}$ consisting of smooth and sublinear veins. Abbreviation: ny, nygmata.

doi:10.1371/journal.pone.0079500.g002

\section{Etymological Sources}

The primary source for Latin and Greek etymology is Simpson [37], buttressed by Brown's compendium [38]. Linnaean designations of genus and species names were configured to be consistently either Latin or Greek, avoiding combinatorial forms with both languages in the same word.

\section{Repository}

All type specimens described in this report are deposited in the Key Laboratory of Insect Evolution and Environmental Change, College of Life Sciences, Capital Normal University, Beijing, China.

\section{Nomenclatural Acts}

The electronic edition of this article conforms to the requirements of the amended International Code of Zoological Nomenclature, and hence the new names contained herein are available under that Code from the electronic edition of this article. This published work and the nomenclatural acts it contains have been registered in ZooBank, the online registration system for the ICZN. The ZooBank LSIDs (Life Science Identifiers) can be resolved and the associated information viewed through any standard web browser by appending the LSID to the prefix "http://zoobank.org/". The LSID for this publication is: urn:lsid:zoobank.org:pub: $\quad$ AC86AB61-87FC-4353-96BBAA03231E3BA5. The electronic edition of this work was published in a journal with an ISSN, and has been archived and is available from the following digital repositories: PubMed Central, LOCKSS (www.lockss.org).

\section{Results}

\section{Taxonomy}

Class Insecta Linnaeus, 1758.

Order Lepidoptera Linnaeus, 1758.

Key to the extant and fossil families of lepidoptera

1. Maxillary galeae forming a proboscis .................Glossata -Maxillary galeae not forming a proboscis...................2

2. M 3-branched.........................................

- M 4-branched.............................................

3. Anterior apophyses present..............Eolepidopterigidae

- Anterior apophyses absent..............................4

4. Sc forked; crossvein present between Sc and R; pterostigma absent.................................... Micropterigidae

- Sc unforked; crossvein absent between Sc and R; pterostigma present.

..Heterobathmiidae 
5. Metatibia without medial spur; $\mathrm{R}_{1}$ forked

.........................Ascololepidopterigidae fam. nov.

-Metatibia with medial spurs; $\mathrm{R}_{1}$ unforked, ................6

6. Mesotibia with medial spurs; crossvein m-cua and crossvein cua-cup present.................Agathiphagidae

- Mesotibia without medial spur; crossvein m-cua

and crosvein cua-cup absent..............Mesokristenseniidae

Suborder Eolepidopterigina Rasnitsyn, 1983.

Family Eolepidopterigidae Rasnitsyn, 1983.

Type genus. Eolepidopterix Rasnitsyn, 1983 [4].

Emended diagnosis. Head with mandibulate mouthparts. Antennae filiform, less than half the length of forewing. Pronotum longer than one third the mesonotum length. Foretibia with an epiphysis. Mesotibia with one pair of spurs; metatibia with two pairs of spurs. Both pairs of wings homoneurous (the venation of the forewings and hind wings alike). Wings covered with scales. Forewing with jugum and number of vein branches as follows: Sc1/2, R 1 -1/2, Rs-4, M-3, GuA-2, CuP-1, and A-2/3. Ovipositor with long apophyses anteriores; papillae anales long, non-piercing.

The synapomorphies for the Eolepidopterigidae are the mesotibia with a pair apical spurs, metatibia with a pair medial spurs and a pair apical spurs, wings homoneurous, forewing $\mathrm{M}$ vein 3-branched, and ovipositor with long apophyses anteriores.

This family is defined as a clade in Amphiesmenoptera, which have three branches of the $M$ vein in the hind wing and the anterior margin of female abdominal segments VIII and IX with long, rod-like apodemes. This family can be assigned to Lepidoptera by the following characters: foretibia with an epiphysis, mesotibia lacking medial spurs, wings covered with scales, and forewing $\mathrm{M}$ vein 3-branched.

Distribution. China, Russia, Kazakhstan, Brazil.

Genera included. Akainalepidopteron gen. nov.; Daiopterix Skalski, 1984 [23]; Dynamilepidopteron gen. nov.; Eolepidopterix Rasnitsyn, 1983 [4]; Gracileopterix Martins-Neto \& Vulcano, 1989 [39]; Grammikolepidopteron gen. nov.; Longcapitalis gen. nov.; Netoxena Sohn, 2012 [3] ( = Xena Martins-Neto, 1999 [24]); Palaeolepidopterix Kozlov, 1989 [40]; Petilicorpus gen. nov.; Quadruplecivena gen. nov.; Seresilepidopteron gen. nov.; Undopterix Skalski, 1979 [10].

Key to the known genera of eolepidopterigidae.

1. Body longer than $9 \mathrm{~mm}$; length of forewing nearly $10 \mathrm{~mm}$; hind wing with crossvein $\mathrm{sc}^{-} \mathrm{r}_{1}$ near the $\mathrm{R}_{1}$ furcation Quadruplecivena gen. nov.

- Body less than $8 \mathrm{~mm}$; length of forewing less than $9 \mathrm{~mm}$;

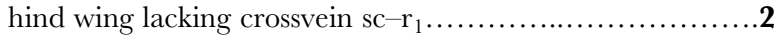

2. Forewing with $\mathrm{Sc}$ not forked........................... 3

- Forewing with Sc forked.................................6

3. Forewing with $\mathrm{R}_{1}$ not forked........................4

- Forewing with $\mathrm{R}_{1}$ forked.............................5

4. Anal veins of a single-Y configuration (Fig. 1E)....... Netoxena

- Anal veins of a double-Y configuration. Grammikolepidopteron gen. nov.

5. Forewing less than $3 \mathrm{~mm}$; $\mathrm{Rs}_{1+2}$ stalked, ca. 1/3 of its total length......................... Gracileopterix

- Forewing longer than $5 \mathrm{~mm}, \mathrm{Rs}_{1+2}$ stalked, more than half of its total length................Palaeolepidopterix

6. Forewing with $\mathrm{R}_{1}$ not forked..............Longcapitalis gen. nov.

- Forewing with $\mathrm{R}_{1}$ forked................................. 7

7. Sc branching near the base of forewing............Eolepidopterix

- Sc branching distally.................................

8. $\mathrm{Rs}_{3+4}$ forking beyond the $\mathrm{Rs}_{1+2}$ furcation................

- $\mathrm{Rs}_{3+4}$ and $\mathrm{Rs}_{1+2}$ forking at the same level.................11

9. Forewing with $\mathrm{Rs}_{3+4}$ forking level with $\mathrm{M}_{1+2}$ furcation Petilicorpus gen. nov.
- Forewing with $\mathrm{Rs}_{3+4}$ forking beyond $\mathrm{M}_{1+2}$ fork (Fig. 1D)

...................................................

10. Humeral vein present on forewing................Undopterix

- Humeral vein absent on forewing..................Daiopterix

11. Hind wing with spines on several veins................... Akainalepidopteron gen. nov.

- Hind wing lacking spines. 12

12. Anterior margins of fore and hind wings lacking cilia; metatibia with irregularly arranged spines.

Dynamilepidopteron gen. nov.

- Anterior margins of fore and hind wings with cilia; metatibia lacking spines...............Seresilepidopteron gen. nov.

Remarks. Kristensen [41] considered Skalski's family assignment of all species, except Eolepidopterix jurassica, to the Eolepidopterigidae [7] unconvincing due to lack of definitive apomorphies. Subsequently, Nieukerken et al. [1] placed only E. jurassica in the Eolepidopterigidae. We assign all the above-mentioned genera to this family for the following reasons. Skalski erected the genus Undopterix in Micropterigidae [10], with the type species as $U$. sukatsheva Skalski 1979. Another supposed congener was added, $U$. caririensis Martins-Neto \& Vulcano, 1989 from the Crato Formation, Brazil [10,39]. The taxonomic position of this genus is controversial: some authors have placed it in Micropterigidae [10]; some assign it to the Undopterigidae [16]; whereas others considered it as Eolepidopterigidae [4,7]. Yet, Undopterix sukatsheva Skalski, 1979, exhibits no autapomorphies of the Micropterigidae [34]. The long apophyses of the last several abdominal segments are comparable to those present in the Eolepidopterigidae [4]. For wing venation, Undopterix shows similarity to Eolepidopterigidae, especially in the hind wing. Undopterix has $\mathrm{R}_{1}$ forked, which is rare in Micropterigidae, but present in some members of Eolepidopterigidae, such as Daiopterix Skalski [23], Seresilepidopteron gen. nov., Akainalepidopteron gen. nov., Quadruplecivena gen. nov., and Petilicorpus gen. nov. Consequently, we believe it is more appropriate to place Undopterix in the Eolepidopterigidae. We agree with Skalski [7], followed by Sohn et al. [3], in considering the Undopterigidae a synonym of the Eolepidopterigidae. In addition, the Eolepidopterigidae are believed to have affinities with the Agathiphagidae [7], based on an ovipositor bearing long apophyses that is not present in Micropterigidae and Heterobathmiidae [34]. When Gracileopterix was erected, it was not assigned to a family [39], and because of its great similarity to Undopterix, we tentatively place this genus in Eolepidopterigidae.

\section{Seresilepidopteron Zhang, Shih, Labandeira \& Ren gen.} nov.

urn:lsid:zoobank.org:act:5AB2FE11-A3A1-4593-B01B-29E7C8 E25C49.

Type species. Seresilepidopteron dualis Zhang, Shih, Labandeira \& Ren sp. nov.

Etymology. The generic name, Seresilepidopteron, is derived from the Greek, Seres $(\Sigma \eta \rho \varepsilon \varsigma)$, the ancient Greek (and later similar Latin) name for northwestern China and its inhabitants, also referring to the land where silk originates; and lepidos, the Greek word for "scale" or "flake"; and pteron, Greek, for "wing" or "fin." The root, lepido, also refers to the Lepidoptera, the ordinal affiliation of this genus. The gender is masculine.

Diagnosis. Mesothorax slightly longer and wider than metathorax. All legs lacking spines. Forewing $\mathrm{Sc}$ and $\mathrm{R}_{1}$ forked, all furcations of $\mathrm{Rs}_{1+2}, \mathrm{Rs}_{3+4}$ and $\mathrm{M}_{1+2}$ at the same level with each other. Humeral vein, sc-r crossvein and crossvein between $\mathrm{R}_{1}$ and Rs present; three anal veins looping into a double-Y configuration; jugum present but short, lacking long setae. Hind wing $\mathrm{Sc}$ not forked; $\mathrm{R}_{1}$ forked; sc-r crossvein present. 


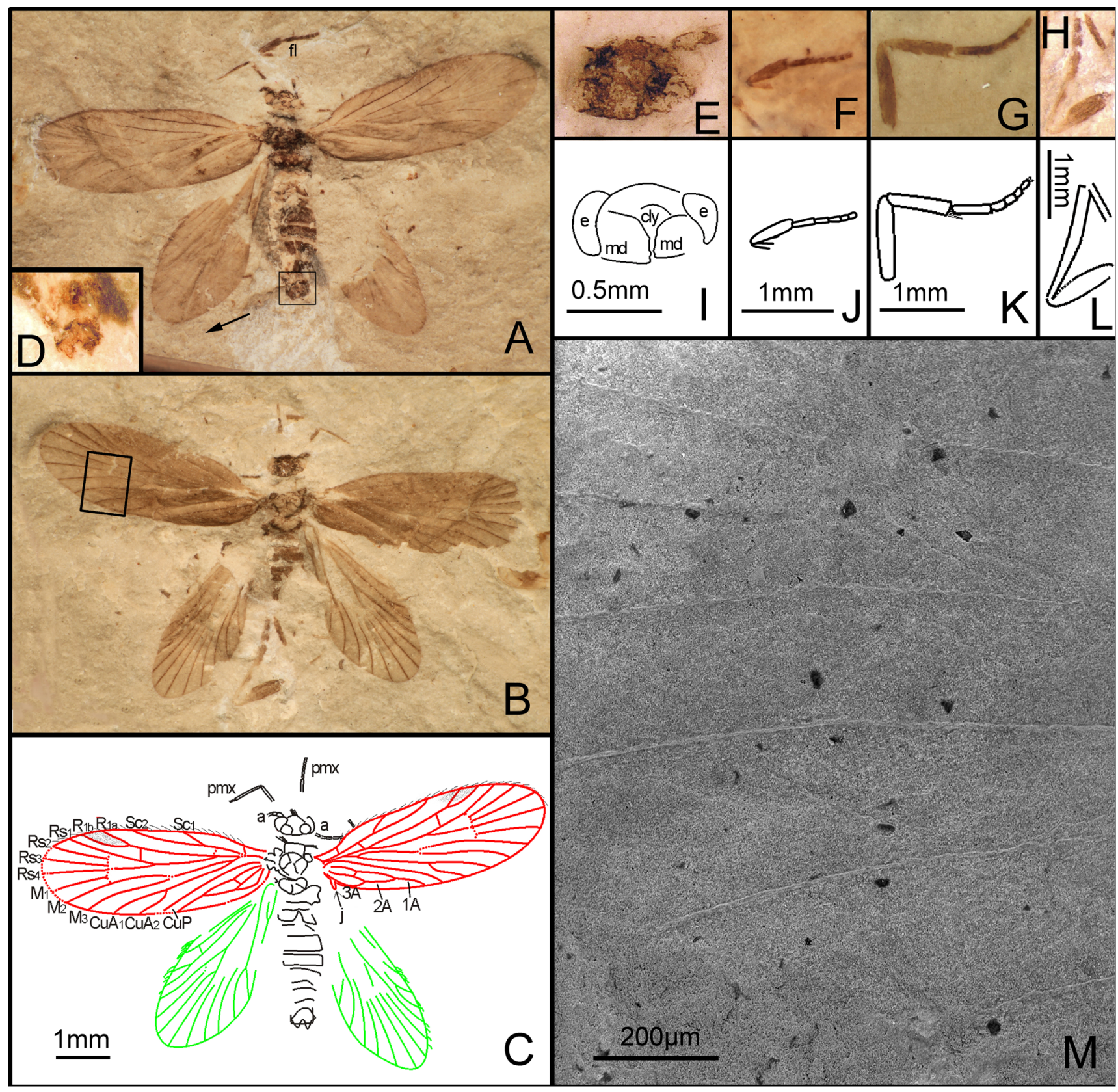

Figure 3. Seresilepidopteron dualis gen. et sp. nov. Male, holotype, CNU-LEP-NN-2006-001P/C. (A), Fossil specimen (counterpart). (B), Fossil specimen (part). (C), Camera lucida drawing of (A), showing overall habitus. (D), Genitalia (counterpart), outlined at (A). (E), Head and associated features (part). (F), Foreleg (counterpart). (G), Middle leg (counterpart). (H), Hind leg (part). (I) to (L), Camera lucida drawings of head (I), foreleg (J), middle leg (K), and hind leg (L). (M), SEM micrograph of left forewing venation, enlarged from the rectangular template in (B). Abbreviations: a, antennae; cly, clypeus; e, eye; fl, foreleg; j, jugum; md, mandible; pmx, maxillary palpus. doi:10.1371/journal.pone.0079500.g003

An Eolepidopterigidae affiliation is supported by: 1), forewing with jugum; 2), M 3-branched; and 3), ovipositor segments with long apophyses anteriores.

Distribution. Inner Mongolia Autonomous Region, China.

Comparison. The venation of Seresilepidopteron resembles that of Daiopterix, but Seresilepidopteron differs from the latter by three anal veins looping into a double-Y configuration (vs. only two anal veins looping into a single-Y configuration). Seresilepidopteron resembles Undopterix, but it differs from the latter by: 1), having $\mathrm{sc}-\mathrm{r}$ and $\mathrm{r}$ crossveins (vs. lacking $\mathrm{sc}-\mathrm{r}$ and $\mathrm{r}$ crossveins); 2), the presence of three anal veins; and 3), a double-Y configuration in the forewing (vs. two anal veins).

\section{Seresilepidopteron dualis Zhang, Shih, Labandeira \& Ren} sp. nov. (Figs. 3, 4)

urn:lsid:zoobank.org:act:C4F29D5D-B13E-4BF3-84A4-

A11E41319C4F.

Etymology. The specific name is derived from the Latin, dualis (dual, twice). 

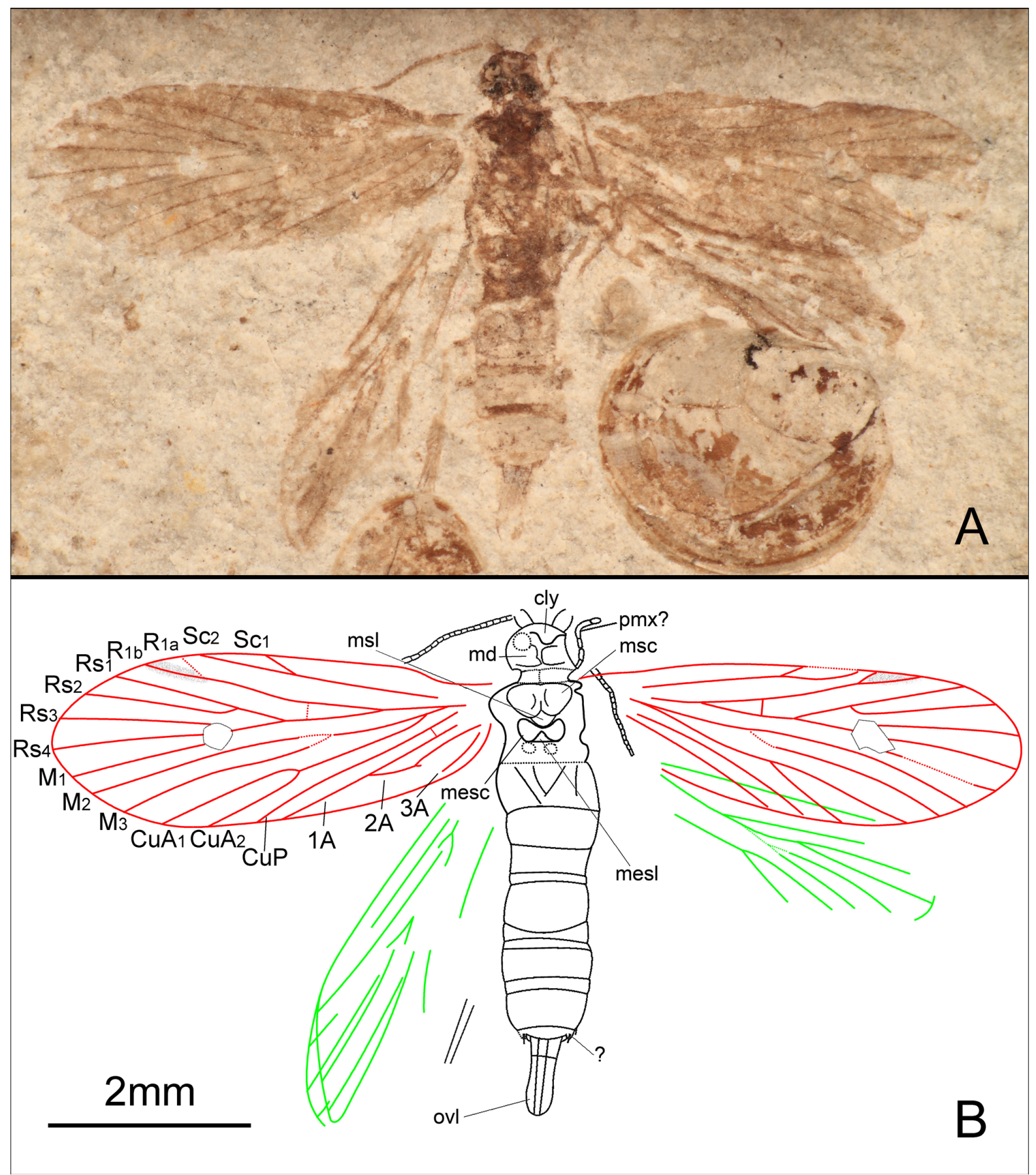

Figure 4. Seresilepidopteron dualis gen. et sp. nov. Female, paratype, CNU-LEP-NN-2006-002. (A), Fossil specimen, with a conchostracan at lowerright. (B), Camera lucida drawing of (A), showing overall habitus. Abbreviations: cly, clypeus; md, mandible; msc, mesoscutum; msl, mesoscutellum; mesc, metascutum; mesl, metascutellum; ovl, ovipositor lobes; pmx, maxillary palpus. doi:10.1371/journal.pone.0079500.g004

Type materials. Holotype: CNU-LEP-NN-2006-001P/C (part and counterpart); or; well preserved head, thorax, abdomen, fore and hind wings, parts of legs. Paratype: o; CNU-LEP-NN2006-002; excellently preserved body and forewings.

Locality and horizon. These specimens were collected from Daohugou Village, Shantou Township, Ningcheng County, Inner Mongolia Autonomous Region, China. The age is latest Middle Jurassic, near the Callovian-Oxfordian boundary.

Diagnosis. Same as generic diagnosis.
Description. Male (Fig. 3). Head partially preserved; antennae filiform; compound eyes widely separated. Portions of two mandibles and clypeus visible on ventral view of head (Figs. 3E, I). Last segment of a maxillary palpus visible, with sparse setae. Mesothorax slightly longer and wider than metathorax. No traces of setal warts on thorax. Almost all segments of abdomen preserved; genitalia visible (Fig. 3D).

Foreleg (Figs. 3F, J) detached and separated ca. $0.8 \mathrm{~mm}$ from the head of the insect, with faint trace of epiphysis; tarsi 5- 
segmented. Midleg (Figs. 3G, K) well preserved, covered with dense hairs, but detached ca. $5.0 \mathrm{~mm}$ from the insect. Tarsi 5segmented, with spines; apical segment with a pair of tarsal claws. A pair of apical spurs apparent on the mesotibia (Fig. 3K). Femur of hindleg robust, detached (Figs. $3 \mathrm{H}, \mathrm{L}$ ); ca. $3.1 \mathrm{~mm}$ apart from the posterior margin of metathorax.

Forewing (Fig. 3C) with a humeral vein; costal margin bearing sparse cilia. Sc forked, stalked, gently curved; $\mathrm{Sc}_{2}$ reaching proximal margin of pterostigma. $\mathrm{R}_{1}$ forked, both branches of $\mathrm{R}_{1}$ extend to pterostigma. Rs 4-branched; $\mathrm{R}_{4}$ to the apex of forewing; $\mathrm{Rs}_{1+2}, \mathrm{R}_{3+4}$, and $\mathrm{M}_{1+2}$ furcations arise at same level in the wing. Crossvein sc $-\mathrm{r}$ oblique, proximal to the $\mathrm{R}_{1}-\mathrm{R}$ s furcation. Crossvein $r$ located midway between $R_{1}$ furcation and $R$ s furcation. $M$ 3-branched, the hyaline zones surround the $r-m$ crossvein at $\mathrm{Rs}_{1+2}, \mathrm{Rs}_{3+4}$ and $\mathrm{M}_{1+2}$ furcations. CuA bifurcated; $\mathrm{CuP}$ simple, slightly curved terminally. Stem of $\mathrm{M}$ divergent from stem of $\mathrm{R}$ basally, just beyond humeral vein. CuA divergent from $\mathrm{M}$ slightly beyond $\mathrm{R}-\mathrm{M}$ furcation; $\mathrm{R}$ forks just after $\mathrm{M}-\mathrm{CuA}$ furcation. Three anal veins looping into a double-Y configuration. Crossvein between $1 \mathrm{~A}$ and $2 \mathrm{~A}$ present. A short, digitate jugum present in the basal posterior margin of forewing, lacking long setae. Hind wing venation (Fig. 3C) resembles forewing except Sc not forked; sc-r crossvein present proximally to $\mathrm{R}_{1}$ furcation. Costal margin bears long bristles. Anal area poorly preserved.

Paratype: Female (Fig. 4). Head with large mandibles; antennae filiform, shorter than forewing; robust scape. Maxillary palpus 5segmented; fourth segment longest. Mesothorax longer and wider than metathorax. Mesoscutum, mesoscutullum, metascutum and metascutullum well preserved. All abdominal segments visible; ovipositor long, well developed, with a pair of inner apophyses.

Wing venation (Fig. 4B) of female similar to male, except for the following differences: 1), $\mathrm{Sc}_{2}$ extends to anterior wing margin at midlength in male, after midlength in female; 2), $\mathrm{R}_{1}$ furcation in female closer to the apex than that in male; 3), in female, crossvein between $\mathrm{R}_{1}$ and $\mathrm{Rs}$ located before $\mathrm{Rs}_{\mathrm{s}}$ furcation on right wing, but in male after Rs furcation; 4), in female, cup-a crossvein present but no crossvein in anal area; and 5), in male, cup-a crossvein absent, but crossvein in anal area present in the female.

Measurements (in mm). CNU-LEP-NN-2006-001P/C: body length 4.3 ; width 0.9 . Forewing length 4.7 ; width 1.7 . Hind wing length 3.8; width 1.7. For GNU-LEP-NN-2006-002: body length 5.0 and width 1.1 ; forewing length 4.5 and width 1.8; and hind wing length 3.9 .

Remarks. Because there are many similarities in provenance and morphology between these two specimens from the same locality, we consider these two specimens to be conspecific male and female. The minor differences in the wing venation between male and female could be attributable to either individual variation or sexual dimorphism.

\section{Akainalepidopteron Zhang, Shih, Labandeira \& Ren gen. nov.}

urn:Isid:zoobank.org:act:F017D748-9F58-407E-87AF-

75063A531CCA.

Type species. Akainalepidopteron elachipteron Zhang, Shih, Labandeira \& Ren sp. nov.

Etymology. The generic name Akainalepidopteron is derived from the Greek akaina, (spine, thorn), referring to the piliform scales on the hind wing veins of this species; and "lepidos," the Greek name for "scale" or "flake"; and "pteron," Greek for "wing" or "fin." The root, lepidos, also refers to the Lepidoptera, the ordinal affiliation of this genus. The gender is masculine.

Distribution. Inner Mongolia Autonomous Region, China.
Diagnosis. Mesotibia with few short spines; metatibia with robust spines. Forewing and hind wing bear cilia on the anterior margin. Humeral vein present in forewing. Sc and $\mathrm{R}_{1}$ forked; all furcations of $\mathrm{Rs}_{1+2}, \mathrm{R}_{3+4}$, and $\mathrm{M}_{1+2}$ ca. at same level with each other. Hind wing Sc not forked. $\mathrm{R}_{1}$ forked; furcations of $\mathrm{Rs}_{1+2}$, $\mathrm{R}_{3+4}$, and $\mathrm{M}_{1+2}$ almost at the same level. Long, piliform scales present on several veins of hind wing. Crossvein cua-cup present.

An Eolepidopterigidae affiliation is supported by: 1), antennae less than half the length of forewing; 2), wings homoneurous; 3), M 3-branched; and 4), crossvein absent between Sc and R.

Comparison. The diagnostic autapomorphy of Akainalepidopteron consists of piliform scales present on the veins of the hind wing, a character not known to exist for any other lepidopteran fossil species. Akainalepidopteron exhibits a great similarity to Seresilepidopteron in venation, but differs in the position of some crossveins. The differences are: 1), in the forewing, Akainalepidopteron lacks $\mathrm{sc}-\mathrm{r}$ and $\mathrm{r}$ crossveins (vs. retention of these crossveins); 2 ), in the hind wing, the cua-cup crossvein is present in Akainalepidopteron (vs. absence); and 3), the sc-r crossvein is absent in Akainalepidopteron (vs. presence).

Akainalepidopteron also is similar to Daiopterix, especially to D. olgae that has wing cilia and metatibial spines. Akainolepidopteron is distinguished from Daiopterix by the following characters: 1), the cup- $\mathrm{a}_{1}$ crossvein is absent in Akainalepidopteron (vs. present); and 2), the humeral vein is present in Akainalepidopteron (vs. absent).

Compared with Undopterix, Akainalepidopteron is different in that: 1), it has forking of $\mathrm{Rs}_{1+2}$ at the same level as forking of $\mathrm{Rs}_{3+4}$ (vs. a stem $\mathrm{Rs}_{1+2}$ only half length of the stem $\mathrm{Rs}_{3+4}$ ); 2), the anterior margin of forewing and hind wing bears cilia in Akainalepidopteron (vs. lacking cilia); and 3), the metatibiae has spines in Akainalepidopteron (vs. lacking spines).

Akainalepidopteron elachipteron Zhang, Shih, Labandeira \& Ren sp. nov. (Figs. 5, 6)

urn:lsid:zoobank.org:act:6D4EBD55-F1FA-4F7F-BA7EB95C0D0C0F65.

Etymology. The specific name is derived from the Greek, elachys (short, small), and pteron (wing, fin), referring to the wing of this species that is shorter than its body length.

Type materials. Holotype: GNU-LEP-NN-2012-024; \&; well preserved fore and hind wings; anal area covered by body and portions of the legs. Paratypes: CNU-LEP-NN-2012-023; o; well preserved legs; anal area covered by body and part of hind wing; and CNU-LEP-NN-2012-026; sex unknown; a well preserved forewing; anal area poorly preserved.

Locality and horizon. These specimens were collected from Daohugou Village, Shantou Township, Ningcheng County, Inner Mongolia Autonomous Region, China. The age is latest Middle Jurassic, near the Callovian-Oxfordian boundary.

Diagnosis. Same as generic diagnosis.

Description. Head length subequal to width, invested with dense setae on the anterior margin. Antennae filiform, tapered to apex; length of segments equal to their diameter. Eyes oval, with sparse setae on the outer margin.

Forecoxae more robust than forefemora; femora ca. 1.6 times as long as foretibiae, slightly longer than foretarsi. Epiphyses indiscernible. Mesocoxae more slender than forecoxae; mesofemora longer than mesotibia; two long spines present at the end of mesofemora; mesotibia with spines. Metafemora robust and short, less than half the length of metatibia; metatibia with irregularly arranged spines at the distal part, and with one pair medial spurs and one pair apical spurs. All tarsal segments with terminal spinules. 


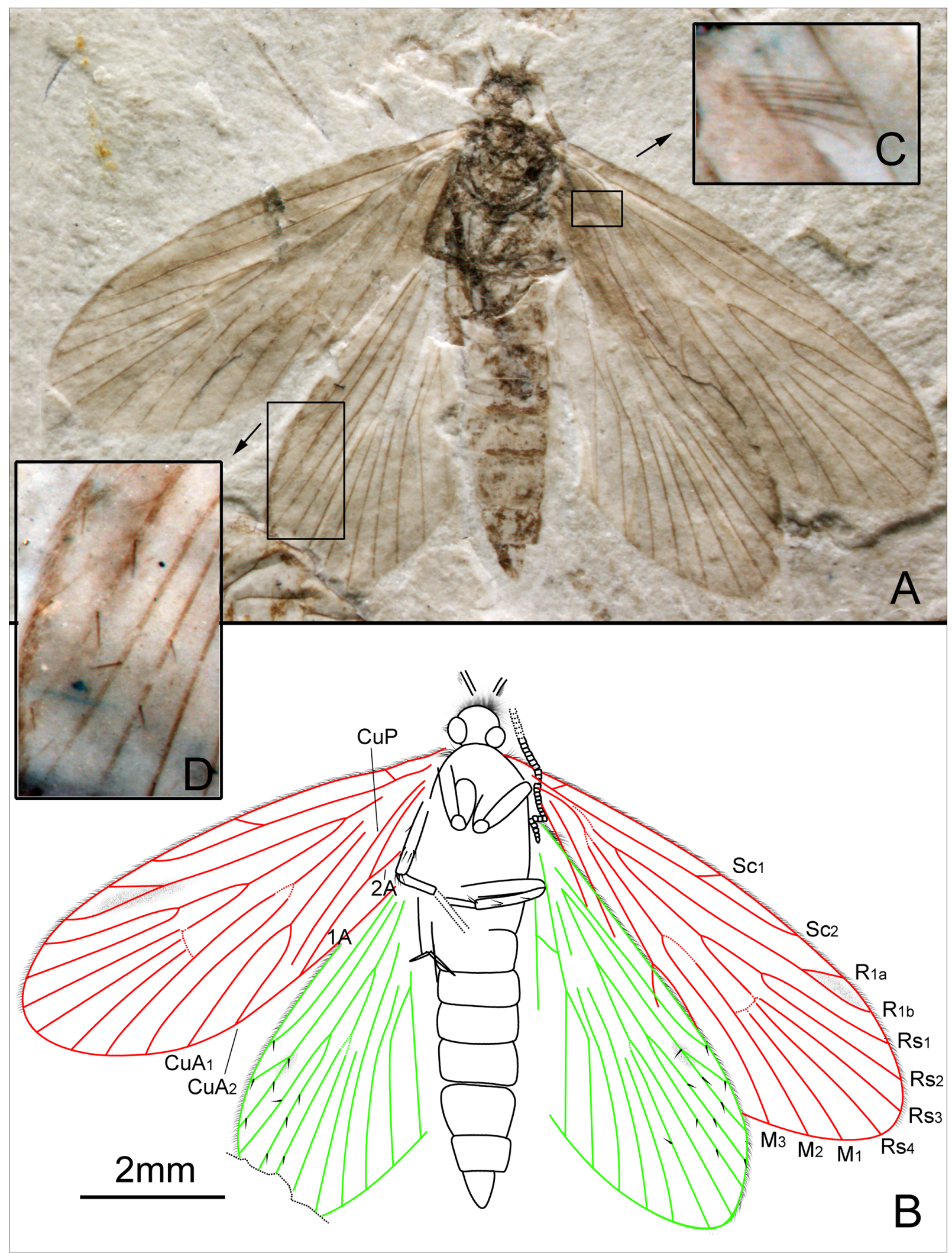

Figure 5. Akainalepidopteron elachipteron gen. et sp. nov. Female, holotype, CNU-LEP-NN-2012-024. (A), Fossil specimen. (B), Camera lucida drawing of (A), showing overall habitus. (C), A cluster of frenular bristles (wing coupling apparatus) on hind wing, outlined at the upper-right rectangular template in (A). (D), Piliform scales on hind wing, outlined at the lower-left rectangular template in (A). doi:10.1371/journal.pone.0079500.g005 

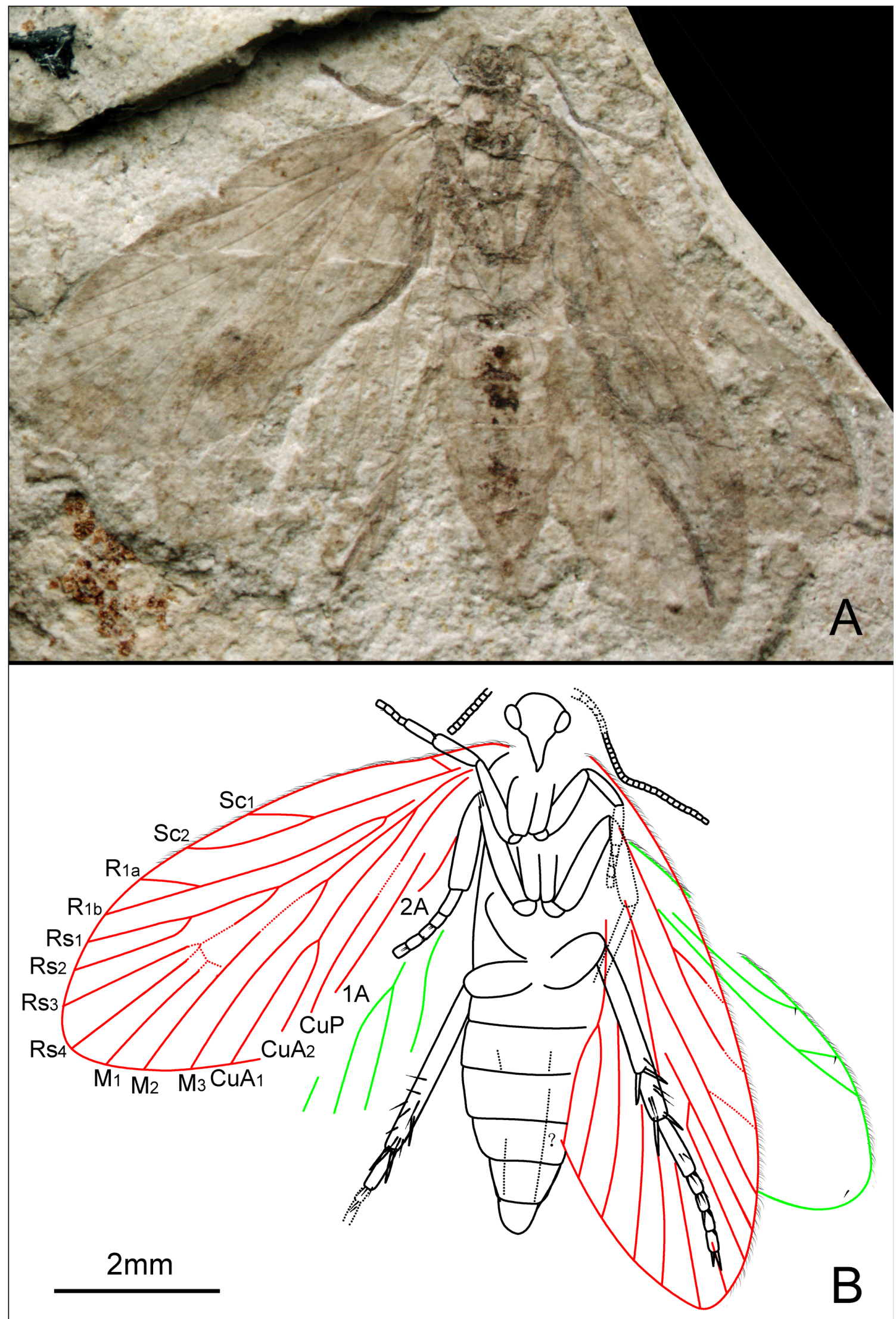

Figure 6. Akainalepidopteron elachipteron gen. et sp. nov. Female, paratype, CNU-LEP-NN-2012-023. (A), Fossil specimen. (B), Camera lucida drawing of (A), showing overall habitus. doi:10.1371/journal.pone.0079500.g006 


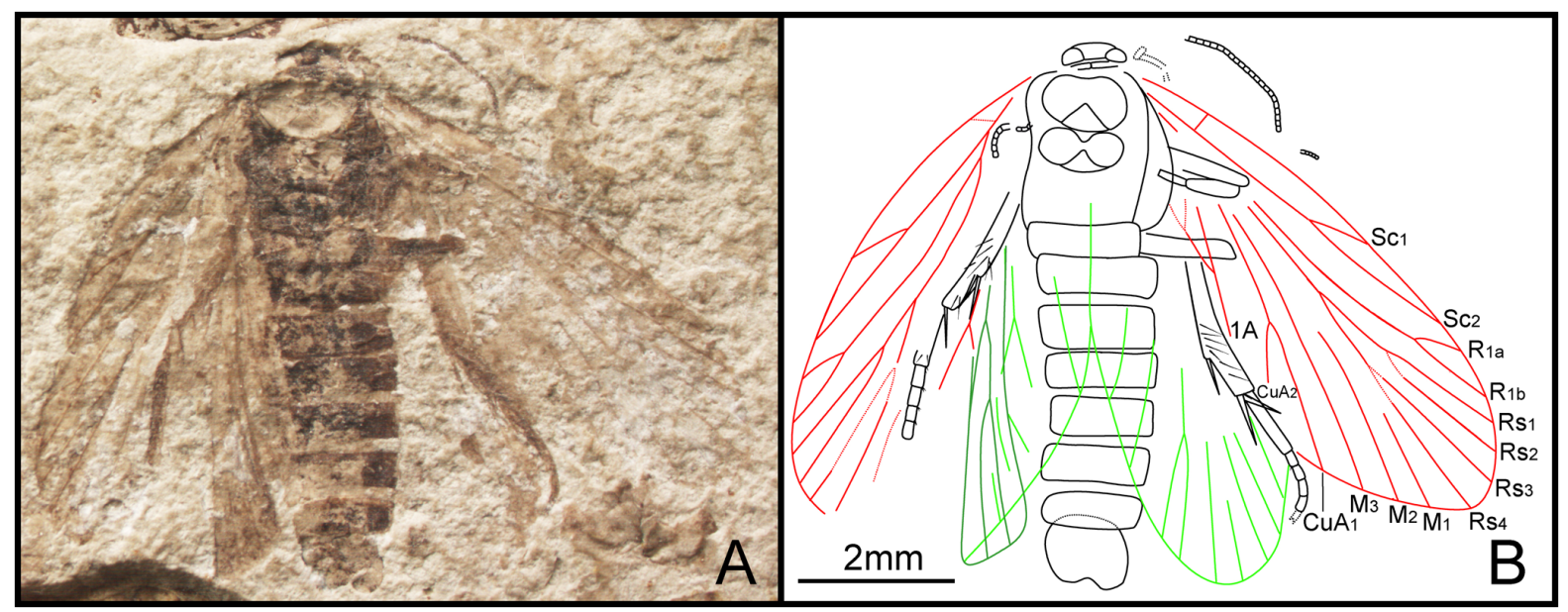

Figure 7. Dynamilepidopteron aspinosus gen. et sp. nov. Male, holotype, CNU-LEP-NN-2012-014. (A), Fossil specimen. (B), Camera lucida drawing of $(A)$, showing overall habitus. doi:10.1371/journal.pone.0079500.g007

Forewing ca. 2.9 times as long as wide; anterior margin bearing cilia; pterostigma present. Humeral vein present. Sc forked from distal 1/3 of stem; $\mathrm{Sc}_{2}$ extending to the costal margin at 2/3 length of the wing from its base. $\mathrm{R}_{1}$ forked distally; $\mathrm{Rs}$ 4-branched; $\mathrm{Rs}_{4}$ ending slightly below the apex of forewing; $\mathrm{Rs}_{1+2}$ stalked ca. $0.3-$ 0.5 of their total length; stem $\mathrm{Rs}_{1+2}$ subequal to stem $\mathrm{Rs}_{3+4}$. M 3branched. Hyaline zones surrounding $\mathrm{r}-\mathrm{m}$ crossvein, at $\mathrm{Rs}_{3+4}$ and $\mathrm{M}_{1+2}$ furcations. CuA bifurcated; CuP simple; anal area not well preserved. CuA divergent from $\mathrm{M}$. R forks immediately after $\mathrm{M}-$ $\mathrm{CuA}$ furcation. Hind wing ca. 2.4 times as long as wide; anterior margin bearing cilia, and a cluster of ca. 7 frenular bristles arising near the base of $\mathrm{C}$ on hind wing (Fig. 5C). Sc not forked, extending 2/3 length of the wing from its base. $\mathrm{R}_{1}$ forked; Rs 4-branched; $\mathrm{Rs}_{1+2}$ forked at the same level with $\mathrm{Rs}_{3+4}$. M 3-branched. CuA bifurcated; CuP simple. Crossvein cua-cup slanted obliquely. Piliform scales ranging from 0.12 to $0.21 \mathrm{~mm}$ in length, present on veins $\mathrm{Sc}, \mathrm{R}_{1 \mathrm{a}}, \mathrm{R}_{1 \mathrm{~b}}, \mathrm{Rs}_{1}, \mathrm{Rs}_{2}, \mathrm{Rs}_{3}$ and $\mathrm{Rs}_{4}$ (Figs. 5 B,D).

Female genitalia with short ovipositor; apophyses probably present.

Measurements (in mm). CNU-LEP-NN-2012-024: body length 7.2 and width 1.5 ; forewing length 7.3 and width ca. 2.5; hind wing length 6.2 and width ca. 2.6. CNU-LEP-NN-2012-023: body length 6.3 and width 1.3; forewing length ca. 6.0 and width ca. 2.4; Hind wing length ca. 5.3. CNU-LEP-NN-2012-026: forewing length ca. 11.1, width 5.1.

Remarks. There are three forms of wing-coupling in Lepidoptera: the jugate, frenate and amplexi conditions. The frenular bristles on the anterior margin of the hind wing of CNULEP-NN-2012-024 (Fig. 5C) probably played an important role in wing-coupling. Because the jugum is not discernible in these specimens and the female possesses multiple frenular bristles, we believe that this species probably possessed a modified jugatefrenate form of wing-coupling.

Piliform scales, with lengths between 0.07 and $0.08 \mathrm{~mm}$, are present on some lepidopterans, e.g. Heterobathmia pseuderiocrania Kristensen \& Nielsen, 1979, with body lengths from 3.2 to $3.6 \mathrm{~mm}$ and forewing lengths from 4.5 to $5.0 \mathrm{~mm}$ [34]. The scales present on the hind wing veins of CNU-LEP-NN-2012-024 are of similar shape and length (adjusted for lengths of body and wings) to those piliform scales along the veins of $H$. pseuderiocrania.
Dynamilepidopteron Zhang, Shih, Labandeira \& Ren gen. nov.

urn:Isid:zoobank.org:act:31AD01ED-D78A-45D0-8E80AB92CC94977F.

Type species. Dynamilepidopteron aspinosus Zhang, Shih, Labandeira \& Ren sp. nov.

Etymology. The generic name is derived from the Greek, dynamis (power, strength), referring to the robust hind leg of this genus; and lepidos, Greek for "scale" or "flake," also referring to the ordinal name, Lepidoptera, to which this genus belongs; and pteron, meaning "wing" or "fin" in Greek. The gender is masculine.

Distribution. Inner Mongolia Autonomous Region, China.

Diagnosis. Body relatively large, ca. $7 \mathrm{~mm}$ long. Metatibia robust, with strong spines. Forewing and hind wing lack cilia on the anterior margin. Humeral vein present in forewing. Sc and $R_{1}$ forked; all furcations of $\mathrm{Rs}_{1+2}$ and $\mathrm{Rs}_{3+4}$ veins at same level. Hind wing lacking spines.

An Eolepidopterigidae affiliation is supported by: 1), antennae less than half the length of forewing; 2), wings homoneurous; 3), M 3-branched; and 4), crossvein absent between Sc and R.

Comparison. Dynamilepidopteron is similar to Akainalepidopteron in venation, but: 1), the former lacks cilia on the anterior wing margins (vs. both forewing and hind wing with cilia); and 2), the hind wing lacks spines on the veins (vs. spines present on the veins).

Dynamilepidopteron aspinosus Zhang, Shih, Labandeira \& Ren sp. nov. (Fig. 7)

urn:lsid:zoobank.org:act:EB75EC3D-5811-43EE-9232-

F755D5B1EED8.

Etymology. The specific name is derived from the Latin, aspinosus (the absence of spines), in reference to the hind wing lacking spines.

Type material. Holotype: CNU-LEP-NN-2012-014; ơ; well preserved forewings, thorax and hind legs.

Locality and horizon. This specimen was collected from Daohugou Village, Shantou Township, Ningcheng County, Inner Mongolia Autonomous Region, China. The age is latest Middle Jurassic, near the Callovian-Oxfordian boundary.

Diagnosis. Same as generic diagnosis.

Description. Head short and broad, possibly due to preservation. Antennae filiform; length of segments equal to their 

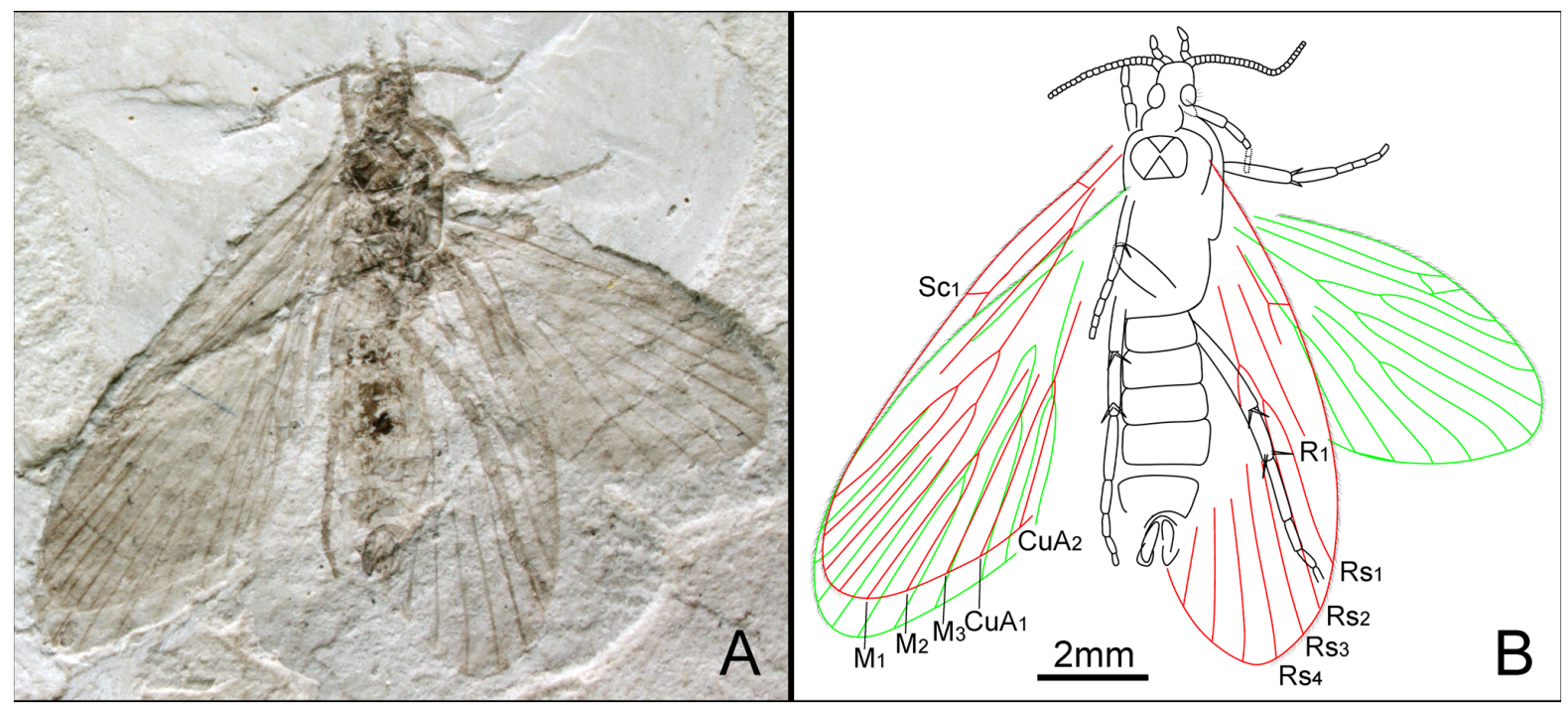

Figure 8. Quadruplecivena celsa gen. et sp. nov. Male, holotype, CNU-LEP-NN-2012-027. (A), Fossil specimen. (B), Camera lucida drawing of (A), showing overall habitus.

doi:10.1371/journal.pone.0079500.g008

diameter basally, the length ca. 1.5 times as long as their diameter distally. Maxillary palpus visible, obtuse aspect apically. Mesoscutum broader than long, posterior edges of mesoscutum concave along midline; mesoscutellum flabellate, relatively large, nearly equal to mesoscutum in length; metascutum dumbbell shaped; metascutellum smaller than mesoscutellum. Metatibia relatively robust; with irregularly arranged spines, bearing two pairs of spurs, one pair apically and the other pair arising slightly beyond middle of tibia; all spurs ca. 1.5-2 times as long as diameter of tibia. Metatarsi 5-segmented; tarsomere I longest, nearly equal to the total length of tarsomeres II, III, IV and V combined; two spinules at the apex of each tarsomere.

Forewing 2.8 times as long as wide. Humeral vein present. Sc forked from $2 / 5$ of the stem length; $\mathrm{Sc}_{1}$, extending midway along costal margin; $\mathrm{Sc}_{2}$ beyond $2 / 3$ the length of the wing from its base. $\mathrm{R}_{1}$ forked distally, slightly beyond $\mathrm{Rs}_{1+2}$ furcation; $\mathrm{Rs}_{\mathrm{s}} 4$-branched; $\mathrm{Rs}_{4}$ terminating slightly below the apex of forewing; $\mathrm{Rs}_{1+2}$ stalked ca. $0.3-0.4$ of their total length; $\mathrm{Rs}_{3}$ and $\mathrm{Rs}_{4}$ free; stem $\mathrm{Rs}_{1+2}$ subequal in length to stem $\mathrm{Rs}_{3+4}$. M 3-branched. CuA bifurcated; $\mathrm{CuP}$ not preserved. Three anal veins looping into a double-Y configuration.

Measurements (in mm). Body length 7.0; width 1.9 . Forewing length 6.7; width ca. 2.4. Hind wing length ca. 5.5.

\section{Quadruplecivena Zhang, Shih, Labandeira \& Ren gen. nov. urn:lsid:zoobank.org:act:878C8B3C-643E-4C46-B56A-AB-} DA90AEB775.

Type species. Quadruplecivena celsa Zhang, Shih, Labandeira \& Ren sp. nov.

Etymology. The generic name, Quadruplecivena, is derived from the Latin, quadruplex (quadruple, fourfold); and vena (vein, blood vessel); which jointly refers to the costal margin of hind wing that consists of a Sc, $\mathrm{sc}-\mathrm{r}_{1}$ crossvein and a $\mathrm{R}_{1 \mathrm{a}}$, forming a quadrate configuration. The gender is feminine.

Distribution. Inner Mongolia Autonomous Region, China.

Diagnosis. Labial palpus 3-segmented. All legs lacking spines. Anterior margins of fore and hind wings with cilia. Forewing with humeral vein; $\mathrm{Sc}$ forked; $\mathrm{R}_{1}$ not forked; $\mathrm{Rs}_{1+2}$ forking at same level with $\mathrm{Rs}_{3+4}$, and before $\mathrm{M}_{1+2}$ forking. Hind wing $\mathrm{Sc}_{\mathrm{c}}$ not forked; $\mathrm{R}_{1}$ forked; $\mathrm{sc}-\mathrm{r}_{1}$ crossvein present.
An Eolepidopterigidae affiliation is supported by: 1), antennae less than half the length of forewing; 2), mesotibia with a pair of spurs; 3), wings homoneurous; and 4), M 3-branched.

Comparison. Quadruplecitvena differs from Seresilepidopteron in the following characters: in the forewing, 1), the $\mathrm{M}_{1+2}$ distinctly extends beyond the $\mathrm{Rs}_{3+4}$ furcation (vs. the $\mathrm{M}_{1+2}$ and $\mathrm{Rs}_{3+4}$ furcations occurring at the same level); 2), the sc-r crossvein is absent (vs. presence of the sc-r crossvein); and 3), hind wing $\mathrm{sc}^{-} \mathrm{r}_{1}$ crossvein is near the $\mathrm{R}_{1}$ furcation (vs. the $\mathrm{sc}-\mathrm{r}$ crossvein considerably removed from the $\mathrm{R}_{1}$ furcation). Quadruplecivena differs from Akainalepidopteron in the following characters: 1), the $\mathrm{M}_{1+2}$ furcation distinctly extends beyond the $\mathrm{Rs}_{3+4}$ furcation (vs. the $\mathrm{M}_{1+2}$ and $\mathrm{Rs}_{3+4}$ furcations occurring at the same level); 2), the $\mathrm{M}_{1}$ is not sharply angulate at the junction with the $\mathrm{r}-\mathrm{m}$ crossvein (vs. $\mathrm{M}_{1}$ sharply angulate at the junction with $\mathrm{r}-\mathrm{m}$ crossvein); 3 ), the hind wing lacks spines (vs. hind wing with spines); 4), the $\mathrm{sc}-\mathrm{r}_{1}$ crossvein is present and the cua-cup crossvein absent (vs. the sc- $\mathrm{r}_{1}$ crossvein absent, and the cua-cup crossvein present); and 5), the legs lack spines (vs. legs with irregularly arranged spines).

Quadruplecivena celsa Zhang, Shih, Labandeira \& Ren sp. nov. (Figs. 8, 9)

urn:lsid:zoobank.org:act:1EBA2307-D14A-4B56-93B2-

2069AA3BA10D.

Etymology. The specific name is derived from the Latin celsa (eminent, noble) in reference to the labial palpi, which are prominent and resemble a crown, providing a noble or regal appearance.

Type material. Holotype: CNU-LEP-NN-2012-027; or; consisting of a well-preserved head, with antennae and labial palpi; well-preserved legs. Left fore- and hind wings overlapping. The right fore- and hind wings are partially preserved; the anal area is poorly preserved. The left hind wing is unusually longer than the right hind wing, probably due to deformation of the matrix or actual wing asymmetry of this particular individual.

Locality and horizon. This specimen was collected from Daohugou Village, Shantou Township, Ningcheng County, Inner Mongolia Autonomous Region, China. The age is latest Middle Jurassic, near the Callovian-Oxfordian boundary. 


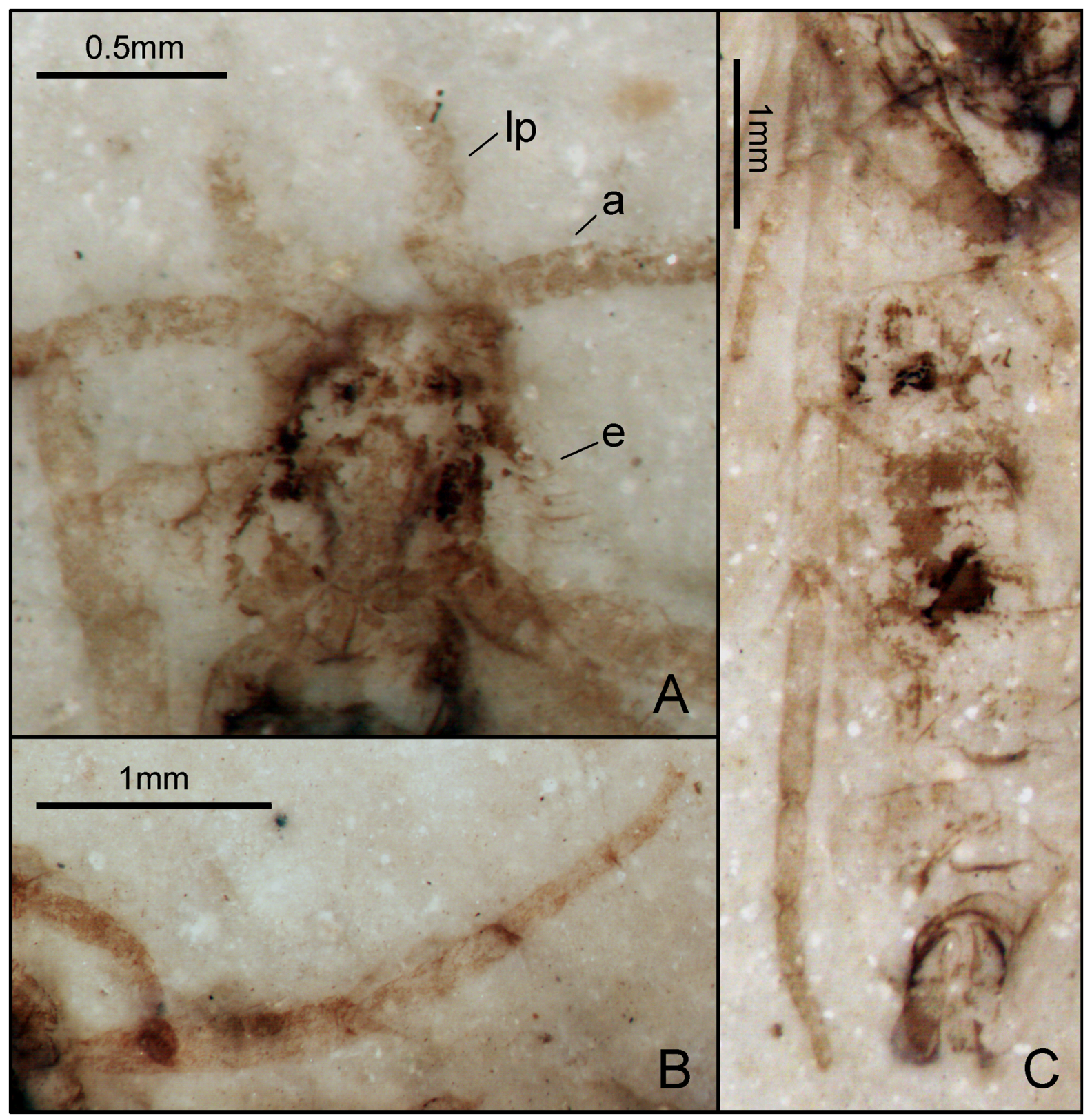

Figure 9. Quadruplecivena celsa gen. et sp. nov. CNU-LEP-NN-2012-027. (A), Head of fossil specimen. (B), Right mid leg. (C), Hind leg and abdomen. Abbreviations: a, antennae; e, eye; lp, labial palpus. doi:10.1371/journal.pone.0079500.g009

Diagnosis. Same as generic diagnosis.

Description. Male. Antennae filiform, tapered to apex, ca. $1 / 3$ as long as forewing; length of segments shorter than their diameter basally, subequal to their diameter distally. Compound eyes bearing long sparse setae. Labial palpi 3-segmented (Fig. 9A), the last two segments nearly equal in length; apical palpal segments tapered toward apex. Mesothorax with large prescutum; anterior and posterior edge of mesonotum distinctly concave along midline; mesoscutellum triangular. Foretibial epiphysis indistinct. Mesotibia with one pair of apical spurs (Fig. 9B). Metatibia with one pair of medial spurs and one pair of apical spurs (Fig. 9C). Metatarsi 5-segmented, tarsomere I ca. 1.9 times as long as tarsomere II; tarsomere II ca. 1.6 times as long as tarsomere III; tarsomere III subequal to tarsomere IV, and slightly longer than tarsomere V. All tarsal segments lacking terminal spinules.

Forewing 3 times as long as wide; anterior margin bearing cilia. Humeral vein present. Sc forked. Rs 4-branched; $\mathrm{Rs}_{1+2}$ stalked ca. 0.2 of their total length; $\mathrm{Rs}_{1+2}$ forked at the same level as $\mathrm{Rs}_{3+4}$ furcation; $\mathrm{Rs}_{4}$ and $\mathrm{M}_{1}$ respectively above and below wing apex. $\mathrm{M}$ 3-branched; $M_{1}$ and $M_{2}$ stalked; $M_{1+2}$ forked beyond $\mathrm{R}_{3+4}$ furcation. $\mathrm{CuA}$ bifurcated. Anal veins not preserved. In hind wing, $\mathrm{Sc}$ not forked. $\mathrm{R}_{1}$ forked; crossvein $\mathrm{sc}-\mathrm{r}_{1}$ present and slightly curved and oblique, originating near end of Sc and terminating near $\mathrm{R}_{1}$ furcation; $\mathrm{Rs}$ 4-branched; stem $\mathrm{Rs}_{1+2}$ slightly longer than $\mathrm{R}_{\mathrm{s}_{3+4}}$. M 3-branched; $\mathrm{M}_{1+2}$ forked beyond $\mathrm{R}_{3+4}$ furcation; $\mathrm{M}_{3}$ curved at 2/3 the length of vein $\mathrm{M}_{3}$ from its base. CuA bifurcated. 


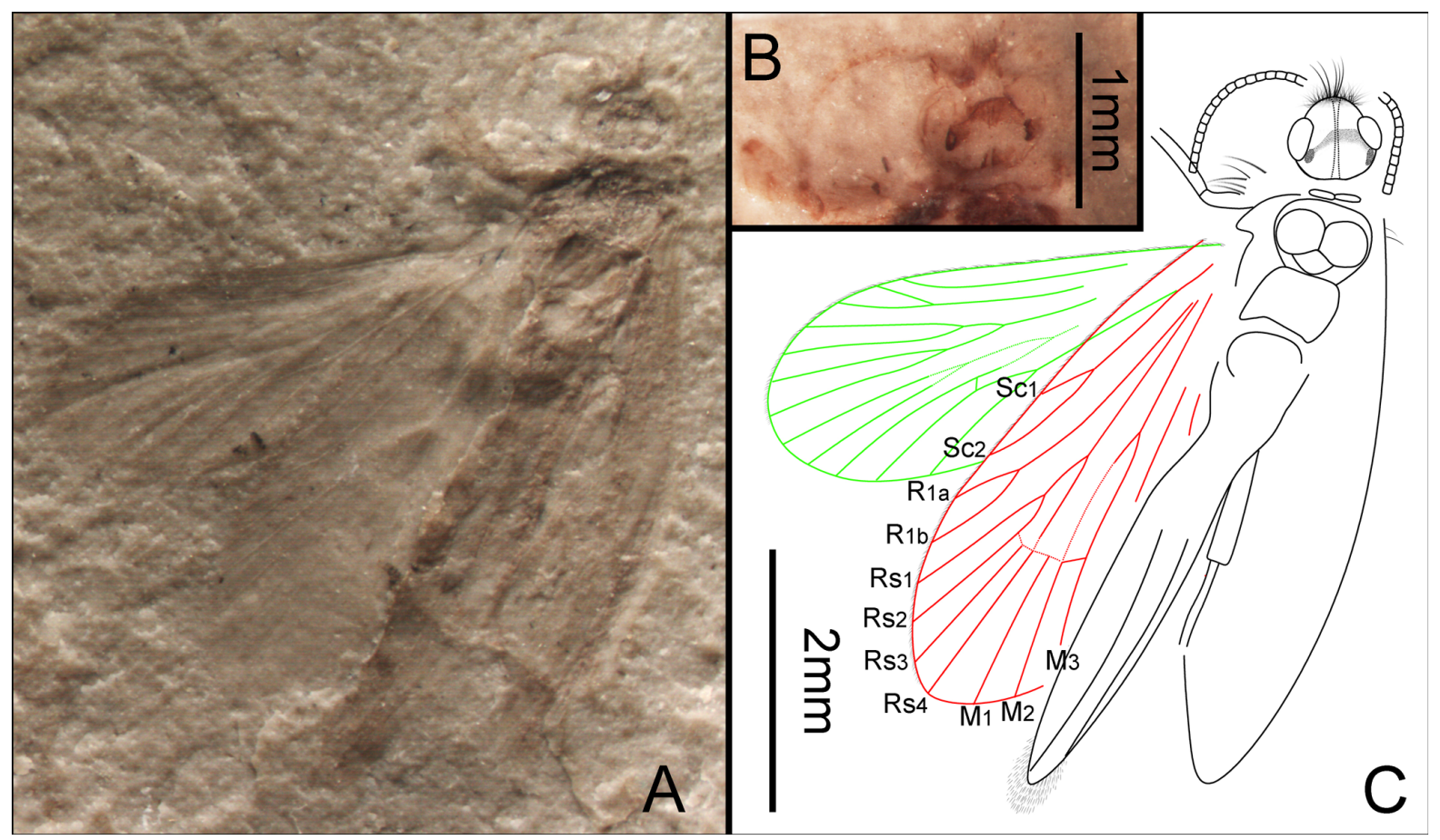

Figure 10. Petilicorpus cristatus gen. et sp. nov. Female, holotype, CNU-LEP-NN-2012-007. (A), Fossil specimen. (B), Head and associated structures. (C), Camera lucida drawing of $(A)$, showing overall habitus. doi:10.1371/journal.pone.0079500.g010

Measurements (in mm). Body length ca. 9.5; width 1.9. Forewing length 9.8; width ca. 3.3. Hind wing length ca. 7.8 (right wing) and 9.8 (left wing); width 3.8 (right wing) and 3.4 (left wing).

\section{Petilicorpus Zhang, Shih, Labandeira \& Ren gen. nov. urn:lsid:zoobank.org:act:070D5F91-A174-4BE8-A0B1- 503475BF1817.}

Type species. Petilicorpus cristatus Zhang, Shih, Labandeira \& Ren sp. nov.

Etymology. The generic name is derived from the Latin petilis (thin, slender), and corpus (body, substance), which collectively refers to the gracile body shape of this species. The gender is masculine.

Distribution. Inner Mongolia Autonomous Region, China.

Diagnosis. Body slender. Anterior margins of fore and hind wing with cilia. In forewing, $\mathrm{Sc}$ and $\mathrm{R}_{1}$ forked; Rs branched into $\mathrm{Rs}_{1+2}$, and $\mathrm{Rs}_{3+4} ; \mathrm{Rs}_{3+4}$ forked beyond that of $\mathrm{Rs}_{1+2} ; \mathrm{Rs}_{3+4}$ furcation nearly at same level as $\mathrm{M}_{1+2}$ furcation; crossvein $\mathrm{m}$ present. Hind wing with $\mathrm{Sc}$ not forked; $\mathrm{R}_{1}$ forked. In female, apophyses well developed.

An Eolepidopterigidae affiliation is supported by: 1), wings homoneurous; 2), M 3-branched; 3), ovipositor segments with long apophyses anteriores; and 4) crossvein absent between Sc and R.

Comparison. Petilicorpus gen. nov. is assigned to the Eolepidopterigina for having a long apophyses in the abdomen and the $M$ vein 3-branched in the forewing. Petilicorpus resembles Eolepidopterix in having the presence of a slender body and similar forewing length and antennal length. However, Petilicorpus differs from Eolepidopterix in the following characters: 1), the pronotum is short with a length of $0.05 \mathrm{~mm}$ and a width/length ratio of 8.0 (vs. pronotum relatively long with length of $0.19 \mathrm{~mm}$ and width/ length ratio of 2.9); 2), the Sc vein is forked distally (vs. the Sc vein branching near the base of the forewing); and 3), the anterior margins of both the fore- and hind wings bear cilia (vs. lacking cilia). The wing of Paleolepidopterix is not well preserved. Based on the present specimen, Petilicorpus can be differentiated from Paleolepidopterix by its longer head and shorter pronotum. The venation of Petilicorpus resembles Daiopterix in the following characters: 1), the $\mathrm{Sc}$ and $\mathrm{R}_{1}$ are forked; and 2), the $\mathrm{Rs}_{1+2}$ stem is shorter than the $\mathrm{Rs}_{3+4}$ stem. In addition, Petilicorpus can be separated from Daiopterix by: 1), possession of a long Sc vein (vs. a short $\mathrm{Sc}$ vein); 2), the $\mathrm{Sc}_{2}$ vein extending beyond the $\mathrm{Rs}_{1+2}$ furcation (vs. the $\mathrm{Sc}_{2}$ not reaching the $\mathrm{Rs}_{1+2}$ furcation); and 3), the $\mathrm{m}$ crossvein is present (vs. m crossvein absent).

\section{Petilicorpus cristatus Zhang, Shih, Labandeira \& Ren sp. nov. (Fig. 10) \\ urn:lsid:zoobank.org:act:7D597FB8-6196-4664-9BB6- 087BCABF95B2.}

Etymology. The specific name is derived from the Latin, cristatus (bearing a crest, cluster of plumes), in reference to setae on the head.

Type material. Holotype: GNU-LEP-NN-2012-007; क; left fore and hind wings well preserved; anal areas are obscured.

Locality and horizon. This specimen was collected from Daohugou Village, Shantou Township, Ningcheng County, Inner Mongolia Autonomous Region, China. The age is latest Middle Jurassic, near the Callovian-Oxfordian boundary.

Diagnosis. Same as generic diagnosis.

Description. Female. Body slender and entirely covered by setae. Head slightly longer than wide, anterior edge with clusters of setae pointing forward. Antennae filiform, less than half length of forewing; length of segments equal to their diameter. Eyes oval. A pair of chaetosemata present near eyes (Fig. 10B). Median ocellus absent. Prothorax much broader than length, with a pair of transverse structures that are adjacent mesially. Mesoscutum broader than long, posterior edge concave along midline; mesoscutellum flabellate, slightly shorter than mesoscutum. 


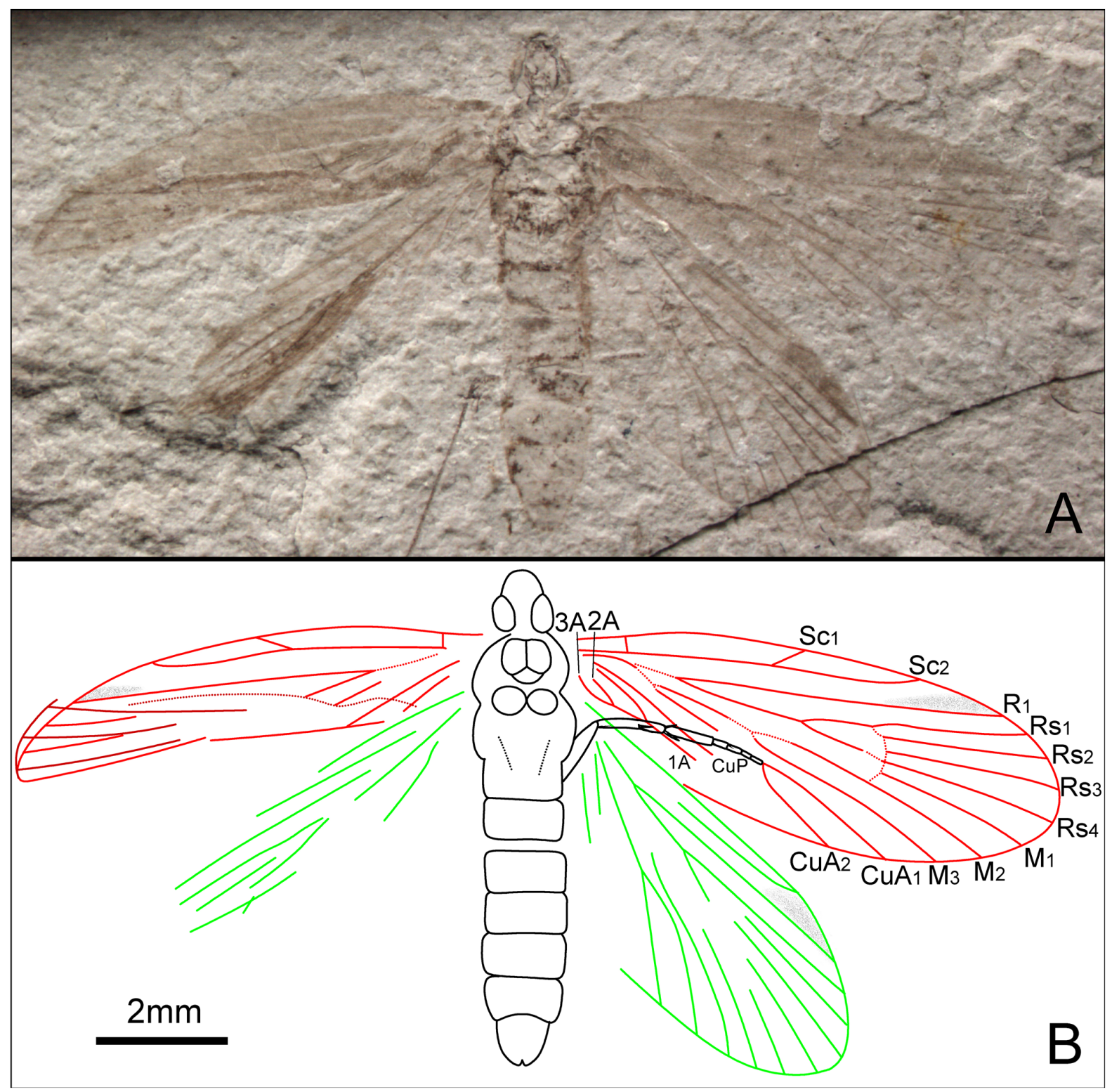

Figure 11. Longcapitalis excelsus gen. et sp. nov. Female, holotype, CNU-LEP-NN-2012-025P. (A), Fossil specimen. (B), Camera lucida drawing of (A), showing overall habitus.

doi:10.1371/journal.pone.0079500.g011

Mesothorax large. Long setae present on the sides of prothorax and mesothorax.

Anterior margins of both fore- and hind wings bear cilia. Forewing humeral vein indiscernible. Sc forked from distal $1 / 3$ of the stem; $\mathrm{Sc}_{1}$ extended to the costal margin beyond the $1 / 3$ the length of the wing from its base; $\mathrm{Sc}_{2}$ extended beyond the $1 / 2$ length of the wing from its base. $\mathrm{R}_{1}$ forked, almost at same level as the $\mathrm{Rs}_{1+2}$ furcation; $\mathrm{Rs}$ 4-branched; $\mathrm{Rs}_{4}$ terminating at apex of forewing; $\mathrm{Rs}_{1+2}$ stalked ca. 0.4 of total vein length; $\mathrm{Rs}_{3}$ and $\mathrm{Rs}_{4}$ free; $\mathrm{Rs}_{1+2}$ stem slightly shorter than $\mathrm{Rs}_{3+4}$ stem. M 3-branched. Hyaline zones surround $\mathrm{r}-\mathrm{m}$ crossvein and at $\mathrm{Rs}_{3+4}$ and $\mathrm{M}_{1+2}$ furcations. Crossvein $\mathrm{m}$ present, originating near $\mathrm{M}_{1+2}$ furcation and terminating at the midpoint of $\mathrm{M}_{3}$. Hind wing ca. 2.3 times as long as wide. Venation similar to forewing; Sc not forked, $\mathrm{m}$ crossvein absent and $\mathrm{m}_{3}-$ cua $_{1}$ crossvein present. CuA bifurcated. In female, apophyses slender, almost $2 / 3$ as long as abdomen.
Abdominal terminus (possibly the papillae anales) covered by dense long setae.

Measurements (in mm). Body length 6.6; width 0.9 . Forewing length 5.2; hind wing length 5.0, width ca. 2.1.

Longcapitalis Zhang, Shih, Labandeira \& Ren gen. nov urn:Isid:zoobank.org:act:5DEA5662-B07C-4DF6-9784008E56B7A61F.

Type species. Longcapitalis excelsus Zhang, Shih, Labandeira \& Ren sp. nov.

Etymology. The generic name is derived from the Latin, longus (long, extended), and capitalis (head of a living creature), in reference to the elongate head of this species. The gender is masculine.

Distribution. Inner Mongolia Autonomous Region, China. 


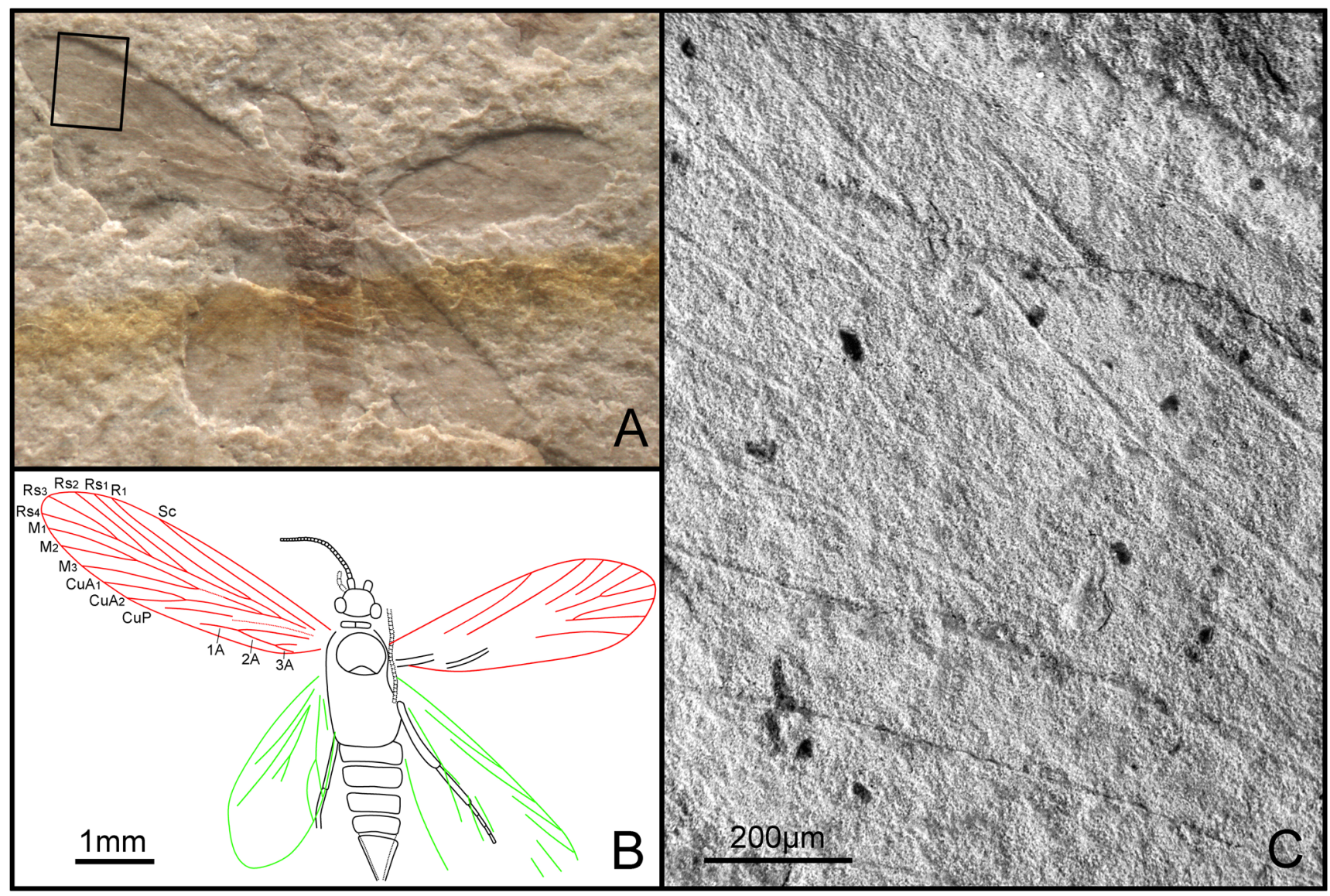

Figure 12. Grammikolepidopteron extensus gen. et sp. nov. Female, holotype, CNU-LEP-NN-2012-006P. (A), Fossil specimen. (B), Camera lucida drawing of (A), showing overall habitus. (C), SEM micrograph showing the left forewing venation, enlarged from the rectangular template in (A). doi:10.1371/journal.pone.0079500.g012

Diagnosis. Head longer than wide. Metatibiae lacking spines. Anterior margin of wings lacking cilia. Humeral vein in forewing present. Sc forked. $\mathrm{R}_{1}$ not forked. All furcations of $\mathrm{R}_{1+2}, \mathrm{R}_{3+4}$, and $\mathrm{M}_{1+2}$ almost at the same level with each other. Anal veins looping into a double-Y configuration. Hind wing with $\mathrm{Sc}_{\mathrm{c}}$ and $\mathrm{R}_{1}$ not forked. Veins on hind wing lacking spines.

An Eolepidopterigidae affiliation is supported by: 1), wings homoneurous; 2), M 3-branched; and 3), crossvein absent between $\mathrm{Sc}$ and $\mathrm{R}$.

Comparison. The venation of Longcapitalis resembles that of other Eolepidopterigidae, but this new genus lacks a $\mathrm{R}_{1}$ furcation in the forewing, making it different from all other species of Eolepidopterigidae. Longcapitalis shows great similarity to the genus Undopterix, but it differs from the latter in the following characters: 1), the $R_{1}$ is not forked in both fore- and hind wings (vs. $R_{1}$ forked in the fore- and hind wings); 2), the $\mathrm{Rs}_{1+2}$ stem is as long as the $\mathrm{Rs}_{3+4}$ stem (vs. the $\mathrm{Rs}_{1+2}$ stem shorter than the $\mathrm{Rs}_{3+4}$ stem); and 3), the anal veins form a double-Y loop (vs. the anal veins forming a single-Y loop). Longcapitalis differs from Akainalepidopteron by the following characters: 1 ), the $\mathrm{R}_{1}$ is not forked in both fore- and hind wings (vs. $\mathrm{R}_{1}$ forked); 2), the hind wing lacks spines (vs. spines present on several veins on hind wing); 3), the wings lack cilia (vs. cilia present on anterior margins of the fore- and hind wings); and 4), the metatibiae lack spines (vs. the metatibiae bearing irregularly arranged spines).
Longcapitalis excelsus Zhang, Shih, Labandeira \& Ren sp. nov. (Fig. 11)

urn:lsid:zoobank.org:act:4C76B3E1-673A-4D9C-958FB866E4DD0055.

Etymology. The specific name is derived from the Latin, excelsus (tall, large), in reference to the comparatively large body size of this species.

Type material. Holotype: GNU-LEP-NN-2012-025P/C (part and counterpart); o; well preserved forewings, hindleg, and portion of hind wings.

Locality and horizon. This specimen was collected from Daohugou Village, Shantou Township, Ningcheng County, Inner Mongolia Autonomous Region, China. The age is latest Middle Jurassic, near the Callovian-Oxfordian boundary.

Diagnosis. Same as generic diagnosis.

Description. Head relatively long (ca. $0.9 \mathrm{~mm}$ ), longer than wide; compound eyes elongate oval. Mesonotum slightly broader than long, with median suture; posterior edge concave along midline; mesoscutellum small, ca. half length of mesoscutum. Metafemora with a spine at the end of femora. Metatibiae with one pair medial spurs and one pair apical spurs. Metatarsi 5segmented, all tarsal segments with terminal spinules.

Forewing 2.7 times as long as wide, bearing a humeral vein; pterostigma present. Sc forked, at distal $2 / 5$ of the stem, $\mathrm{Sc}_{1}$, almost extending to the midpoint of wing costal margin; $\mathrm{Sc}_{2}$ 
extending to costal margin of wing, beyond 2/3 length of wing from base. $\mathrm{R}_{1}$ not forked; Rs 4-branched; $\mathrm{Rs}_{4}$ extending to apex of forewing; $\mathrm{Rs}_{1+2}$ stalked ca. to 0.4 of the total vein length; $\mathrm{Rs}_{3}$ and $\mathrm{Rs}_{4}$ free; and $\mathrm{Rs}_{1+2}$ stem subequal to $\mathrm{Rs}_{3+4}$ stem. M 3-branched. Hyaline zones surround $\mathrm{r}-\mathrm{m}$ crossvein at $\mathrm{Rs}_{1+2}$ furcation, and at the $\mathrm{Rs}_{3+4}, \mathrm{M}_{1+2}$ and $\mathrm{M}_{1+2}-\mathrm{M}_{3}$ furcations. CuA bifurcated; $\mathrm{CuP}$ simple. Anal veins looping into a double-Y configuration. Hind wing 2.6 times as long as wide. Sc not forked. $\mathrm{R}_{1}$ not forked. Rs 4branched. M 3-branched. CuA bifurcated; CuP simple. Anal area not well preserved.

Measurements (in mm). Body length ca. 7.9; width 1.7. Forewing length 8.2; width 3.0. Hind wing length ca. 7.3; width 2.8 .

\section{Grammikolepidopteron Zhang, Shih, Labandeira \& Ren gen. nov. \\ urn:lsid:zoobank.org:act:6EB3F8BB-B784-4239-8FEE-} BEA4B8FA5D9D.

Type species. Grammikolepidopteron extensus Zhang, Shih, Labandeira \& Ren sp. nov.

Etymology. The generic name is from the Greek, combining grammikos (line, linear), in reference to the linearly aligned branching points of veins $\mathrm{R}_{1}$ and $\mathrm{Rs}_{1}$ to $\mathrm{R}_{3}$; and lepidos, meaning "scale" or "flake," representing the Lepidoptera, the ordinal assignment of this species; and pteron, meaning "wing" or "fin.". The gender is masculine.

Distribution. Inner Mongolia Autonomous Region, China.

Diagnosis. Body small, less than $4.0 \mathrm{~mm}$. Forewing elongate. Humeral vein and sc- $-\mathrm{r}$ crossvein absent. $\mathrm{Sc}$ and $\mathrm{R}_{1}$ not forked. $\mathrm{R}_{3}$ terminating only slightly before wing apex. Branching points of $\mathbf{R}_{1}$ and $R_{s}$ to $R_{s}$ linearly aligned. $M$ divided into $M_{3}$ and $M_{1+2}$. $\mathrm{M}_{1+2}$ subdivided iteratively into veins $\mathrm{M}_{1}$ and $\mathrm{M}_{2}$ at an angle of ca. 15 degrees; $\mathrm{M}_{1}$ linear and smooth. $\mathrm{CuA}$ bifurcated; $\mathrm{CuP}$ simple. Three anal veins looping into a double-Y configuration. Apophyses short.

An Eolepidopterigidae affiliation is supported by: 1), antennae less than half the length of forewing; 2), M 3-branched; and 3), crossvein absent between Sc and R.

Comparison. Grammikolepidopteron resembles Netoxena Sohn, 2012, but Grammikopidopteron is separated from Netoxena by: 1), absence of a sc $-\mathrm{r}$ crossvein (vs. $s c-r$ crossvein present); 2), the $\mathrm{M}_{1+2}$ furcation extending beyond the $\mathrm{CuA}$ furcation (vs. the $\mathrm{CuA}$ furcation extending beyond the $\mathrm{M}_{1+2}$ furcation); and 3), three anal veins looping into a double-Y configuration (vs. two anal veins looping into a single-Y configuration).

Grammikolepidopteron resembles one fossil species within Micropterix, Micropterix pervetus Cockerell, 1919 [42]. However, Grammikolepidopteron differs from $M$. pervetus in: 1), the forewing having $\mathrm{Sc}$ and $\mathrm{R}_{1}$ veins that are not forked (vs. Sc and $\mathrm{R}_{1}$ that are forked); 2), anal veins that form a double-Y configuration (vs. $1 \mathrm{~A}$ and $2 \mathrm{~A}$ veins that are parallel); and 3), presence of a $\mathrm{CuP}$ vein (vs. absence of the CuP vein).

\section{Grammikolepidopteron extensus Zhang, Shih, Labandeira \& Ren sp. nov. (Fig. 12) \\ urn:lsid:zoobank.org:act:AD3B8CA4-5935-48A5-823F- 46C48D0D2C01.}

Etymology. The specific name is derived from the Latin, extensus (outstretched, extended), in reference to the expansive forewings.

Type material. Holotype: CNU-LEP-NN-2012-006P/C (part and counterpart); ᄋ; right forewings well preserved; body and hind wing not well preserved. Forewings asymmetrical; left forewing and right hind wing are much longer and slender than the right forewing and left hind wing. This asymmetry probably is attributable to sediment deformation.

Locality and horizon. This specimen was collected from Daohugou Village, Shantou Township, Ningcheng County, Inner Mongolia Autonomous Region, China. The age is latest Middle Jurassic, near the Callovian-Oxfordian boundary.

Diagnosis. Same as generic diagnosis.

Description. Antennae with scape swollen; flagellum filiform; length of segments equal to their diameter. Eyes relatively small. Last segment of a maxillary (or labial) palpus visible. Posterior edge of mesoscutum concave; mesoscutellum small, half the length of mesoscutum. Metatarsi 5-segmented, tarsomere I longest, almost subequal to the total length of tarsomeres II, III, IV and $\mathrm{V}$ combined. Female genitalia with long ovipositor partially preserved.

Forewings distinctly narrow and elongate, slightly rounded apically, ca. 3.6 times as long as wide. Sc not forked, extending to costal margin of wing, at $2 / 3$ the length of wing from base. $R_{1}$ not forked, extending to costal margin of wing at a point 4/5 length of wing from base; Rs 4-branched; $\mathrm{Rs}_{3}$ terminating slightly before wing apex; branching points of $\mathrm{R}_{1}$ and $\mathrm{Rs}_{1}$ to $\mathrm{Rs}_{3}$ linearly aligned. $\mathrm{M}$ arising from $\mathrm{CuA}$, 3-branched; $\mathrm{M}_{1}$ and $\mathrm{M}_{2}$ stalked, ca. 0.4 of their total length. CuA furcation distal of $\mathrm{M}$ furcation and before the $\mathrm{M}_{1+2}$ furcation; CuP simple. Three anal veins looping into a double-Y configuration. Hind wing relatively elongate, rounded apically, 3 times as long as wide. Sc and $\mathrm{R}_{1}$ not forked. CuA bifurcated.

Measurements (in mm). Body length over 3.8, as preserved (missing part of terminalia); width 0.9. Forewing length ca. 4.2 (left wing) and 3.5 (right wing); width ca. 1.1 (left wing) and 1.2 (right wing). Hind wing length ca. 2.9 (left wing) and 3.3 (right wing); width ca. 1.2 (left wing) and 1.3 (right wing).

\section{Suborder Incertae sedis}

Family Mesokristenseniidae Huang, Nel \& Minet, 2010

Type genus. Mesokristensenia Huang, Nel \& Minet, 2010 [25].

Distribution. Inner Mongolia Autonomous Region, China.

Emended diagnosis. Antenna less than half length of forewing. Labial palpi long. Mesotibia lacking medial spurs; spur formula of legs: 1-1-4. Number of forewing vein branches: Sc-2, $\mathrm{R}_{1}-1$, Rs-4, M-4, CuA-2, CuP-1, A-3; $\mathrm{Rs}_{3}$ and $\mathrm{Rs}_{4}$ separate. Ovipositor nonpiercing, with anterior apophyses.

The synapomorphies for the Mesokristenseniidae are mesotibia with only an apical spur, wings homoneurous, $\mathrm{R}_{1}$ unforked, $\mathrm{M}$ vein 4-branched, and ovipositor with anterior apophyses.

The lepidopteran affiliation of this family has been established by Huang et al. [25] based on the following characters: 1), apex of the foretibia with at most one spur; 2), wings covered with overlapping scales; 3), wings lacking nygmata; and 4), the $\mathbf{M}_{1}$ sharply angulate at the junction with $r-m$ crossvein.

Genera included. Kladolepidopteron gen. nov. and Mesokristensenia Huang, Nel \& Minet, 2010.

\section{Mesokristensenia Huang, Nel \& Minet, 2010}

Type species. Mesokristensenia latipenna Huang, Nel \& Minet, 2010.

Distribution. Inner Mongolia Autonomous Region, China.

Emended diagnosis. Antenna short, ca. 1/3 the length of forewing; scape prominently swollen; pedicel relatively robust. Metatibia with spines and two pairs of spurs. $\mathrm{M}_{1}$, after separation from $\mathrm{M}_{2}$, subtended by an angle of greater than 60 degrees, sharply angulate at junction with $\mathrm{r}-\mathrm{m}$ crossvein. Crossvein $\mathrm{sc}-\mathrm{r}$ absent. 


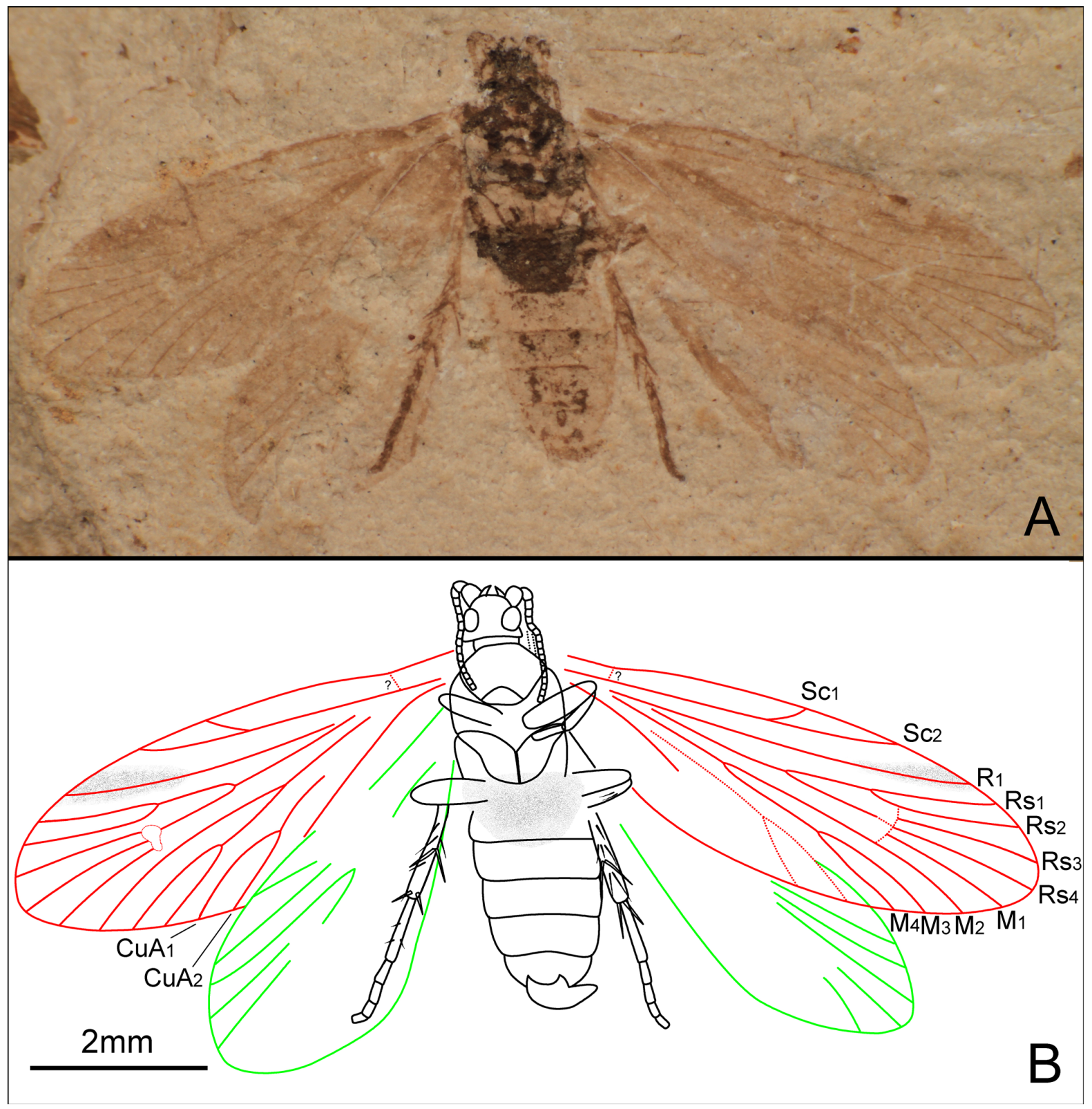

Figure 13. Mesokristensenia sinica Huang, Nel \& Minet. Male, CNU-LEP-NN-2009-003. (A), Fossil specimen. (B), Camera lucida drawing of (A), showing overall habitus.

doi:10.1371/journal.pone.0079500.g013

Species included. M. angustipenna Huang, Nel \& Minet, 2010 [25]; M. latipenna Huang, Nel \& Minet, 2010 [25]; M. sinica Huang, Nel \& Minet, 2010 [25] and M. trichophora sp. nov.

\section{Mesokristensenia sinica Huang, Nel \& Minet, 2010 (Figs. 1F and 13)}

Type materials. Holotype NIGP-150462 deposited in Nanjing Institute of Geology and Palaeontology [25]. Additional specimen CNU-LEP-NN-2009-003; O; forewings well preserved anal areas are covered by hind wings.

Locality and horizon. This specimen was collected from Daohugou Village, Shantou Township, Ningcheng County, Inner
Mongolia Autonomous Region, China. The age is latest Middle Jurassic, near the Callovian-Oxfordian boundary.

Description of additional specimen. Antenna with the scape prominently swollen and pedicel relatively large; flagellum filiform; length of segments equal to their diameter. Compound eyes moderately developed. Apex of labial palpi acute. Mesothorax large; mesonotum slightly broader than long, posterior edge concave; mesoscutellum small, half the length of mesoscutum. Mesofemora and metafemora robust. Metatibia with irregularly arranged spines; a pair of apical spurs and additional spurs arising from distal third or fourth of tibia; all spurs ca. 2 times diameter of tibia. Metatarsi 5-segmented; tarsomere I longest, with short spine.

Forewing 3.2 times as long as wide; prominent pterostigma present. Humeral vein possibly present. Sc forked, from distal 1/3 


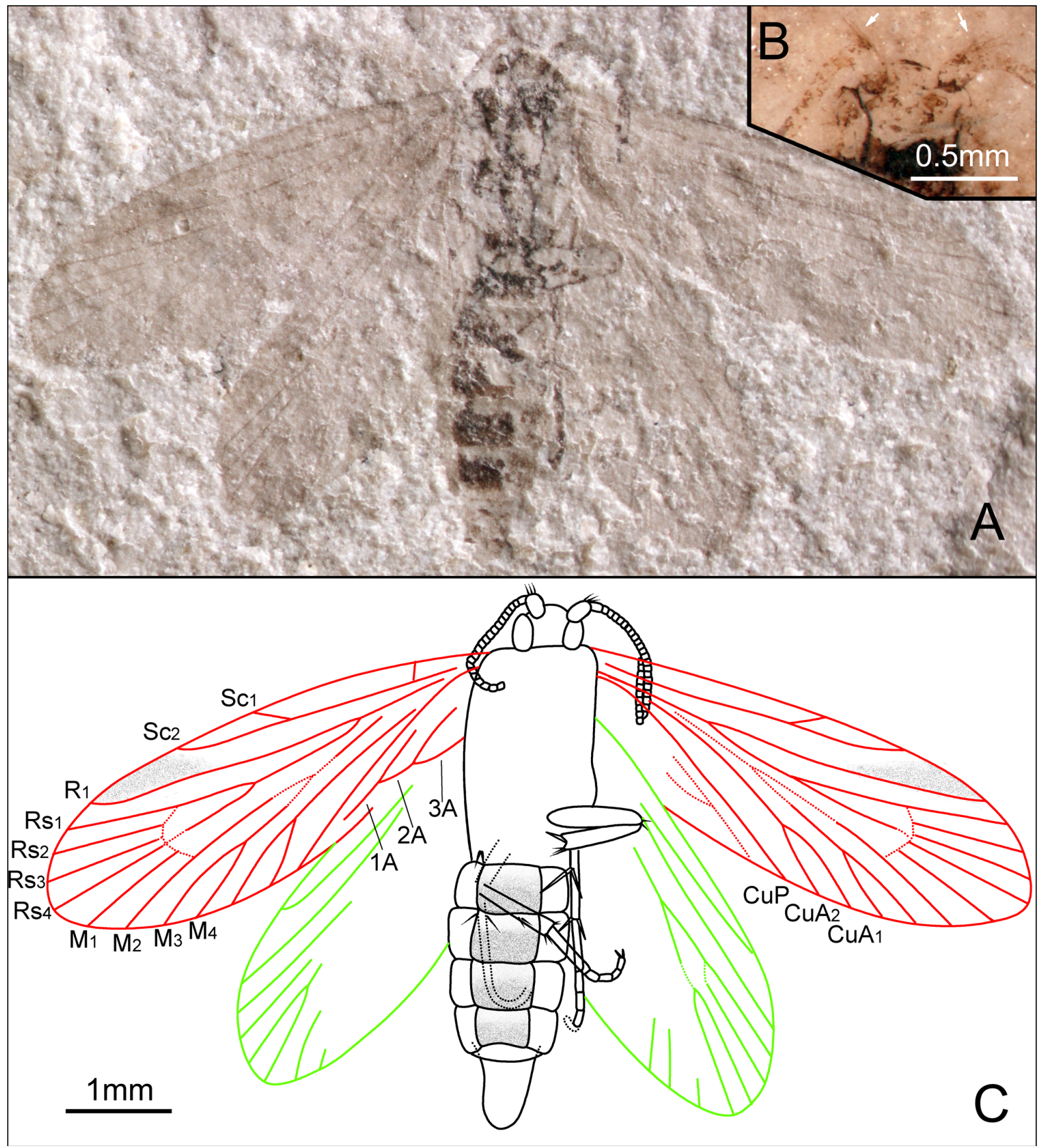

Figure 14. Mesokristensenia trichophora sp. nov. Female, holotype, CNU-LEP-NN-2012-032. (A), Fossil specimen. (B), Head, showing scape with setae distally. (C), Camera lucida drawing of (A), showing overall habitus. doi:10.1371/journal.pone.0079500.g014

of the stem; $\mathrm{Sc}_{2}$ extending to costal margin of wing at 2/3 length from wing base; sc $-\mathrm{r}$ crossvein absent. $\mathrm{R}_{1}$ not forked; Rs 4branched; $\mathrm{Rs}_{4}$ slightly below the apex of forewing; $\mathrm{Rs}_{1+2}$ stalked ca. 0.3 of their total length. $\mathrm{M}$ 4-branched, stem $\mathrm{M}_{1+2}$ longer than stem $\mathrm{M}_{3+4}$. Hyaline zones surrounding $\mathrm{r}-\mathrm{m}$ crossvein at $\mathrm{R}_{3+4}$ and $\mathrm{M}_{1+2}$ furcations. $\mathrm{CuA}$ forked before $\mathrm{M}_{3+4}$ furcation. Hind wing 2.45 times as long as wide.

Measurements (in mm). CNU-LEP-NN-2009-003: body length ca. 5.0; width 1.5. Forewing length ca. 6.0; width 1.9. Hind wing length 4.9 ; width 2.0 .
Remarks. This specimen, collected from the same locality as the holotype of $M$. sinica, matches the characters of $M$. sinica in the venation, wing index and body size. We deem this specimen conspecific with $M$. sinica.

Mesokristensenia trichophora Zhang, Shih, Labandeira \& Ren sp. nov. (Fig. 14)

urn:lsid:zoobank.org:act:A70E3B9C-22EC-455E-820278153C4B8E90. 


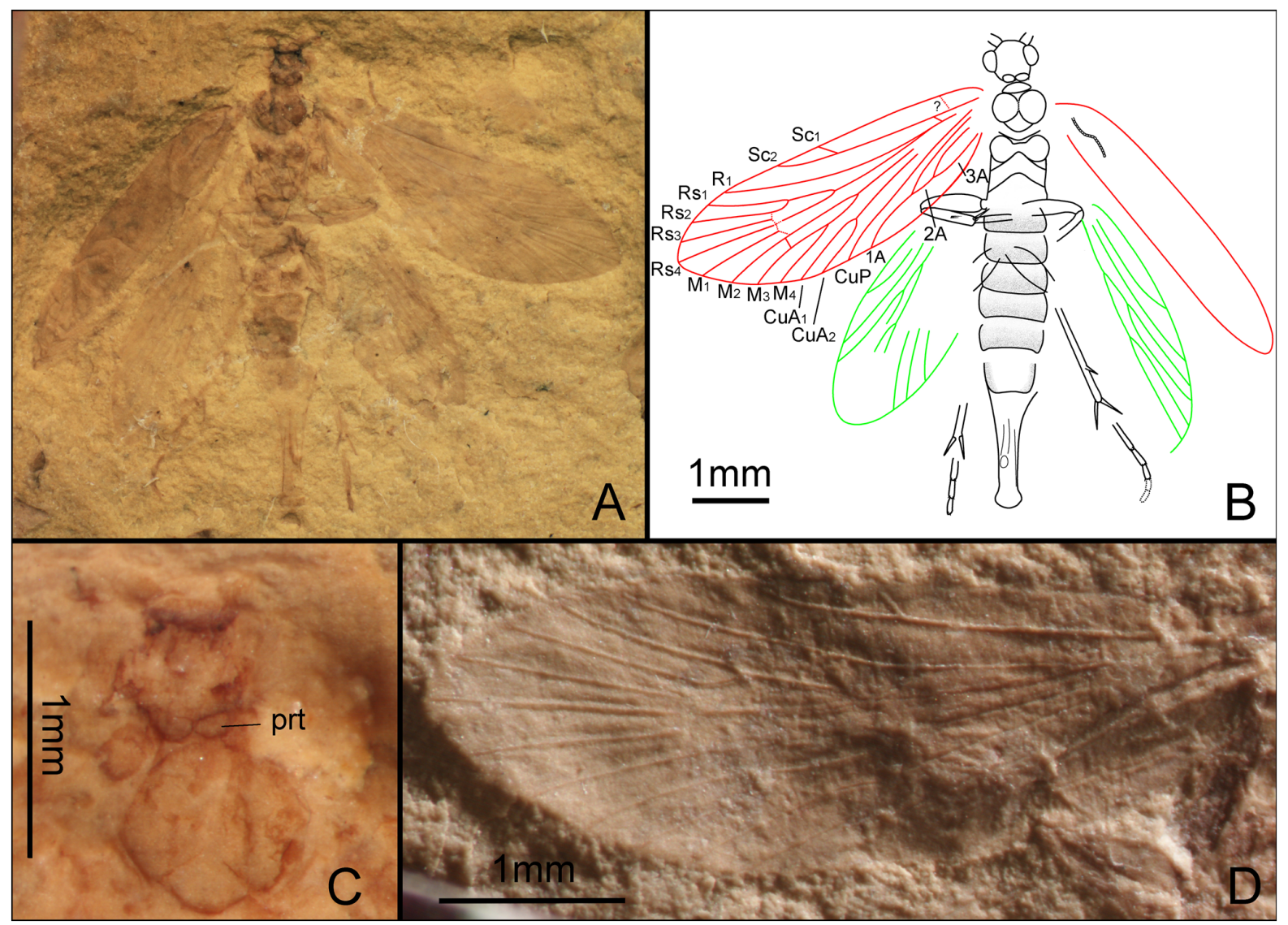

Figure 15. Kladolepidopteron oviformis gen. et sp. nov. Female, holotype, CNU-LEP-NN-2009-007C. (A), Fossil specimen. (B), Camera lucida drawing of (A), showing overall habitus. (C), Head and thorax. (D), Forewing. Abbreviation: prt, prothorax. doi:10.1371/journal.pone.0079500.g015

Etymology. The specific name is derived from the Greek, trichos (hair), and phoro- (bearing, carrying), in reference to hirsute antennal scape present in this species.

Type material. Holotype: CNU-LEP-NN-2012-032; ᄋ; wings well preserved; legs partially preserved.

Locality and horizon. This specimen was collected from Daohugou Village, Shantou Township, Ningcheng County, Inner Mongolia Autonomous Region, China. The age is latest Middle Jurassic, near the Callovian-Oxfordian boundary.

Diagnosis. Antennal scape with setae. Forewing of $M$. trichophora (with wing index of 0.34) narrower than M. latipenna (wing index 0.38); slightly broader than M. sinica (wing index 0.32/ 0.33), and broader than $M$. angustipenna (wing index 0.31).

Description. Compound eyes oval; antennae filiform; scape large and elongate, with setae distally placed (Fig. 14B); pedicel longer than one segment of flagellum; flagellum slender, the length of segments basally ca. 0.5 times as long as their diameter; length equal to their diameter distally. Metatibia with one pair of medial spurs, ca. 3 times as long as the diameter of the tibia; one pair of apical spurs, ca. 1.5 times as long as the diameter of the tibia; metatarsi 5-segmented, tarsomere I longest. Ovipositor relatively long and robust.

Forewing 2.9 times as long as wide; prominent pterostigma present. Forewing bearing a humeral vein. Sc forked at distal 1/3 of the stem; $\mathrm{Sc}_{2}$ extending to costal margin of wing at 2/3 distance from wing base; sc- $\mathrm{r}$ crossvein absent. $\mathrm{R}_{1}$ not forked; $\mathrm{Rs}_{4} 4-$ branched; $\mathrm{Rs}_{4}$ extending to the apex of forewing; $\mathrm{Rs}_{1+2}$ stalked ca. $1 / 3$ of their total length; $\mathrm{Rs}_{3}$ and $\mathrm{Rs}_{4}$ free. $\mathrm{M}$ 4-branched; $\mathrm{M}_{1+2}$ stem longer than $\mathrm{M}_{3+4}$ stem. Hyaline zones surround $\mathrm{r}-\mathrm{m}$ crossvein at $\mathrm{Rs}_{1+2}, \mathrm{Rs}_{3+4}$ and $\mathrm{M}_{1+2}$ furcations. $\mathrm{CuA}$ forked before $\mathrm{M}_{3+4}$ furcation; $\mathrm{CuA}_{1+2}$ stalked over half of their length; CuP simple. Three anal veins looping into a double- $\mathrm{Y}$ configuration; $1 \mathrm{~A}$ and 2A separate beyond basal half of vein length. Hind wing length ca. 2.6 times the width. Sc not forked; $\mathrm{R}_{1}$ not forked; $\mathrm{Rs} 4-$ branched; $\mathrm{Rs}_{3+4}$ stem slightly longer than stem $\mathrm{Rs}_{1+2}$.

Comparison. $M$. trichophora differs from other species of Mesokristensenia in bearing an antennal scape with setae and in the afore-mentioned wing index.

Measurements (in mm). Body length ca. 5.1; width 1.3. Forewing length 5.0; width 1.7. Hind wing length 4.1; width 1.6.

\section{Kladolepidopteron Zhang, Shih, Labandeira \& Ren gen.} nov.

urn:lsid:zoobank.org:act:3D602334-A178-4752-8EB003053E2982C7.

Type species. Kladolepidopteron oviformis Zhang, Shih, Labandeira \& Ren sp. nov.

Etymology. The generic name is derived from the Greek, combining klados (twig, branch, stem), in reference to the presence of crossvein sc-r; and lepidos, meaning "scale" or "flake," also signifying assignment to the order Lepidoptera; and pteron, the word for "wing" or "fin." The gender is masculine.

Distribution. Inner Mongolia Autonomous Region, China.

Diagnosis. Vein M 4-branched in forewing. Prothorax with a pair of oval structures. Metatibia lacking spines. Crossvein sc-r present at forewing base. 


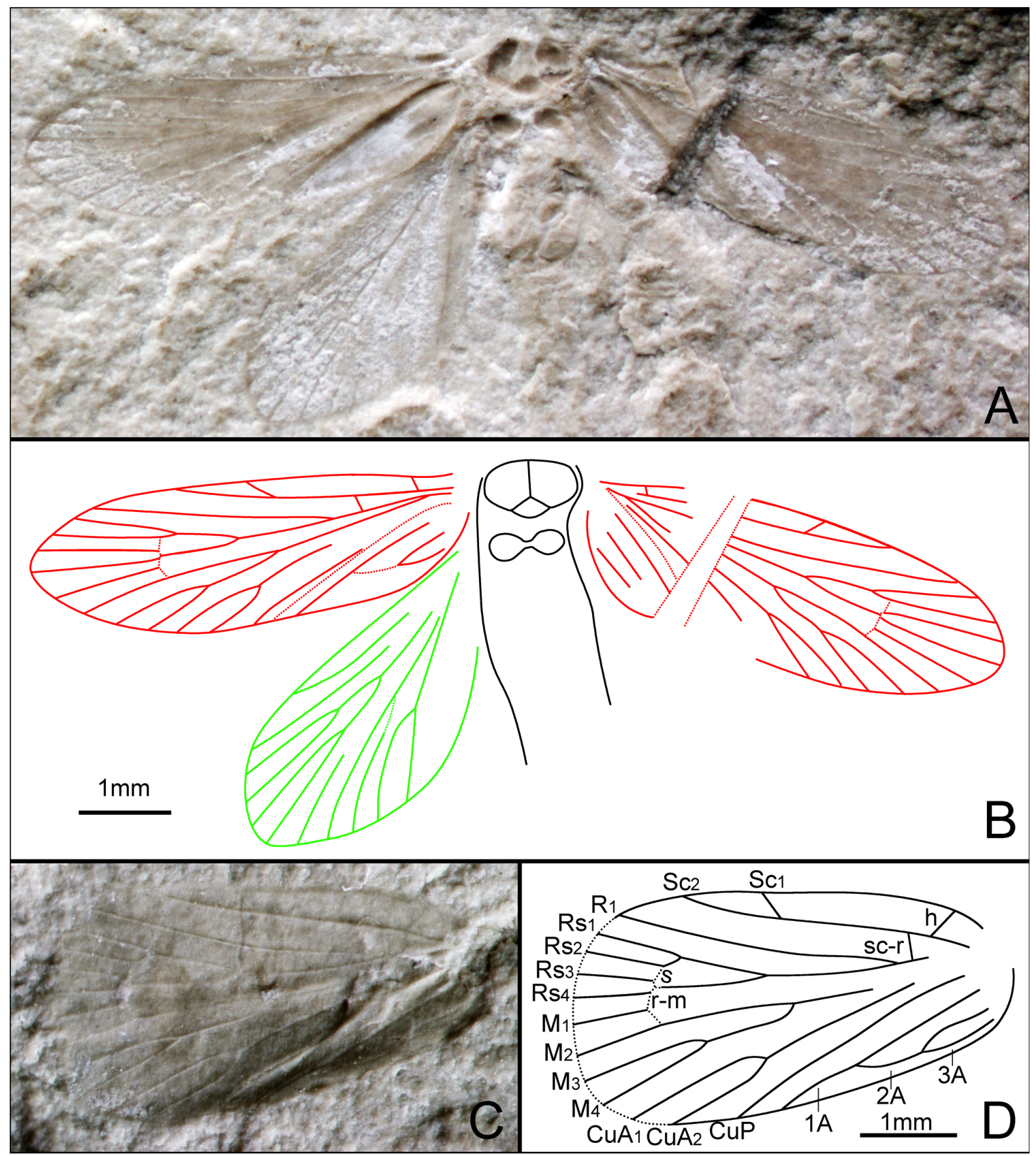

Figure 16. Kladolepidopteron subaequalis gen. et sp. nov. Holotype, CNU-LEP-NN-2012-020. (A), Fossil specimen. (B), Camera lucida drawing of (A), showing overall habitus. Paratype, CNU-LEP-NN-2012-022. (C), Fossil specimen. (D), Camera lucida drawing of wing at (C). doi:10.1371/journal.pone.0079500.g016

A Mesokristenseniidae affiliation is supported by: 1), antenna less than half length of forewing; 2), mesotibia with only one apical spur; 3), wings homoneurous; 4), $\mathrm{R}_{1}$ unforked; and 5), $\mathrm{M}$ 4branched.

Comparison. Kladolepidopteron differs from Mesokristensenia in: 1), having the $\mathrm{sc}-\mathrm{r}$ crossvein present at the base of the forewing (vs. sc- $-\mathrm{r}$ absence); and 2), the metatibia lacking spines (vs. hind legs bearing irregularly arranged spines).
Compared to the sole genus of the Agathiphagidae, Agathiphaga, Kladolepidopteron can be distinguished by the following characters: 1), the sc-r crossvein is present at the base of the forewing (vs. the $\mathrm{sc}-\mathrm{r}$ crossvein present near the distal tip of the $\mathrm{Sc}_{2}$ ); 2 ), absence of the $\mathrm{m}-$-cup and cup-a crossveins (vs. presence of the $\mathrm{m}-$ cup and cup-a crossveins); and 3), presence of the m crossvein (vs. absence of the $m$ crossvein).

Species included. Kladolepidopteron oviformis sp. nov; K. parva sp. nov.; and K. subaequalis sp. nov. 


\section{Kladolepidopteron oviformis Zhang, Shih, Labandeira \&}

Ren sp. nov. (Fig. 15)

urn:lsid:zoobank.org:act:5FAB0FF0-53B9-4117-8363-

FA375B4909B9.

Etymology. The specific name is derived from the Latin ovum (egg, egg-like); and formis, (shape of, likeness, form), in reference to the pair of oval structures on the prothorax.

Type material. Holotype: CNU-LEP-NN-2009-007P/C (part and counterpart); ; well preserved body and left forewing; mid and hind legs partially preserved.

Locality and horizon. This specimen was collected from Daohugou Village, Shantou Township, Ningcheng County, Inner Mongolia Autonomous Region, China. The age is latest Middle Jurassic, near the Callovian-Oxfordian boundary.

Diagnosis. Body relatively large. Wing index 0.33. Forewing with crossvein $\mathrm{m}$ present. In the hind wing, $\mathrm{Rs}_{1+2}$ stem shorter than $\mathrm{Rs}_{3+4}$ stem.

Description. Body slender. Compound eyes rounded. Antenna filiform, slender, length of segments 1.5 times their diameter.

Prothorax relatively large, with a pair of oval, slightly transverse structures that are adjacent mesially (Fig. 15C). Mesothorax with relatively large prescutum; mesoscutum broader than long; mesoscutellum small, posterior edge concave along midline, slightly shorter than mesoscutum. Mesoscutellum fan-shaped; metascutum dumbbell shaped; metascutellum relatively large and broad. Mesofemora ca. 2 times as wide as mesotibia; mesofemora and mesotibia almost subequal in length. Mesotibia with one apical spur; two spines present at middle of mesotibia. Metatibia with one pair of medial spurs, one pair slightly longer than diameter of tibia, and other pair of apical spurs ca. 2 times as long as the diameter of the tibia. Metatarsi 5-segmented; two very short setae present on the apex of each tarsomere.

Forewings moderately slender, gradually tapering to a subacute apex (Fig. 15D). Length ca. 3.0 times the width. Forewing bearing a humeral vein. Sc forked, from distal $1 / 4$ of the stem; $\mathrm{Sc}_{2}$ extending to costal margin of wing at $3 / 5$ length of wing from base. Crossvein sc-r present. $\mathrm{R}_{1}$ not forked; Rs 4-branched; $\mathrm{Rs}_{4}$ extending to the apex of forewing; $\mathrm{Rs}_{1}$ and $\mathrm{Rs}_{2}$ stalked; $\mathrm{Rs}_{1+2}$ stalked ca. 0.38 of their total length; $\mathrm{Rs}_{3}$ and $\mathrm{Rs}_{4}$ free. M 4branched; stem $\mathrm{M}_{1+2}$ longer than stem $\mathrm{M}_{3+4}, \mathrm{M}_{1}$ after separation from $\mathrm{M}_{2}$ subtending an angle of 60 degrees, sharply angulate at junction with crossvein $\mathrm{r}-\mathrm{m}$. Crossvein $\mathrm{m}-\mathrm{ca}$. originating near $\mathrm{M}_{1+2}$ furcation and terminating near the midpoint of $\mathrm{M}_{3}$. Hyaline zones surrounding $\mathrm{r}-\mathrm{m}$ crossvein at $\mathrm{R}_{3+4}$ and $\mathrm{M}_{1+2}$ furcations. $\mathrm{CuA}_{1+2}$ stalked over half of their length; $\mathrm{CuP}$ simple. Three anal

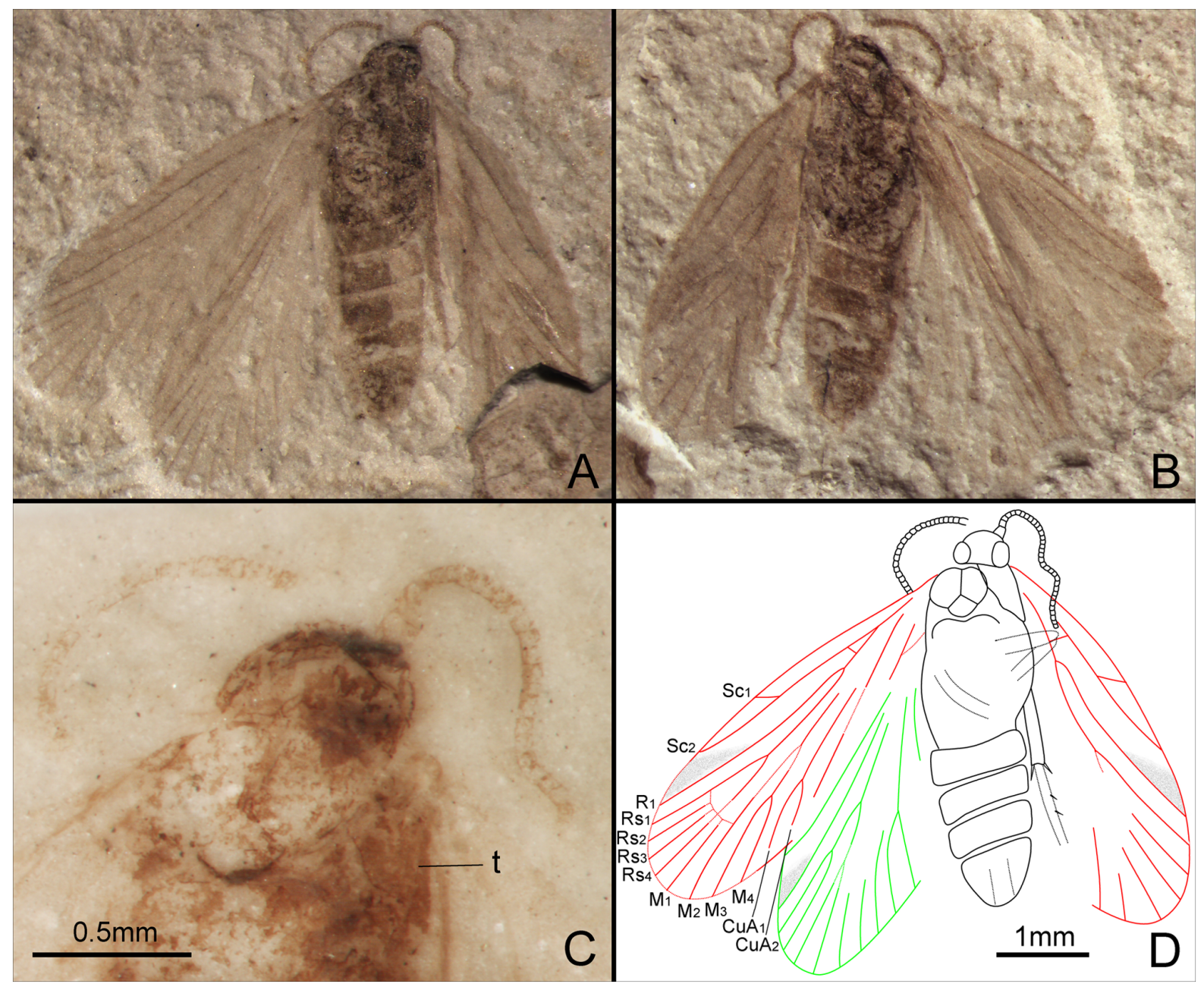

Figure 17. Kladolepidopteron parva gen. et sp. nov. Male, holotype, CNU-LEP-NN-2012-011P/C. (A), Fossil specimen (counterpart). (B), Fossil specimen (part). (C), Head and thorax. (D), Camera lucida drawing of (A), showing overall habitus. Abbreviation: $t$, tegula. doi:10.1371/journal.pone.0079500.g017 
veins looping into a double-Y configuration; $1 \mathrm{~A}$ and $2 \mathrm{~A}$ separate at basal half. Hind wing length ca. 2.8 times the width. Sc not forked. $\mathrm{R}_{1}$ not forked; $\mathrm{Rs}$ 4-branched; $\mathrm{Rs}_{3+4}$ stem ca. 2 times as long as stem $\mathrm{Rs}_{1+2}$. Abdomen lacking specialized integumental modifications. Ovipositor long; apophyses not evident.

Measurements (in mm). Body length ca. 6.3; width 1.1. Forewing length 4.8; width 1.6. Hind wing length ca. 3.6; width 1.3 .

\section{Kladolepidopteron subaequalis Zhang, Shih, Labandeira \& Ren sp. nov. (Fig. 16)}

urn:lsid:zoobank.org:act:4356A7DD-DEF5-450C-B17B389E685ABA09.

Etymology. The specific name is derived frpm the Latin preposition, sub (under, below), and aequalis (equal), in reference to the subequal length of the basal stems to the hind wing veins $\mathrm{Rs}_{1+2}$ and $\mathrm{R}_{3+4}$.

Type materials. Holotype: CNU-LEP-NN-2012-020; sex unknown; well preserved forewings and left hind wing. Paratype. CNU-LEP-NN-2012-022; sex unknown; only forewing, with distal part not preserved.

Diagnosis. Wing index 0.32 . In forewing, crossvein $\mathrm{m}$ absent. Hind wing relatively broad; the stem $\mathrm{Rs}_{1+2}$ and $\mathrm{R}_{3+4}$ subequal in length.

Comparison. Kladolepidopteron. subaequalis resembles $K$. oviformis in: 1 ), the forewing index (0.32 vs. 0.33); and 2), the wing apex is moderately acute. Kladolepidopteron subaequalis differs from $K$. oviformis in the following characters: 1), the crossvein $m$ absent (vs. crossvein $\mathrm{m}$ present); 2), the hind wing has a slightly shorter $\mathrm{Rs}_{1+2}$ stem than the $\mathrm{Rs}_{3+4}$ stem (vs. $\mathrm{Rs}_{1+2}$ stem only half length of $\mathrm{Rs}_{3+4}$ stem); and 3 ), the hind wing of $K$. subaequalis is broader than that of K. oviformis.

Description. Mesothorax large, with prominent scutum and small scutellum; prescutum not preserved. Mesoscutum with distinct median suture, broader than long, posterior edge concave along midline; mesoscutellum fan-shaped, half the length of mesoscutum; metascutum dumbbell shaped.

Forewing moderately slender, tapering gradually to apex. Length ca. 3.1 times the width. Forewing bearing a humeral vein. $\mathrm{Sc}$ forked from distal $1 / 3$ of the stem; $\mathrm{Sc}_{2}$ extending to costal margin of wing at $3 / 5$ length of wing from base. Crossvein sc $-\mathrm{r}$ present. $\mathrm{R}_{1}$ not forked; $\mathrm{Rs}_{\mathrm{s}}$ 4-branched; $\mathrm{R}_{4}$ extending to the apex of forewing; $\mathrm{Rs}_{1}$ and $\mathrm{Rs}_{2}$ stalked, $\mathrm{Rs}_{1+2}$ stalked ca. 0.35 of their total length; $\mathrm{Rs}_{3}$ and $\mathrm{Rs}_{4}$ free; $\mathrm{Rs}_{1+2}$ furcation almost at same level as $\mathrm{Rs}_{3+4}$. Crossvein s present (Figs. 16C, D). M 4-branched; $\mathrm{M}_{1}$, after separation from $\mathrm{M}_{2}$ subtending an angle of 75-80 degrees, sharply angulate at junction with $\mathrm{r}-\mathrm{m}$ crossvein (Figs. 16C, D); stem $\mathrm{M}_{1+2}$ longer than stem $\mathrm{M}_{3+4}$. $\mathrm{CuA}$ bifurcated; CuP simple. Three anal veins forming a double- $\mathrm{Y}$ configuration; $1 \mathrm{~A}$ and $2 \mathrm{~A}$ separate at basal half. Hind wing length ca. 2.3 times the width; broader than forewing. Sc not forked. $\mathrm{R}_{1}$ not forked; Rs 4branched; $\mathrm{Rs}$ branching into veins $\mathrm{Rs}_{1+2}$ and $\mathrm{R}_{3+4}$, and then further subdividing into four branches of $\mathrm{Rs}_{1}, \mathrm{Rs}_{2}, \mathrm{Rs}_{3}$, and $\mathrm{Rs}_{4}$; furcations of $\mathrm{Rs}_{1+2}$, and $\mathrm{Rs}_{3+4}$ almost at the same level to each other. M 4-branched. CuA bifurcated; CuP difficult to discern.

Measurements (in mm). Forewing length 5.0; width 1.6. Hind wing length ca. 4.1; width 1.8.

\section{Kladolepidopteron parva Zhang, Shih, Labandeira \& Ren} sp. nov. (Fig. 17)

urn:lsid:zoobank.org:act:032CD405-AC08-4D0B-A489-

FB6231FE7560.

Etymology. The specific name is derived from the Latin parva (small, little, stunted), in reference to its small body size.

Type material. Holotype: CNU-LEP-NN-2012-011P/C (part and counterpart); O; well preserved forewing and hind wing; anal wing region indiscernible.

Locality and horizon. This specimen was collected from Daohugou Village, Shantou Township, Ningcheng County, Inner Mongolia Autonomous Region, China. The age is latest Middle Jurassic, near the Callovian-Oxfordian boundary.

Diagnosis. The new species has narrower wings (wing index 0.31 ) than $K$. oviformis (wing index 0.33 ) and $K$. subaequalis (wing index 0.32). Crossvein $\mathrm{m}$ absent in forewing. Hind wing with $\mathrm{Rs}_{1+2}$ forking almost at the same level as $\mathrm{Rs}_{3+4}$.

Comparison. Kladolepidopteron parva resembles $K$. oviformis and $K$. subaequalis in venation. However, $K$. parva differs from $K$. oviformis by: 1), its short body, ca. $4.1 \mathrm{~mm}$ in length (vs. a relatively long body ca. $6.3 \mathrm{~mm}$ long); 2), short forewing length of $4.1 \mathrm{~mm}$ (vs. long forewing length of $4.8 \mathrm{~mm}$ ); and 3), the $\mathrm{Rs}_{1+2}$ stem slightly shorter than the $\mathrm{Rs}_{3+4}$ stem (vs. the $\mathrm{Rs}_{1+2}$ stem only half the length of the $\mathrm{Rs}_{3+4}$ stem). Kladolepidopteron parva differs from $K$. subaequalis by: 1), its short forewing (vs. long forewing with a length of $5.0 \mathrm{~mm}$ ); and 2), a forewing without a pterostigma (vs. an otherwise prominent pterostigma).

Description. Antenna filiform, ca. half the length of forewing; scape swollen; flagellum filiform; length of segments equal to their diameter. Compound eyes widely separated. Tegula large, triangular (Fig. 17G). Mesoscutum with median suture, slightly broader than long; posterior edge of mesoscutum concave

Table 2. Character comparisons of Agathiphagidae, Mesokristenseniidae and Ascololepidopterigidae.

\begin{tabular}{|c|c|c|c|}
\hline \multirow[t]{2}{*}{ Character } & \multicolumn{3}{|l|}{ Family } \\
\hline & Agathiphagidae & Mesokristenseniidae & Ascololepidopterigidae fam. nov. \\
\hline Spur formula & $1-4-4$ & $1-1-4$ & $\begin{array}{l}\text { metatibia without medial spur; } \\
\text { foretibia and mesotibia unknown }\end{array}$ \\
\hline Subcostal vein (Sc) & forked & not forked or forked & not forked or forked \\
\hline Radial vein $\left(\mathbf{R}_{\mathbf{1}}\right)$ & not forked & not forked & Forked \\
\hline $\begin{array}{l}\text { Furcations of } R s_{1+2} \\
\text { and } R s_{3+4}\end{array}$ & $\begin{array}{l}\text { Furcation of } \mathrm{Rs}_{3+4} \text { distally, } \\
\text { distinctly beyond furcation of } \mathrm{Rs}_{1+2}\end{array}$ & $\begin{array}{l}\text { approximately at the same } \\
\text { level to each other }\end{array}$ & $\begin{array}{l}\text { approximately at the same } \\
\text { level to each other }\end{array}$ \\
\hline Crossvein m-cua & Present & absent & Present \\
\hline Crossvein cua-cup & Present & absent & Present \\
\hline
\end{tabular}




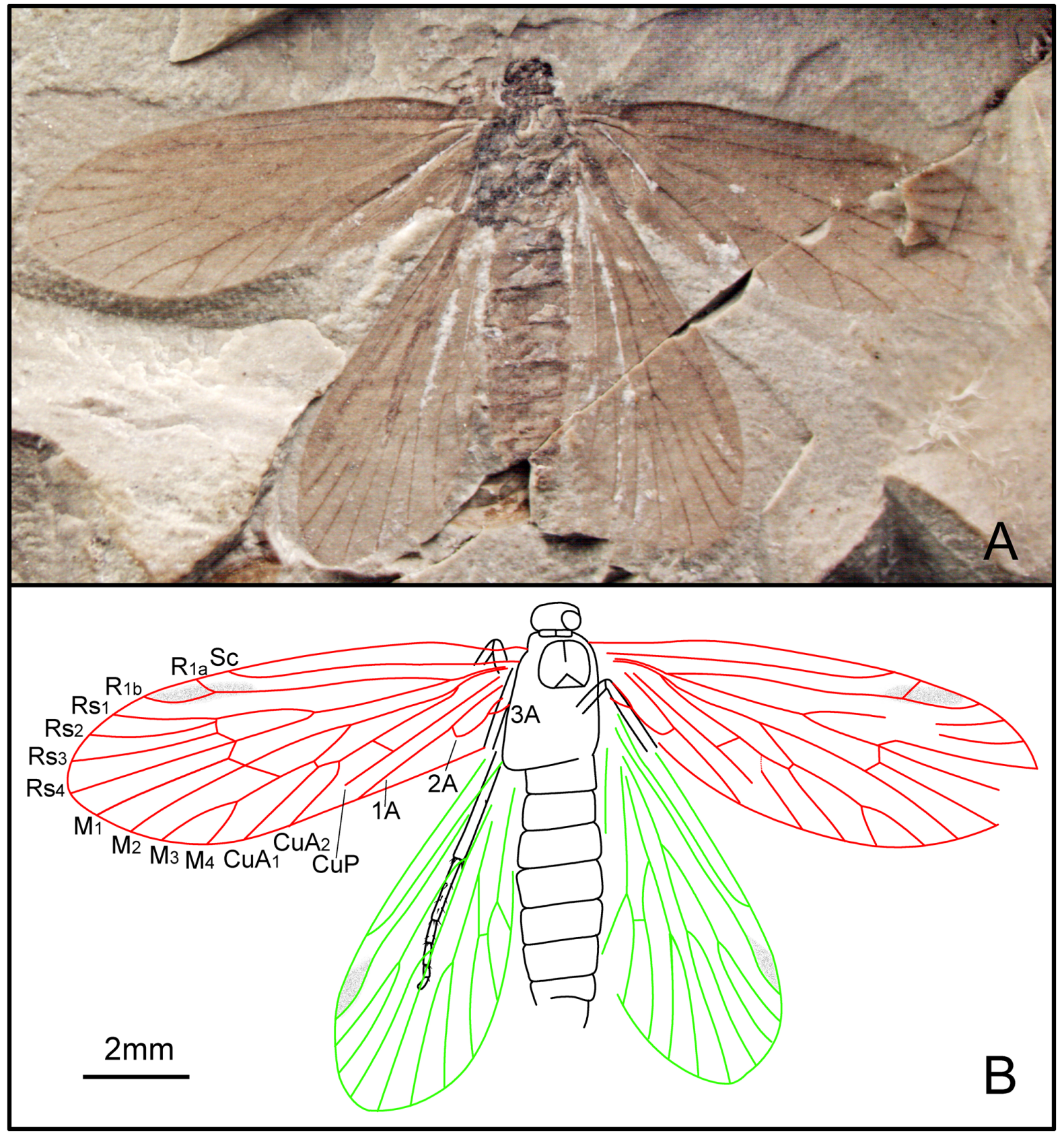

Figure 18. Ascololepidopterix multinerve gen. et sp. nov. Holotype, CNU-LEP-NN-2012-028. (A), Fossil specimen. (B), Camera lucida drawing of (A), showing overall habitus.

doi:10.1371/journal.pone.0079500.g018

along midline. Mesoscutellum small, fan-shaped, slightly shorter than mesoscutum. Metatibia with a pair apical spurs, ca. 1.5 times the diameter of the tibia; medial spurs difficult to discern.

Forewing ca. 3.2 times as long as wide; a prominent pterostigma present. Forewing lacking a humeral vein. Sc forked from distal $1 /$ 3 of the stem; $\mathrm{Sc}_{2}$ extending to costal margin of wing, beyond $2 / 3$ the length of wing from base. Crossvein $\mathrm{sc}-\mathrm{r}$ present; $\mathrm{R}_{1}$ not forked; Rs 4-branched; $\mathrm{Rs}_{1+2}$ stalked ca. 1/2 of vein total length; $\mathrm{Rs}_{3}$ and $\mathrm{Rs}_{4}$ free. $\mathrm{M}$ 4-branched. Hyaline zones surrounding $\mathrm{r}-\mathrm{m}$ crossvein at $\mathrm{Rs}_{1+2}, \mathrm{Rs}_{3+4}, \mathrm{M}_{1+2}$, and $\mathrm{M}_{1+2}-\mathrm{M}_{3}$ furcations and along $\mathrm{CuP}$. CuA bifurcated; CuP simple. Hind wing Sc not forked.
$\mathrm{R}_{1}$ not forked; $\mathrm{Rs}$ 4-branched; $\mathrm{Rs}_{1}$ and $\mathrm{Rs}_{2}$ stalked; $\mathrm{Rs}_{3}$ and $\mathrm{Rs}_{4}$ stalked. M 3-branched. CuA bifurcated.

Measurements (in mm). Body length ca. 4.1; width 1.2. Forewing length ca. 4.1; width ca. 1.3. Hind wing length ca. 3.4.

Family Ascololepidopterigidae Zhang, Shih, Labandeira \& Ren fam. nov.

urn:lsid:zoobank.org:act:4C3FD7D0-DD02-4575-BA4A94600DFD80EB.

Type genus. Ascololepidopterix Zhang, Shih, Labandeira \& Ren gen. nov. 
Distribution. Inner Mongolia Autonomous Region, China.

Diagnosis. Antennae filiform, ca. half the length of forewing. Metatibiae lacking medial spurs, at most with one pair of short apical spurs. Both pairs of wings homoneurous. In forewing, number of vein branches as follows: $\mathrm{Sc}-1 / 2, \mathrm{R}_{1}-2$, Rs-4, M-4, $\mathrm{CuA}-2$, CuP-1, A-3, and furcations of $\mathrm{Rs}_{1+2}$, and $\mathrm{Rs}_{3+4}$ almost at the same level of branching with each other. Crossveins $\mathrm{m}-$-cua and cua-cup present. Ovipositor with apophyses anteriores.

The synapomorphies for the Ascololepidopterigidae fam. nov. are: 1), metatibiae lacking medial spurs; 2), wings homoneurous; 3), forewing $\mathrm{R}_{1}$ forked; 4), $\mathrm{M}$ vein 4-branched; 5), crossveins $\mathrm{m}-$ cua and cua-cup present; and 6), ovipositor with apophyses anteriores.

This family is defined as a clade of the Amphiesmenoptera by having a double anal furcation on the forewing and a hind wing $\mathbf{M}$ vein with at most three branches. This family is assigned to Lepidoptera by presence of a $\mathrm{M}_{1}$ vein which, after separation from $\mathrm{M}_{2}$ vein, subtends an angle greater than 60 degrees and is sharply angulate at the junction with the $r-m$ crossvein.

Comparison. This new family with a 4-branched $\mathrm{M}$ is different from most other Lepidoptera, except for Agathiphagidae and Mesokristenseniidae. The differences among these three families are listed in Table 2.

Genera included. Trionolepidopteron gen. nov., Pegolepidopteron gen. nov. and Ascololepidopterix gen. nov.

Key to known genera of Ascololepidopterigidae fam. nov.

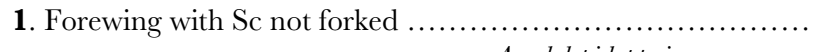

- Forewing with Sc forked. Ascololepidopterix gen. nov.

2. Forewing length more than $7.0 \mathrm{~mm}$; forewing lacking crossvein $\mathrm{rs}_{1}-\mathrm{rs}_{2}$; crossvein $\mathrm{r}$ present

..Pegolepidopteron gen. nov.

- Forewing length less than $5.0 \mathrm{~mm}$; forewing

with crossvein $\mathrm{rs}_{1}-\mathrm{rs}_{2}$; crossvein $\mathrm{r}$ absent....

Trionolepidopteron gen. nov.

\section{Ascololepidopterix Zhang, Shih, Labandeira \& Ren gen.} nov.

urn:lsid:zoobank.org:act:8F418F30-2094-4D03-A8C1455119AE64EC.

Type species. Ascololepidopterix multinerve Zhang, Shih, Labandeira \& Ren sp. nov.

Etymology. The generic name is derived from the Greek, $a^{-}$ ,meaning "not" or "without"; and scolos, meaning a "spur", "thorn" or "anything pointed", referring to the absence or reduction of metatibial spurs in this Middle Jurassic fossil; and lepidos, meaning "scale" or "flake," and the ordinal name of Lepidoptera, to which the fossil belongs; and pteron, meaning "wing" or "fin." The gender is feminine.

Distribution. Inner Mongolia Autonomous Region, China.

Diagnosis. Body relatively large. Forewing $\mathrm{Sc}$ not forked. $\mathrm{R}_{1}$ forked. Crossveins $\mathrm{s}$ and $\mathrm{r}-\mathrm{m}$ present. Stem $\mathrm{M}_{1+2}$ shorter than stem $\mathrm{M}_{3+4}$; crossvein $\mathrm{m}$ present, originating near $\mathrm{M}_{1+2}$ furcation and terminating on $\mathrm{M}_{3+4}$; crossvein $\mathrm{m}_{3+4}-\mathrm{cua}_{1}$, distant from the $\mathrm{M}$ and $\mathrm{CuA}$ furcations. Crossvein cua-cup originating at ca. 2/3 the length of $\mathrm{CuA}$ from its base and terminating beyond the midpoint of $\mathrm{CuP}$. Hind wing $\mathrm{R}_{1}$ not forked. The distal part of $2 \mathrm{~A}$ curved upward.

An Ascololepidopterigidae affiliation is supported by: 1), wings homoneurous; 2), $\mathrm{R}_{1}$ forked; 3), $\mathrm{M}$ 4-branched; and 4), crossveins $\mathrm{m}-$ cua and cua-cup present.

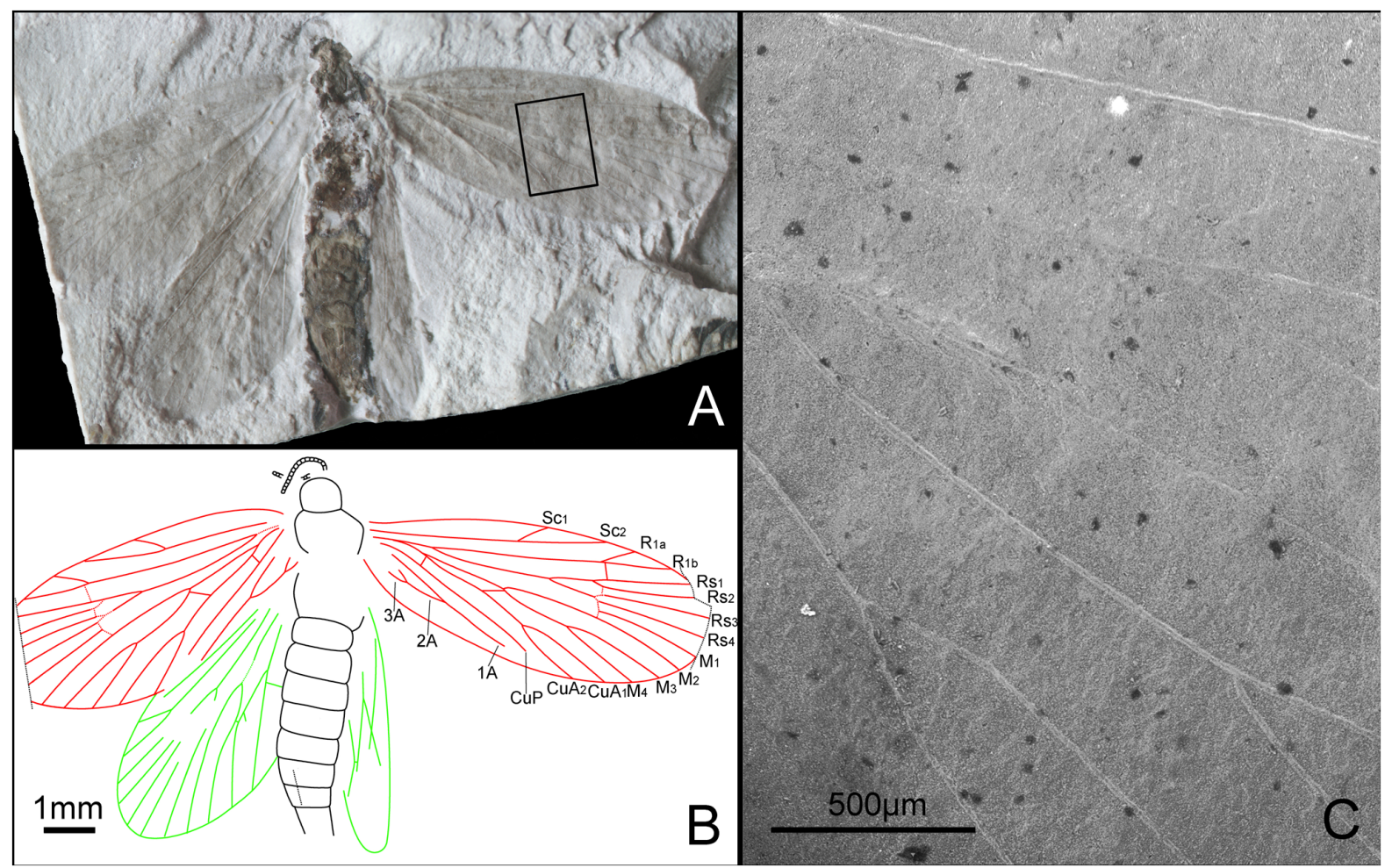

Figure 19. Pegolepidopteron latiala gen. et sp. nov. Female, holotype, CNU-LEP-NN-2012-001. (A), Fossil specimen. (B), Camera lucida drawing of (A), showing overall habitus. (C), SEM of right forewing venation, enlarged from the rectangular template in (A). doi:10.1371/journal.pone.0079500.g019 
Ascololepidopterix multinerve Zhang, Shih, Labandeira \&

Ren sp. nov. (Fig. 18)

urn:lsid:zoobank.org:act:7B3EA809-9A7A-4AE9-AD90-

7075315CCB91.

Etymology. The specific name is derived from the Latin, multi (many, much), and nervis (sinew, tendon, vein), in reference to the numerous crossveins in the forewings.

Type material. Holotype: CNU-LEP-NN-2012-028; sex unknown; well preserved forewings and hind wings; hind legs partially preserved.

Locality and horizon. This specimen was collected from Daohugou Village, Shantou Township, Ningcheng County, Inner Mongolia Autonomous Region, China. The age is latest Middle Jurassic, near the Callovian-Oxfordian boundary.

Diagnosis. Same as generic diagnosis.

Description. Head wider than long. Mesoscutum large, posterior edge concave along midline; mesoscutellum triangular. Metatibia with one pair apical spurs, the spurs subequal to the diameter of the tibia. Metatarsi 5-segmented; tarsomere I ca. 3 times as long as tarsomere II; metatarsi with short spines.

Forewing ca. 2.8 times as long as wide; lacking humeral vein; prominent pterostigma present. Sc not forked. $\mathrm{R}_{1}$ forked distally; $\mathrm{R}_{1 \mathrm{~b}}$ curved; $\mathrm{Rs}$ 4-branched; $\mathrm{Rs}_{4}$ to the apex of forewing; $\mathrm{Rs}_{1+2}$ stalked ca. 0.45 of vein total length; stem $\mathrm{Rs}_{1+2}$ as long as stem $\mathrm{Rs}_{3+4}$; s crossvein present. M 4-branched; $\mathrm{M}_{1}$, after separation from $\mathrm{M}_{2}$, subtends an angle of 63 (right wing) and 53 (left wing) degrees, sharply angulated at junction with $\mathrm{r}-\mathrm{m}$ crossvein. Stem $\mathrm{M}_{1+2}$ shorter than stem $\mathrm{M}_{3+4} ; \mathrm{m}$ crossvein originating near $\mathrm{M}_{1+2}$ furcation, ending at $\mathrm{M}_{3+4}$. CuA bifurcated; $\mathrm{CuP}$ simple. Crossvein $\mathrm{m}_{3+4}$-cua 1 originating at ca. $1 / 3$ length of $\mathrm{M}_{3+4}$ from its base and terminating near $\mathrm{CuA}$ furcation; cua-cup crossvein originating at ca. 2/3 length of $\mathrm{CuA}$ from its base and terminating slightly beyond midpoint of $\mathrm{CuP}$. Anal veins looping into a double-Y configuration; distal part of 2A curved upward. Hind wing ca. 2.6 times as long as wide. Sc not forked. $\mathrm{R}_{1}$ not forked, the distal part curved; Rs 4-branched; stem $\mathrm{Rs}_{1+2}$ longer than stem $\mathrm{Rs}_{3+4}$. M 4branched; $M_{1}$ and $M_{2}$ stalked; furcation of $M_{1+2}$ at same level with furcation of $\mathrm{Rs}_{1+2}$. CuA bifurcated; $\mathrm{CuP}$ simple. Crossvein $\mathrm{m}_{3}-$ cua ${ }_{1}$ present.

Measurements (in mm). Body length ca. 8.1; width 1.8. Forewing length 8.8; width ca. 3.1. Hind wing length ca. 7.7; width 3.0 .

\section{Pegolepidopteron Zhang, Shih, Labandeira \& Ren gen. nov.}

urn:lsid:zoobank.org:act:EF7 16898-92B6-450F-BDC682E71602324E.

Type species. Pegolepidopteron latiala Zhang, Shih, Labandeira \& Ren sp. nov

Etymology. This generic name is derived from the Greek pegos (strong, solid), in reference to the large body of this species, and lepidos, for "scale" or "flake," also referring to this species' assignment to the Lepidoptera; and pteron, for "wing" or "fin." The gender is feminine.

Distribution. Inner Mongolia Autonomous Region, China.

Diagnosis. Body relatively large. Forewing with Sc forked, $\mathrm{R}_{1}$ forked. Crossvein $\mathrm{r}$ absent, $\mathrm{r}-\mathrm{m}$ crossvein weak. Stem $\mathrm{M}_{1+2}$ longer than stem $\mathrm{M}_{3+4} ; \mathrm{m}_{3+4}$-cua crossvein originating near $\mathrm{M}$ furcation and terminating at midpoint of $\mathrm{CuA}$. Crossvein cua-cup located at the base of forewing. The distal part of $2 \mathrm{~A}$ normal, not curved upward. Hind wing $\mathrm{R}_{1}$ forked.

An Ascololepidopterigidae affiliation is supported by: 1), antennae less than half the length of forewing; 2), wings homoneurous; 3), $\mathrm{R}_{1}$ forked; 4), $\mathrm{M}$ 4-branched; and 5), crossveins $\mathrm{m}$-cua and cua-cup present.

Comparison. Pegolepidopteron differs from Ascololepidopterix in the following characters: 1), the forewing Sc is forked (vs. Sc not forked); 2), the $\mathrm{r}$ crossvein is present (vs. the $\mathrm{r}$ crossvein absent); 3), the $\mathrm{m}$ crossveins are absent (vs. the $\mathrm{m}$ crossveins present); 4), 2A is rectilinear (vs. the distal part of $2 \mathrm{~A}$ curved upward); and 5), the hind wing $R_{1}$ is forked (vs. $R_{1}$ not forked and curved). When compared to Agathiphaga of the monogeneric Agathiphagidae, Pegolepidopteron can be separated by the following characters: 1), the $\mathrm{R}_{1}$ is forked (vs. the $\mathrm{R}_{1}$ not forked); 2), the sc- $\mathrm{r}$ crossvein is absent (vs. the sc-r crossvein present); 3), the $\mathrm{r}$ crossvein is present (vs. the $r$ crossvein absent); 4 ), the location of the $m_{3+4}$-cua crossvein and the cup-a crossvein; and 5), the hind wing venation of Pegolepidopteron is much different from that of Agathiphaga.

\section{Pegolepidopteron latiala Zhang, Shih, Labandeira \& Ren} sp. nov. (Fig. 19)

urn:lsid:zoobank.org:act:C34FB273-675E-4A4E-BA00-1589E 5F70CAD.

Etymology. The specific name is derived from the Latin of latus (broad, wide), and ala, (a bird's wing), in reference to the broad wings of this species.

Type material. Holotype: CNU-LEP-NN-2012-001; \&; well preserved forewings and hind wings.

Locality and horizon. This specimen was collected from Daohugou Village, Shantou Township, Ningcheng County, Inner Mongolia Autonomous Region, China. The age is latest Middle Jurassic, near the Callovian-Oxfordian boundary.

Diagnosis. Same as generic diagnosis.

Description. Antennae partially preserved, filiform, length of segments equal to their diameter.

Forewing ca. 2.5 times as long as wide; shape of wing apex unknown. Forewing lacking humeral vein. Sc forked, from distal $1 / 3$ of vein stem; $\mathrm{Sc}_{2}$ extending to costal margin of wing at 2/3 length of wing from its base. Crossvein $s c-r$ absent. $\mathrm{R}_{1}$ forked from distal 1/4 of stem, slightly beyond the $\mathrm{Rs}_{1+2}$ furcation; $\mathrm{Rs} 4$ branched; $\mathrm{Rs}_{1+2}$ stalked ca. 0.45 of their vein length; stem $\mathrm{Rs}_{1+2}$ as long as stem $\mathrm{Rs}_{3+4}$; $\mathrm{r}$ crossvein located beyond the $\mathrm{R}_{1}$ furcation. $\mathrm{M}$ 4-branched; $\mathrm{M}_{1}$, after separation from $\mathrm{M}_{2}$, subtending an angle of 70 (left wing) and 100 (right wing) degrees, sharply angulated at junction with $\mathrm{r}-\mathrm{m}$ crossvein; stem $\mathrm{M}_{1+2}$ slightly longer than stem $\mathrm{M}_{3+4} ; \mathrm{m}_{3+4}$-cua crossvein slanted obliquely toward $\mathrm{M}_{3+4}$, originating near $\mathrm{M}$ furcation and terminating near the midpoint of $\mathrm{CuA}$. Hyaline zones surrounding $\mathrm{r}-\mathrm{m}$ crossveins at $\mathrm{Rs}_{1+2}, \mathrm{Rs}_{3+4}$ and $\mathrm{M}_{1+2}$ furcations. CuA bifurcated; $\mathrm{CuP}$ simple; cua-cup crossvein present, located at base of forewing. The stem of $\mathrm{CuA}$ diverges from stem of $\mathrm{R}$ basally, The stem of $\mathrm{M}$ diverges from stem of CuA beyond R-CuA furcation. Three anal veins loop into a double-Y configuration. Hind wing $\mathrm{R}_{1}$ forked; $\mathrm{Rs}_{\mathrm{s}}$ 4-branched. $\mathrm{M}$ 4-branched. Crossvein $\mathrm{m}_{3}-$ cua $_{1}$ present between $\mathrm{M}_{3}$ and $\mathrm{CuA}$; cua $_{2}$-cup crossvein present. Anal area poorly preserved.

The anterior apophyses extending forward to distal margin of segment VII.

Measurements (in mm). Body length ca. 7.7; width 1.2. Forewing length 7.2; width 2.9. Hind wing length ca. 5.8; width 2.8 .

Trionolepidopteron Zhang, Shih, Labandeira \& Ren gen. nov.

urn:lsid:zoobank.org:act:B2E35225-7FFD-4E66-B153D6D638B6056E.

Type species. Trionolepidopteron admarginis Zhang, Shih, Labandeira \& Ren sp. nov. 

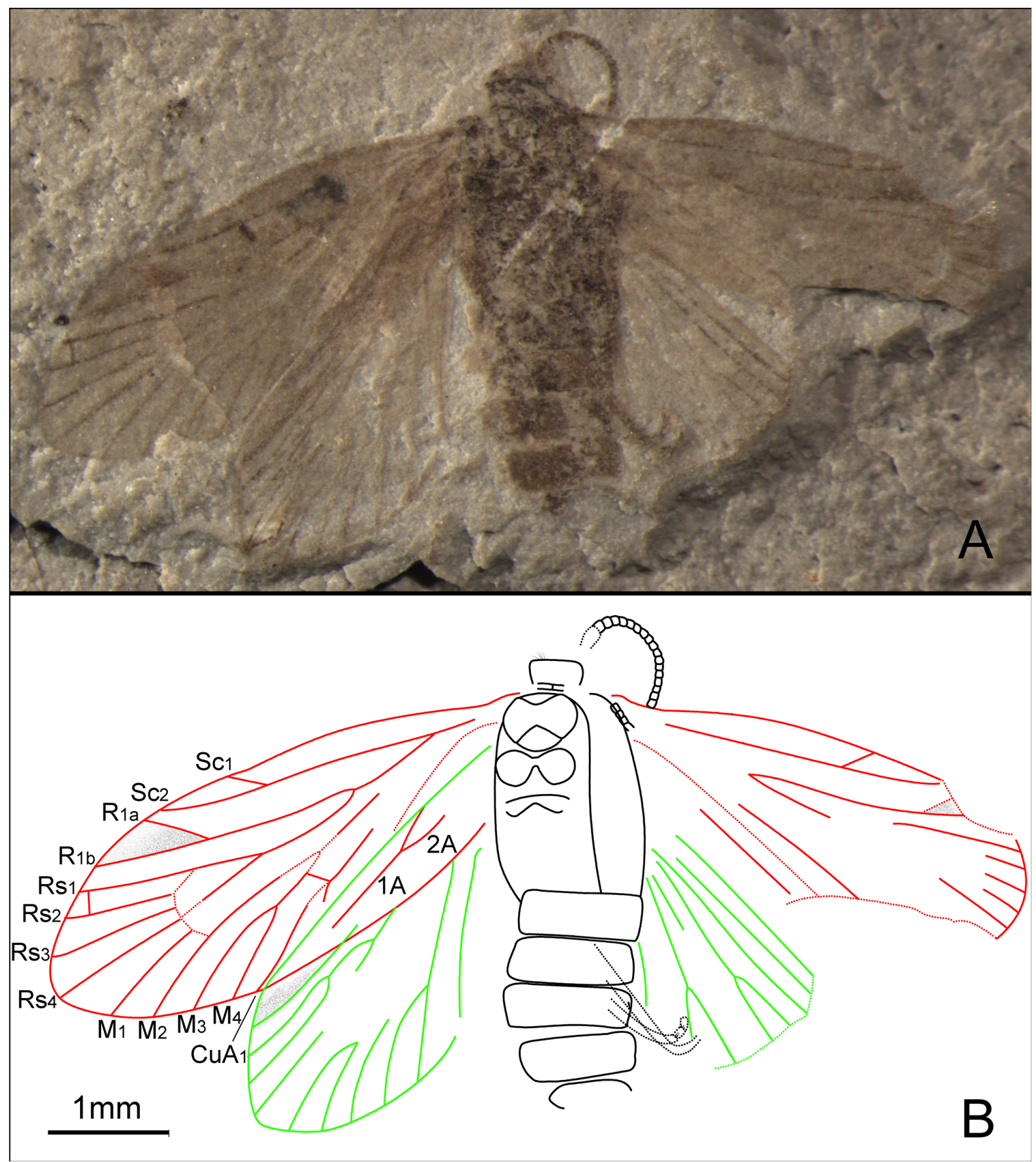

Figure 20. Trionolepidopteron admarginis gen. et sp. nov. Holotype, CNU-LEP-NN-2012-012. (A), Fossil specimen. (B), Camera lucida drawing of (A), showing overall habitus.

doi:10.1371/journal.pone.0079500.g020

Etymology. The generic name is derived from the Greek trion (three) for the threefold branched Rs vein in the hind wing; and lepidos (scale, flake), referring to the Lepidoptera, the order to which this taxon is assigned; and pteron (a bird's wing, fin). The gender is masculine.

Distribution. Inner Mongolia Autonomous Region, China.

Diagnosis. Body small; forewing with $\mathrm{Sc}$ forked. $\mathrm{R}_{1}$ forked. Crossvein $\mathrm{rs}_{1}-\mathrm{rs}_{2}$ present. Stem $\mathrm{M}_{1+2}$ longer than stem $\mathrm{M}_{3+4}$. Crossvein $\mathrm{m}_{3+4}-$ cua located at the $\mathrm{CuA}$ furcation. Hind wing with both Rs and M 3-branched.
An Ascololepidopterigidae affiliation is supported by: 1), antennae less than half the length of forewing; 2), $\mathrm{R}_{1}$ forked; 3), M 4-branched; and 4), crossvein $\mathrm{m}-$-cua present.

Comparison. Trionolepidopteron resembles Pegolepidopteron in the venation of the forewing, including: 1), presence of the Sc and $\mathrm{R}_{1}$

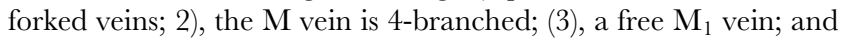
4), presence of the $\mathrm{m}_{3+4}$-cua crossvein. Trionolepidopteron is differs from Pegolepidopteron by the following characters: 1), $\mathrm{rs}_{1}-\mathrm{rs}_{2}$ crossveins are present on the forewing (vs. absent); 2), $r$ crossvein is absent on forewing (vs. present); 3 ), $\mathrm{m}_{3+4}$-cua crossvein is 

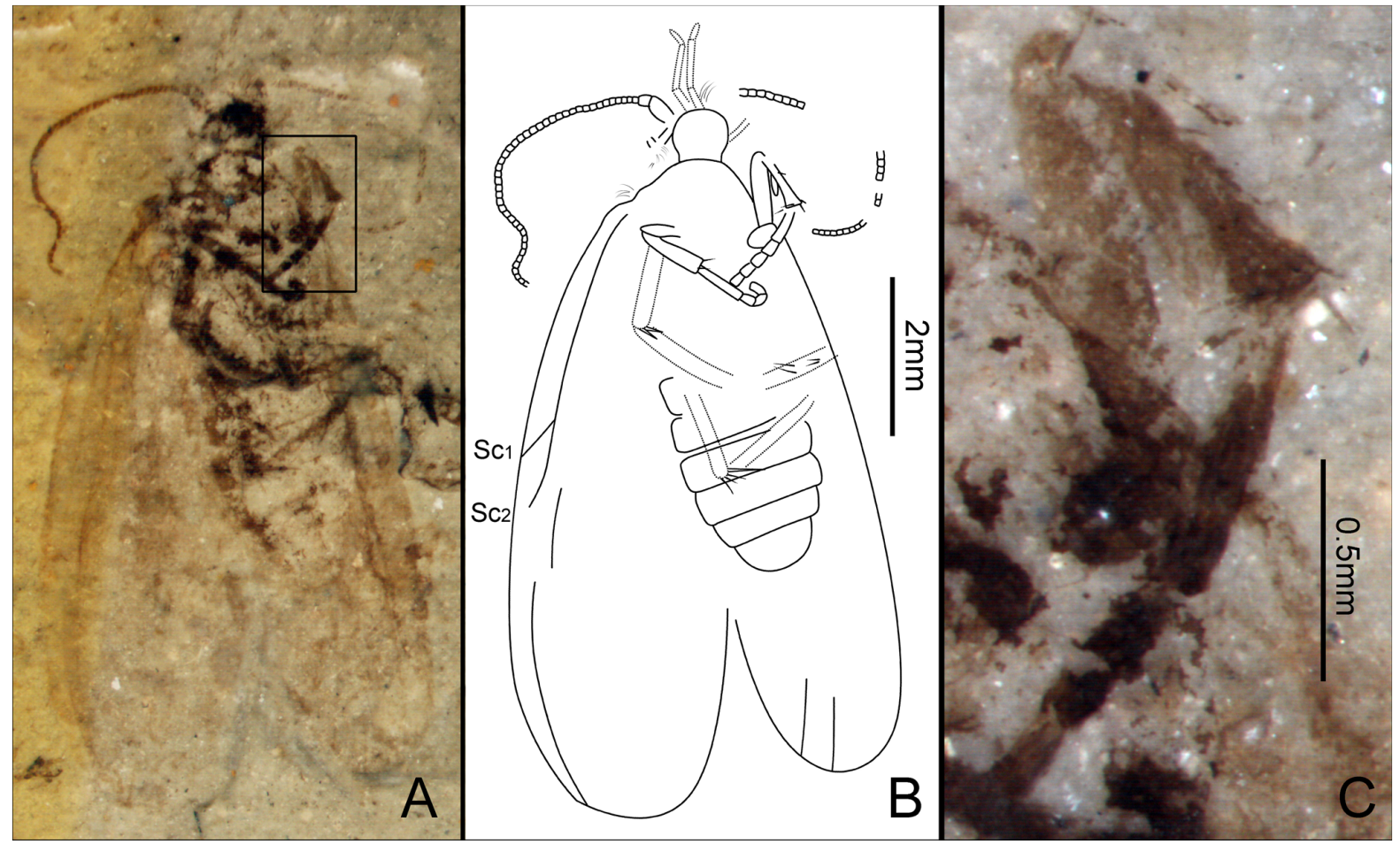

Figure 21. An unidentified moth. Male, CNU-LEP-NN-2012-013. (A), Fossil specimen. (B), Camera lucida drawing of (A), showing overall habitus. (C), Foreleg showing the tibial epiphysis, as outlined at the rectangular template in (A).

doi:10.1371/journal.pone.0079500.g021

located near the $\mathrm{CuA}$ furcation (vs. more remote from the $\mathrm{CuA}$ furcation); and 4), the hind wing has a 3-branched Rs (vs. 4branched). Differences also occur in gross body size, with Trionolepidopteron having a body length of ca. $4.0 \mathrm{~mm}$ long (vs. body lengths of more than $7.0 \mathrm{~mm}$ long for Ascololepidopterix and Pegolepidopteron).

\section{Trionolepidopteron admarginis Zhang, Shih, Labandeira \&} Ren sp. nov. (Fig. 20)

urn:lsid:zoobank.org:act:EC28A0BA-58AD-4630-860EC558307500C1.

Etymology. The specific name is derived from the Latin preposition ad (toward, adjacent to), and marginis (border, edge), in reference to the $\mathrm{rs}_{1}-\mathrm{rs}_{2}$ crossvein occurring near the costal margin of the forewing.

Type material. Holotype: CNU-LEP-NN-2012-012; sex unknown left forewing well preserved; anal area overlapping with hind wing.

Locality and horizon. This specimen was collected from Daohugou Village, Shantou Township, Ningcheng County, Inner Mongolia Autonomous Region, China. The age is latest Middle Jurassic, near the Callovian-Oxfordian boundary.

Diagnosis. Same as generic diagnosis.

Description. Antennae filiform; scape swollen; flagellum filiform; length of segments equal to their diameter. Short setae on anterior head margin. Mesothorax with small prescutum; mesoscutum broader than long; anterior and posterior edges of mesoscutum concave along midline; mesoscutellum fan-shaped, relatively large; mesoscutellum almost subequal to mesoscutum in length. Mesothorax slightly longer than metathorax; metascutum dumbbell shaped. Two short spines present on the apex of each tarsomere.
Forewing ca. 2.8 times as long as wide; pterostigma present. Humeral vein absent. Sc forked from $1 / 4$ of vein stem distance; $\mathrm{Sc}_{2}$ extending to costal margin of wing, beyond 2/3 length of wing from base. $\mathrm{R}_{1}$ forked; sc-r crossvein absent; Rs 4-branched; $\mathrm{Rs}_{4}$ terminating at forewing apex; $\mathrm{Rs}_{1+2}$ stalked ca. 0.37 of their total length; stem $\mathrm{Rs}_{1+2}$ subequal to stem $\mathrm{Rs}_{3+4}$. Crossvein $\mathrm{rs}_{1}-\mathrm{rs}_{2}$ present and located near the costal margin of forewing. M 4branched; stem $\mathrm{M}_{1+2}$ longer than stem $\mathrm{M}_{3+4} ; \mathrm{M}_{1}$, after separation from $\mathrm{M}_{2}$ at an angle of ca. 70 degrees, sharply angulated at junction with $\mathrm{r}-\mathrm{m}$ crossvein. Hyaline zones surround $\mathrm{r}-\mathrm{m}$ crossveins at $\mathrm{Rs}_{1+2}, \mathrm{Rs}_{3+4}, \mathrm{M}_{1+2}$, and $\mathrm{M}_{1+2}-\mathrm{M}_{3}$ furcations. $\mathrm{CuA}$ bifurcated. Crossvein $\mathrm{m}_{3+4}$-cua present, originating on $\mathrm{M}_{3+4}$ and terminating near the $\mathrm{CuA}$ furcation. Hind wing ca. 2.5 times as long as wide. Sc and $\mathrm{R}_{1}$ not forked. Rs and M 3-branched. $\mathrm{CuA}$ bifurcate.

Measurements (in mm). Body length over 3.8 as preserved (terminalia missing); width 1.6. Forewing length ca. 4.5; width ca. 1.6. Hind wing length ca. 3.7; width ca. 1.5 .

\section{Family Incertae sedis}

Gen. et sp. incertae sedis (Fig. 21)

Material. GNU-LEP-NN-2012-013; o'; antennae and forelegs well preserved; venation on both fore- and hind wings difficult to discern.

Locality and horizon. This specimen was collected from Daohugou Village, Shantou Township, Ningcheng County, Inner Mongolia Autonomous Region, China. The age is latest Middle Jurassic, near the Callovian-Oxfordian boundary.

Description. Antennae longer than half the length of forewing; scape swollen; pedicel relatively robust; flagellum filiform, length of flagellar segments equal to their diameter. Maxillary palpus long, the last segment short. Foretibia with epiphysis and spines (Fig. 21C); pretarsi 5-segmented. Both 
mesotibia and metatibia with one pair of apical spurs; medial spurs not discernible.

Forewings extremely long, distinctly exceeding end of the abdomen. Sc forked; other wing venation not discernible.

Measurements (in mm). Body length 5.9; width 1.8 . Forewing length 7.3; width ca. 2.6.

Remarks. The tibial epiphysis is well preserved on this specimen. The foretibia is characterized by well-developed epiphyses, an autapomorphy of the Lepidoptera. Based on this character, we consider this specimen is assigned to the Lepidoptera. However, due to indistinct venational characters, it cannot be placed in any lepidopteran family.

\section{Discussion}

Lepidopteran Characters from the Daohugou Specimens

Amphiesmenopteran fossils can be recognized by either the anal veins in the forewing forming a "double-Y" loop or by the hind wing $M$ veins with at most three branches. Amphiesmenopteran specimens from the Middle Jurassic Jiulongshan Formation at Daohugou show that they had already acquired at least some lepidopteran or trichopteran apomorphies. Definitive Trichoptera and Lepidoptera from Daohugou previously have been reported by Gao et al. [43] and Huang et al. [25]. Daohugou Lepidoptera described here reveal an earlier underestimated diversity of Lepidoptera from this deposit. These specimens possess some of the most recently proposed lepidopteran autapomorphies.

Although Kristensen listed 23 autapomorphies for adult Lepidoptera [44], few of these can be observed on compression fossils. Grimaldi [8] specified three critical, external apomorphies that should be present in adults of early lepidopteran fossils: 1), absence of a forewing $\mathrm{M}_{4}$ vein; 2), presence of an epiphysis on the foretibia of (most) species; and 3), the occurrence of wing scales on both fore- and hind wings. In addition, the presence of mandibulate mouthparts $[12,40,45]$, a well-developed jugum and associated setae [40], and a frenulum [12,45] also are present and often used as diagnostic characters of basal moths [41].

One feature mentioned above, wing scales, have long been regarded as a diagnostic character for the Lepidoptera. Although a few trichopteran species also possess wing scales, they are always from rather derived lineages [46]. Grimaldi [8] mentioned that, differing from the Lepidoptera, the Trichoptera have wing scales that very occasionally occur on the forewings. However, some rare Trichoptera, such as Monocentra lepidoptera Rambur, do have wing scales on both wings $[47,48]$. In primitive Lepidoptera, the scales are typically "solid", lacking a lumen; wing-surface scales are nonperforate; and the outer surface of wing scales are densely set with transverse flutes [49]. Interestingly, only one lepidopteran fossil (CNU-LEP-NN-2012-024) from Daohugou exhibits evidence of scales, as robust piliform scales. Huang et al. [25] indicated the presence of wing scales from the Mesokristenseniidae, but their interpretation of the wing scales appears ambiguous. We believe that the absence of wing scales from Daohugou Lepidoptera is due to taphonomic factors. While scales are often preserved in amber ( $[11,12]$, and other examples), scales are known but seldom preserved in compression fossils. Another possible explanation involves the unlikely secondary loss of wing scales from Daohugou Lepidoptera. Such an explanation, however, would require an unparsimonious assumption that these lepidopterans represent a monophyletic lineage. The morphological diversity displayed in these specimens appears to undermine such an interpretation.

Based on our survey of the literature, we consider that the following four amphiesmenopteran apomorphies $[15,25]$ are sufficient for identifying specimens in this report as Amphiesmenoptera (Table 3).

\section{The forewing anal veins form a "double-Y" loop.}

2. The hind wing $M$ vein bears at most three branches. This condition also indicates that veins $\mathrm{M}_{3}$ and $\mathrm{M}_{4}$ are entirely merged.

3. The pronotum has paired setose prominences.

4. The anterior margin of female segments VIII and IX are accompanied by long, rod-like apodemes.

5. In addition, we cite the following, additional nine lepidopteran apomorphies $[15,25]$ as providing evidence for an affiliation to the Lepidoptera (Table 3).

6. The median ocellus is absent. The loss of median ocellus represents an autapomorphy of Lepidoptera, as this structure is present in Trichoptera [46]. The detailed structure of the head in most of these twenty specimens is difficult to discern. However, one of our better-preserved specimens, Petilicorpus cristatus gen. et sp. nov. (CNU-LEP-NN-2012-007, Fig. 10), displayed a head capsule in which a median ocellus was clearly lacking, indicating an assignment to the Lepidoptera.

7. The foretibia possesses an epiphysis. Except for the fossil genus Mesokristensenia, the epiphysis is a long-established and diagnostic character of modern Lepidoptera [46]. The foretibia bears a well-developed epiphysis and lacks apical spurs, often considered is an autapomorphous condition of the Lepidoptera. Eolepidopterix jurassica, belonging to the extinct lepidopteran family Eolepidopterigidae, possesses a foretibial epiphysis $[4,6]$. In addition, an epiphysis occurs on the foretibia of Seresilepidopteron dualis gen. et sp. nov. (CNU-LEP-NN-2006001, Fig. 3), and on specimen CNU-LEP-NN-2012-013, the latter a species of uncertain familial status (Fig. 21), confirming assignment of these two specimens to the Lepidoptera.

8. The foretibia bears at most a single apical spur. Except for the Agathiphagidae and Mesokristenseniidae that possess a single apical spur on their foretibiae, most other Lepidoptera lack foretibial spurs. A spur is absent on the foretibia of Quadruplecivena celsa gen. et sp. nov. (CNU-LEP-NN2012-027, Figs, 8, 9), and on the unaffiliated species (CNULEP-NN-2012-013, Fig. 21), consistent with assignment of both specimens to the Lepidoptera.

9. The mesotibia lacks medial spurs. The absence of medial spurs on the tibiae of the Aglossata is consistent with an affiliation of some Daohugou specimens to the Lepidoptera.

10. Absence of nygmata on the wings. Nygmata are distinctive pustulate structures located at the base of the $\mathrm{Rs}_{3}-\mathrm{Rs}_{4}$ vein in almost all Trichoptera (Fig. 2B) [36]. By contrast, nygmata are absent in the Lepidoptera. All twenty specimens, except for one specimen with indeterminate wing venation, have wings that lack nygmata. The absence of nygmata on 19 specimens that exhibit good wing preservation cannot exclude the possible presence of nygmata, but strongly suggests that early Lepidoptera lacked these interesting wing structures.

11. Forewing $\mathbf{M}$ vein is 3-branched. A 3-branched medial vein, $\mathrm{M}$, has long been considered a lepidopteran autapomorphy [6], but exceptions occur in both Lepidoptera and Trichoptera. For example, the $\mathrm{M}_{4}$ is present in the Aglossata, Mesokristenseniidae and Ascololepidopterigidae fam. nov. (Lepidoptera); and the $\mathrm{M}_{4}$ is absent in the extinct family Dysoneuridae (Trichoptera). In spite of these 
Table 3. Amphiesmenopteran and Lepidopteran apomorphies for our specimens.

\begin{tabular}{|c|c|c|c|c|c|c|c|c|c|c|c|c|c|c|c|}
\hline \multirow[t]{2}{*}{ Genus } & \multirow[t]{2}{*}{ Species } & \multirow[t]{2}{*}{ Specimen } & \multicolumn{4}{|c|}{$\begin{array}{l}\text { Amphiesmenopteran } \\
\text { apomorphies }{ }^{1}\end{array}$} & \multicolumn{9}{|c|}{ Lepidopteran apomorphies ${ }^{1}$} \\
\hline & & & 1 & 2 & 3 & 4 & 5 & 6 & 7 & 8 & 9 & 10 & 11 & 12 & 13 \\
\hline \multirow[t]{2}{*}{ Sereslepidopteron } & S. dualis & CNU-LEP-NN-2006-001 & 0 & $\mathrm{O}$ & $?$ & $?$ & $?$ & 0 & $?$ & 0 & $?$ & 0 & 0 & $?$ & $?$ \\
\hline & & CNU-LEP-NN-2006-002 & $?$ & $?$ & $?$ & 0 & $?$ & $?$ & $?$ & $?$ & $?$ & 0 & $?$ & $?$ & $?$ \\
\hline \multirow[t]{3}{*}{ Akainalepidopteron } & A. elachipteron & CNU-LEP-NN-2012-023 & $?$ & $?$ & $?$ & $?$ & $?$ & $?$ & $?$ & $\mathrm{O}$ & $?$ & $\mathrm{O}$ & $\mathrm{O}$ & $?$ & $?$ \\
\hline & & CNU-LEP-NN-2012-024 & $?$ & 0 & $?$ & $?$ & $?$ & $?$ & $?$ & $\mathrm{O}$ & $?$ & 0 & 0 & $?$ & $?$ \\
\hline & & CNU-LEP-NN-2012-026 & $?$ & $?$ & $?$ & $?$ & $?$ & $?$ & $?$ & $?$ & $?$ & 0 & 0 & $?$ & $?$ \\
\hline Dynamilepidopteron & D. aspinosus & CNU-LEP-NN-2012-014 & $?$ & $?$ & $?$ & $?$ & $?$ & $?$ & $?$ & 0 & $?$ & $\mathrm{O}$ & $?$ & $?$ & $?$ \\
\hline Quadruplecivena & Q. celsa & CNU-LEP-NN-2012-027 & $?$ & $\mathrm{O}$ & $?$ & $?$ & $?$ & $?$ & 0 & 0 & $?$ & 0 & $\mathrm{x}$ & $?$ & $?$ \\
\hline Petilicorpus & P. cristatus & CNU-LEP-NN-2012-007 & $?$ & 0 & $?$ & 0 & $\mathrm{O}$ & $?$ & $?$ & 0 & $?$ & 0 & $\mathrm{O}$ & $?$ & $?$ \\
\hline Longcapitalis & L. excelsus & CNU-LEP-NN-2012-025 & $\mathrm{O}$ & 0 & $?$ & $?$ & $?$ & $?$ & $?$ & $?$ & $?$ & $\mathrm{O}$ & 0 & $?$ & $?$ \\
\hline Grammikolepidopteron & G. extensus & CNU-LEP-NN-2012-006 & 0 & $?$ & $?$ & 0 & $?$ & $?$ & $?$ & $?$ & $?$ & 0 & $\mathrm{x}$ & $?$ & $?$ \\
\hline \multirow[t]{2}{*}{ Mesokristensenia } & M. sinica & CNU-LEP-NN-2009-003 & $?$ & $?$ & $?$ & $?$ & $?$ & $?$ & $?$ & 0 & $?$ & $\mathrm{x}$ & 0 & $?$ & $?$ \\
\hline & M. trichophora & CNU-LEP-NN-2012-032 & 0 & $?$ & $?$ & $?$ & $?$ & $?$ & $?$ & 0 & $?$ & $\mathrm{x}$ & $\mathrm{O}$ & $?$ & $?$ \\
\hline \multirow[t]{4}{*}{ Kladolepidopteron } & K. oviformis & CNU-LEP-NN-2009-007 & 0 & $?$ & $?$ & $?$ & $?$ & $?$ & $?$ & 0 & $?$ & $\mathrm{x}$ & 0 & $?$ & $?$ \\
\hline & K. subaequalis & CNU-LEP-NN-2012-020 & 0 & 0 & $?$ & $?$ & $?$ & $?$ & $?$ & $?$ & $?$ & $\mathrm{x}$ & 0 & $?$ & $?$ \\
\hline & & CNU-LEP-NN-2012-022 & 0 & $?$ & $?$ & $?$ & $?$ & $?$ & $?$ & $?$ & $?$ & $\mathrm{x}$ & 0 & $?$ & $?$ \\
\hline & K. parva & CNU-LEP-NN-2012-011 & $?$ & 0 & $?$ & $\mathrm{O}$ & $?$ & $?$ & $?$ & $?$ & $?$ & $\mathrm{x}$ & 0 & $?$ & $?$ \\
\hline Ascololepidopterix & A. multinerve & CNU-LEP-NN-2012-028 & $\mathrm{O}$ & 0 & $?$ & $?$ & $?$ & $?$ & $?$ & $?$ & $?$ & $\mathrm{x}$ & 0 & $?$ & $?$ \\
\hline Pegolepidopteron & P. latiala & CNU-LEP-NN-2012-001 & 0 & 0 & $?$ & $\mathrm{O}$ & $?$ & $?$ & $?$ & $?$ & $?$ & $\mathrm{x}$ & 0 & $?$ & $?$ \\
\hline Trionolepidopteron & T. admarginis & CNU-LEP-NN-2012-012 & $?$ & 0 & $?$ & $?$ & $?$ & $?$ & $?$ & $?$ & $?$ & $\mathrm{x}$ & 0 & $?$ & $?$ \\
\hline incertae sedis & $?$ & CNU-LEP-NN-2012-013 & $?$ & $?$ & $?$ & $?$ & $?$ & 0 & 0 & 0 & $?$ & $?$ & $?$ & $?$ & $?$ \\
\hline
\end{tabular}

${ }^{1}$ Numbers refer to apomorphies listed in the text; $\mathrm{O}=$ character presence, $\mathrm{X}=$ character absence, $?=$ unknown state.

exceptions, most of the specimens with 3-branched $\mathrm{M}$ veins (Figs. 1C, D, E and 2A) are most likely Lepidoptera.

12. Separation of the $M_{1}$ from the $M_{2}$ veins is accompanied by an angle greater than 60 degrees and a sharp, angulate intersection at the junction with the r-m crossvein (Fig. 2A). Huang et al. [25] proposed that Lepidoptera can be distinguished from Trichoptera by this character of the $\mathrm{M}_{1}$ vein. In Lepidoptera, the $\mathrm{M}_{1}$ usually separates from $\mathrm{M}_{2}$ at an angle greater than 60 degrees, followed by sharp angulation at junction with the $\mathrm{r}-\mathrm{m}$ crossvein (Figs. $1 \mathrm{C}, \mathrm{F}$, and 2A). By contrast, nearly all Trichoptera have branches of the $\mathrm{M}_{1+2}$ with the $\mathrm{M}_{1}$ and $\mathrm{M}_{2}$ veins at an angle of less than 45 degrees; in addition, and $\mathrm{M}_{1}$ is linear and smooth (Figs. $1 \mathrm{G}$ and $2 \mathrm{~B})$. Not all Lepidoptera have a $\mathrm{M}_{1}$ vein that is sharply angulated at the junction with $\mathrm{r}-\mathrm{m}$ crossvein, such as Undopterix sukatshevae that was identified as a lepidopteran based on the presence of scales (Fig. 1D), and Netoxena nana based on its 3-branched $\mathrm{M}$ vein (Fig. 1E). If a fossil species has this feature, it is most likely a lepidopteran. Most of our twenty specimens exhibit wings with this character, except for two lacking this feature and three that have it as an ambiguous presence (as shown in Table 3).

13. The male valva is primarily undivided.

14. The cerci are absent in both sexes.

\section{The Early Evolution of the Amphiesmenoptera}

The Amphiesmenoptera likely originated from the stem panorpoid stock [15]. Although no fossils unambiguously represent the common ancestry of Lepidoptera and Trichoptera, the extinct family Necrotauliidae has been suggested as the best candidate (Fig. 1A) [5]. This family is a paraphyletic assemblage of species that existed from the Triassic to the Cretaceous [50]. The earliest fossil member of the Lepidoptera, Archaeolepis mane (Fig. 1B), was reported from Sinemurian Stage, of the mid Early Jurassic age, an assignment based primarily on distinctive lepidopteran scales [18]. Characters of the wing venation, legs and axial part of the body of the various new species in this report indicate the presence of autapomorphies in both the Amphiesmenoptera and the Lepidoptera. These features provide supplemental evidence to support the hypothesized divergence of the Lepidoptera and Trichoptera occurring by the Early Jurassic. This differentiation of the Lepidoptera and Trichoptera likely had transpired during the Triassic-Jurassic boundary [50], or possibly Late Triassic [6,51]. Notably, gracile, lepidopteran-like, epidermal leaf mines reminiscent of the Nepticulidae and more basal monotrysian leaf mining lineages are present in a Late Triassic (Carnian) flora from South Africa (C Labandeira, R Prevec, E Currano, J Anderson and H Anderson, unpublished data), perhaps indicating an earlier, Middle Triassic date for the origin of basalmost lepidopteran lineages. 


\section{Acknowledgments}

We are grateful to Dr. Alexandr Rasnitsyn for his valuable input and contribution in the study of Sereslepidopteron dualis gen. et sp. nov. and loan of Protolepis cuprealata for this study. Scott Whittaker of the NMNH Electron Microscopy Laboratory provided important assistance in fossil specimen preparation. This is contribution 273 from the Evolution of Terrestrial Ecosystems consortium at the National Museum of Natural History, in Washington, D.C.

\section{References}

1. van Nieukerken EJ, Kaila L, Kitching IJ, Kristensen NP, Lees DC, et al. (2011) Order Lepidoptera Linnaeus, 1758. In: Zhang ZQ editor. Animal Biodiversity: An Outline of Higher-level Classification and Survey of Taxonomic Richness. Zootaxa 3148: 212-221.

2. Labandeira CC, Sepkoski.JJJr (1993) Insect diversity in the fossil record. Science 261: $310-315$.

3. Sohn JC, Labandeira CC, Davis D, Mitter C (2012) An annotated catalog of fossil and subfossil Lepidoptera (Insecta: Holometabola) of the world. Zootaxa 3286: 1-132.

4. Rasnitsyn AP (1983) First find of a moth from the Jurassic. Proc Paleontol Inst USSR Acad Sci 84: 467-471. [In Russian].

5. Grimaldi DA, Engel MS (2005) Amphiesmenoptera: The caddisflies and Lepidoptera. In: Grimaldi DA, Engel MS, editors. Evolution of the Insects, New York: Cambridge University Press. 548-555.

6. Whalley PE (1986) A review of the current fossil evidence of Lepidoptera in the Mesozoic. Biol Bull Linn Soc 28: 253-271.

7. Skalski AW (1990) An annotated review of fossil records of lower Lepidoptera. Bull Sugadaira Mon Res Cen Tsukuba Univ 11: 125-128.

8. Grimaldi DA (1999) The co-radiations of pollinating insects and angiosperms in the Cretaceous. Ann Missouri Bot Gard 86: 373-406.

9. MacKay RM (1970) Lepidoptera in Cretaceous amber. Science 167: 379-380.

10. Skalski AW (1979) A new member of the family Micropterigidae (Lepidoptera) from the lower Cretaceous of Transbaikalia. Paleontol Zh 2: 90-96. In Russian].

11. Kühne WG, Kubig K, Schlüter T (1973) Eine Micropterygide (Lepidoptera, Homoneura) aus mittelkretazische Harz Nordwestfrankreichs. Mitt Deut Entomol Ges 32: 61-65.

12. Whalley PE (1977) Lower Cretaceous Lepidoptera. Nature 266: 526.

13. Labandeira CG, Dilcher DL, Davis DR, Wagner DL (1994) Ninety-seven million years of angiosperm-insect association: paleobiological insights into the meaning of coevolution. Proc Natl Acad Sci U S A 91: 12278-12282.

14. Stevenson J (1991) Evidence of Plant/Insect Interactions in the Late Cretaceous and Early Tertiary. Ph.D. thesis, University of London. 378 p.

15. Kristensen NP, Skalski AW (1998) Phylogeny and palaeontology. In: Kristensen NP, editor. Lepidoptera, Moths and Butterflies, Vol. 1 (Evolution, Systematics, and Biogeography). Handbook of Zoology, Vol. IV (Arthropoda: Insecta), Part 35. Berlin \& New York: Walter de Gruyter. 7-25.

16. Kozlov MV (1988) Palaeontological data and the problems phylogeny of the order Papilionida. In: Ponomarenko AG, editor. The Cretaceous Biocoenotic Crisis in the Evolution of Insects, Moscow: Academy of Sciences. 16-69. [In Russian].

17. Wang MX, Zhao YY, Ren D (2009) New fossil caddisfly from Middle Jurassic of Daohugou, Inner Mongolia, China (Trichoptera: Philopotamidae). Prog Nat Sci 19: $1427-1431$.

18. Whalley PE (1985) The systematics and palaeogeography of the Lower Jurassic insects of Dorset, England. Bull Brit Mus (Nat Hist) Geol Ser 39: 107-189.

19. de Jong R (2007) Estimating time and space in the evolution of the Lepidoptera. Tijd Entomol 150: 319-346.

20. Handlirsch A (1906-08) Die Fossilien Insekten und die Phylogenie der rezenten Formen: Ein Handbuch für Paläontologen und Zoologen. Leipzig: Engelmann. $1430 \mathrm{p}$.

21. Ansorge J (2002) Revision of the "Trichoptera" described by Geinitz and Handlirsch from the Lower Toarcian of Dobbertin (Germany) based new material. Nova Suppl. Entomol Keltern 15: 55-74.

22. Ansorge J (2002) Upper Liassic Amphiesmenopterans (Trichoptera+Lepidoptera) from Germany-a review. Acta Zool Cracov 46 (Suppl._Fossil Insects): 285 290.

23. Skalski AW (1984) A new Lower Cretaceous Lepidoptera (Homoneura). Bull Pol Acad Sci Biol Sci 32: 389-392.

24. Martins-Neto RG (1999) New genus and new species of Lepidoptera (Insecta, Eolepidopterigidae) from Santana Formation (Lower Cretaceous, Northeast Brazil). Bol Simp Cret Brasil 5: 531-535.

25. Huang D, Nel A, Minet J (2010) A new family of moths from the Middle Jurassic (Insecta: Lepidoptera). Acta Geol Sin 84: 874-885.

26. He HY, Wang XL, Zhou ZH, Zhu RX, Jin F, et al. (2004) ${ }^{40} \mathrm{Ar} /{ }^{39} \mathrm{Ar}$ dating of ignimbrite in Inner Mongolia, northeastern China, indicates a post-Middle Jurassic age for the overlying Daohugou bed. Geophys. Res Lett 31: 206-209.

27. Zhou ZH, Barrett PM, Hilton J (2003) An exceptionally preserved Lower Cretaceous ecosystem. Nature 421: 807-814.

\section{Author Contributions}

Conceived and designed the experiments: DR CGL CKS. Performed the experiments: WTZ CKS DRD JCS CCL JAS OF DR. Analyzed the data: WTZ CKS DRD JCS GCL JAS OF DR. Contributed reagents/materials/ analysis tools: WTZ CKS DRD JCS GCL JAS OF DR. Wrote the paper: WTZ CKS CGL DRD JCS. Photographs: WTZ CKS JAS CAL. Line drawings: WTZ CKS JCS DRD.

28. Gradstein FM, Ogg JG, Schmitz MD, Ogg F (2012) The Geologic Time Scale 2012. Amsterdam: Elsevier. 1144 p.

29. Ren D, Shih CK, Gao TP, Yao YZ, Zhao YY (2010) Silent Stories-Insect Fossil Tasures from Dinosaur Era of the Northeastern China. Beijing: Science Press. $322 \mathrm{p}$.

30. Gao TP, Shih CK, Xu X, Wang S, Ren D (2012) Mid-Mesozoic flea-like ectoparasites of feathered or haired vertebrates. Current Biology 22: 732-735.

31. Wang YJ, Labandeira CG, Shih CK, Ding QL, Wang C, et al. (2012) Jurassic mimicry between a hangingfly and a ginkgo from China. Proceedings of the National Academy of Sciences USA 109: 20514-20519.

32. Gu JJ, Montealegre ZF, Robert D, Engel MS, Qiao GX, et al. (2012) Wing stridulation in a Jurassic katydid (Insecta, Orthoptera) produced low-pitched musical calls to attract females. Proceedings of the National Academy of Sciences USA 109: 3868-3873.

33. Yang Q Makarkin VN, Winterton SL, Khramov AV, Ren D (2012) A remarkable new family of Jurassic Insects (Neuroptera) with primitive wing venation and its phylogenetic position in Neuropterida. PLoS ONE 7(9): e44762. doi:10.1371/journal.pone.0044762.

34. Kristensen NP, Nielsen ES (1979) A new subfamily of micropterigid moths from South America. A contribution to the morphology of the Micropterigidae, with a generic catalogue of the Family (Lepidoptera: Zeugloptera). Steenstrupia 5: 69147.

35. Wootton RJ (1979) Function, homology and terminology in insect wings. Syst Entomol 4: 81-93.

36. Holzenthal RW, Blahnik RJ, Prather AL, Kjer KM (2007) Order Trichoptera Kirby 1813 (Insecta), Caddisflies. In: Zhang ZQ, Shear WA, editors. Linneaus Tercentenary: Progress in Invertebrate Taxonomy. Zootaxa 1668: 639-698.

37. Simpson DP (1959) Cassell's New Latin Dictionary. New York: Funk \& Wagnalls. $883 \mathrm{p}$.

38. Brown RW (1991) Composition of Scientific Words. Washington, D.C.: Smithsonian Institution Press. 882 p.

39. Martins-Neto RG, Vulcano MA (1989) Amphiesmenoptera (Trichoptera+Lepidoptera) na Formação Santana (Cretáceo Inferior). Bacia do Araripe, Nordeste do Brasil. I- Lepidoptera (Insecta). Anais Acad Bras Cien 61: 459-466.

40. Kozlov MV (1989) New Lepidoptera (Papilionida) from the Upper Jurassic and Lower Cretaceous. Paleontol Zh 4: 37-42. [In Russian].

41. Kristensen NP (1998) Lepidoptera: Moths and Butterflies. Vol. 1. (Evolution, Systematics and Biogeography). In: \Fischer M, editor. Handbook of Zoology, Vol. IV (Arthropoda: Insecta), Part 35. Berlin \& New York: Walter de Gruyter. $491 \mathrm{p}$.

42. Cockerell TDA (1919) Two interesting insects in Burmese amber. Entomologist 52: 193-195.

43. Gao Y, Yao YZ, Ren D (2013) A new Middle Jurassic caddisfly (Trichoptera, Hydrobiosidae) from China. Fossil Record 16: 111-116.

44. Kristensen NP (2007) Lepidoptera phylogeny and systematics: the state of inventorying moth and butterfly diversity. Zootaxa 1668: 699-747.

45. Whalley PE (1978) New taxa of fossil and recent Micropterigidae with a discussion of the evolution and a comment on the evolution of the Lepidoptera (Insecta). Ann Transvaal Mus 31: 72-86.

46. Kristensen NP (1984) Studies on the morphology and systematics of primitive Lepidoptera. Steenstrupia 10: 141-191.

47. McLachlan R (1876) A monographic revision and synopsis of the Trichoptera of the European fauna. London: J.V. Voorst. 523 p.

48. Bicchierai MC, Moretti GP (1991) The wing scales of Monocentra lepidoptera Ramb. (Trichoptera: Limnephilidae). In: Tomaszewski C, editor. Int Symp Trichoptera 6: 299-303.

49. Scoble MJ (1992) The Lepidoptera: Form, Function and Diversity. Oxford: Oxford University Press. $404 \mathrm{p}$.

50. Ivanov VD, Sukatsheva ID (2002) Order Trichoptera Kirby, 1813. The caddisflies. In: Rasnitsyn AP, Quicke DLJ, editors. History of Insects, Dordrecht, Kluwer Academic Publishers. 199-219.

51. Kristensen NP (1997) Early evolution of the Trichoptera+Lepidoptera lineage: phylogeny and the ecological scenario. Mém Mus Natl Hist Nat 173: 253-271.

52. Sohn JC, Labandeira CC, Davis D, Mitter C (2013) An overview of the lepidopteran fossil record: diversity, taphonomy and implications for divergencetime. Syst Entomol, submitted.

53. Azar D, Gèze R, Acra F (2010) Lebanese amber. In: Penney D, editor. Biodiversity of Fossils in Amber from the Major World Deposits. Manchester: Siri Scientific Press. 271-298. 
54. Grimaldi DA, Engel MS, Nascimbene PC (2002) Fossiliferous Cretaceous amber from Myanmar (Burma): Its rediscovery, biotic diversity, and paleontological significance. Am Mus Novit 3361: 1-72.

55. Martínez-Delclòs X, Arillo A, Ortuño V, Peñalver E (1999) El ámbar del Cretácico Inferior de Peñacerrada (Álava, España). Temas Geol Min ITGE 26: 13-17.

56. Rasnitsyn AP, Ross AJ (2000) A preliminary list of arthropod families present in the Burmese amber collection at the Natural History Museum, London. Bull Nat Hist Mus Lond Geol 56: 21-24.

57. Schlüter T (1974) Kritisches zum Nachweis von Schmetterlingsschuppen aus einem fossilen Harz der mittleren Kreide Nordwestfrankreichs. Entomol Z 84: 253-256.

58. Skalski AW (1976) Les lépidoptères fossiles de l'ambre: État actuel de nos connaissances. Linn Belg 6: 154-169.
59. Handlirsch A (1939) Neue Untersuchungen über die fossilen Insekten mit Ergänzungen und Nachträgen sowie Ausblicken auf phylogenetische, palaeogeographische und allgemein biologische Probleme. II Teil. Ann Naturhist Mus Wien 49: $1-240$

60. Sukatsheva ID (1990) Caddisflies. Phryganeina. In: Rasnitsyn AP, editor. Late Mesozoic Insects of Eastern Transbaikalia. Tr Paleontol Inst Akad Nauk SSSR 239: 94-122. [In Russian].

61. Grimaldi DA, Shedrinsky A, Wampler TP (2000) A remarkable deposit of fossiliferous amber from the Upper Cretaceous (Turonian) of New Jersey. In: Grimaldi DA, editor. Studies on Fossils in Amber, with Particular Reference to the Cretaceous of New Jersey. Leiden: Backhuys Publishers. 1-76.

62. Grimaldi DA (1996) Amber, Window to the Past. New York: Abrams. 216 p.

63. Alonso J, Arillo A, Barrón B, Corral JC, Grimalt J, et al. (2000) A new fossil resin with biological inclusions in Lower Cretaceous deposits from Álava (northern Spain, Basque-Cantabrian Basin. J Paleontol 74: 158-178. 